\title{
II. Die Entstehung des Kontrollrats. Planungen und Konzeptionen 1943-45
}

\section{Moskau 1943: Italien und die Folgen}

Als sich die Außenminister der Sowjetunion, der USA und Großbritanniens vom 18. Oktober bis 1 . November 1943 in Moskau trafen, hatte der Krieg gegen die Mittelmächte ein Stadium erreicht, das es dringend erforderlich machte, die Ziele, Formen und Aufgaben der zukünftigen Besatzungsverwaltung in den befreiten bzw. eroberten Gebieten festzulegen. Im Osten war es nur eine Frage der Zeit, wann die Rote Armee die sowjetische Westgrenze überschritt. Im Mittelmeerraum hatte die Landung der anglo-amerikanischen Truppen in Sizilien den Sturz Mussolinis provoziert, und die nachfolgende Regierung Badoglio hatte mit dem Sonderwaffenstillstand vom 3. September den Weg für die Landung auf dem italienischen Festland freigemacht.

Der Zwang, die kämpfende Truppe von den Aufgaben der Besatzungsverwaltung freizustellen, machte eine pragmatische ad hoc-Regelung der alliierten Militärverwaltung in Italien erforderlich. Da entsprechende Planungsarbeiten aufgrund von Unstimmigkeiten zwischen Briten und Amerikanern nicht hatten abgeschlossen werden können, ordnete General Eisenhower als alliierter Oberbefehlshaber am 14. Oktober, vier Tage vor Beginn der Moskauer Außenministerkonferenz, die Errichtung einer Alliierten Kontrollkommission an, die am 10. November offiziell ins Leben treten sollte $^{1}$. Er griff damit auf einen von ihm selbst vorgeschlagenen und von den Briten nachhaltig unterstützten Stufenplan zurück, der auf Zeitgewinn und unkomplizierte Konsensbildung zielte: Die zunächst nur als „Skelett“ errichtete Alliierte Kontrollkommission beim Oberkommandierenden sollte nach Abschluß der Kampfhandlungen im Rahmen der militärischen Besatzungsverwaltung „voll“ ausgebildet werden; ihre Kompetenzen würden in einer dritten Phase auf eine alliierte zivile Hochkommission übergehen. Diese wiederum konnte aus der „beratenden Kommission“ hervorgehen, die aufgrund der Mitspracheforderungen Stalins eingerichtet wurde, um sowohl die Sowjetunion als auch die französische Exilregierung unmittelbar in die Politikberatung einzubinden ${ }^{2}$.

Diese ad hoc getroffene Entscheidung zur Einsetzung einer Kontrollkommission in Italien hatte weitreichende Folgen. Da die Sowjetunion weder an diesen Festlegungen noch an der Kontrollkommission selbst beteiligt, sondern lediglich nachträglich informiert worden war, sahen sich die Westmächte auf der Moskauer Konferenz der AuBenminister genötigt, sowohl der Einsetzung einer Beratenden Kommission für Italien mit sowjetischer Beteiligung als auch der Bildung einer Europäischen Beratenden

\footnotetext{
1 Miller, United States, S. 35 ff., 67 ff. Harris, Allied Military Administration.

2 Eisenhower Papers, Bd. III, S. 1509 f. FRUS, 1943/I, S. 588, 603 ff., 707 ff., 758 f. Moskauer Konferenz 1943, S. 244-252, 265 f., 304 ff.
} 
Kommission (EAC) $)^{3}$ mit Sitz in London zuzustimmen. Zugleich gelang es der Sowjetunion, die im Mittelmeer strategisch Fuß zu fassen suchte ${ }^{4}$, das taktische Ungeschick der Westmächte in einen Erfolg umzuwandeln, indem diese ihr als Kompensation ein entsprechend einseitiges Vorgehen in Osteuropa zubilligen mußten ${ }^{5}$. Da die AngloAmerikaner die Besatzungsverwaltung Italiens zudem ohne konzeptionelle Vorbereitung in Angriff nahmen, standen sie bald hilflos dem Intrigenspiel zwischen dem König und Badoglio gegenüber und banden sich an soziale Gruppen bzw. politische Strömungen, die ihrem Befreiungsimage wenig förderlich waren.

Eine Wiederholung derartiger Fehler mußte künftig vermieden werden: durch einen langfristig angelegten, nationalen Planungsprozeß einerseits, durch eine interalliierte Kooperation und Abstimmung andererseits, um - so die Absicht der Westmächte - die Sowjetunion für den Fall eines unerwartet raschen Vorrückens der Roten Armee an einem ähnlich einseitigen Vorgehen in Osteuropa nach Möglichkeit doch noch hindern zu können ${ }^{6}$. Die Briten entwickelten aus diesen Erfahrungen in Italien die Vorstellung bzw. die Hoffnung, mit Hilfe der EAC und der gemeinsamen Besatzung Deutschlands alle sowjetischen Absichten, Europa in "Interessensphären“ aufzuteilen, zu durchkreuzen und Moskau in eine "gemeinsame Verantwortung für Europa" einzubinden ${ }^{7}$. Ausgangspunkt und Grundlage ihrer Vorschläge für die Besatzungsverwaltung in Deutschland und Europa wurde Eisenhowers Drei-Phasen-Modell: militärische Rumpf-Kontrollkommission, voll ausgebildete Kontrollkommission, zivile Hohe Kommission.

Die Sowjetunion, die bis dahin „nur die Umrisse künftiger Forschungen und Konstruktionen bestimmt" hatte, setzte ihrerseits am 23. September 1943, als Reaktion auf die Ereignisse in Italien, im Außenministerium eine Kommission für die Friedensverträge und die Nachkriegsordnung unter der Leitung Litwinows sowie eine Waffenstillstandskommission unter der Leitung von Woroschilow ein ${ }^{8}$. Zunächst scheint sie, um sich Einfluß auf ganz Europa zu erhalten, eher den britischen Vorschlägen einer „militärisch-politischen Kommission" zugeneigt zu haben, die als eine zentrale europäische Kontrollkommission den jeweiligen Kontrollkommissionen in den einzelnen Ländern übergeordnet sein und das Recht haben sollte, „Instruktionen und Direktiven“ zu erteilen?. Angesichts der britischen Bestrebungen, auf Osteuropa Einfluß durch Mitsprache zu gewinnen, war davon auf der Moskauer Außenministerkonferenz keine Rede mehr. Molotow wollte die Zuständigkeit der EAC allein auf Deutschland begrenzt wissen, ihr aber nicht nur die Planung, sondern auch die Durchführung der Waffenstillstandsbedingungen übertragen ${ }^{10}$. Differenzen über die Organisation der Kontrolle in Deutschland bahnten sich an.

${ }^{3}$ Kowalski, European Advisory Commission, S. $261 \mathrm{ff}$. Kettenacker, Krieg, S. $238 \mathrm{ff}$.

4 Moskauer Konferenz 1943, S. 15 ff. FRUS, Potsdam II, S. 256 ff., $1408 \mathrm{ff}$.

5 Krim(Jalta)konferenz 1945, S. 170 f. Potsdamer (Berliner) Konferenz 1945, S. 110.

${ }^{6}$ NA, RG 59/CED, box 1, folder: General Policy (The Work of the EAC, 12. 7. 1945). FRUS, 1944/I, S. 10-16, 30. Als Testfall galt Bulgarien, über das im September 1944 in der EAC parallel zu Deutschland verhandelt wurde.

7 FRUS, 1943/l, S. 525. Vgl. Moskauer Konferenz 1943, S. 168 ff.

${ }^{8}$ Maiski, Memoiren, S. 838. Moskauer Konferenz 1943, S. 18. Vgl. Fischer, Sowjetische Deutschlandpolitik, S. $83 \mathrm{ff}$.

9 Moskauer Konferenz 1943, S. 71, 75, 77, 114, 121 ff., 147 ff., 155, 170, 228 f., 264, 272 ff., 308 f.

10 Moskauer Konferenz 1943, S. 75, 77, 125, 144, 214 f. Vgl. FRUS, 1944/I, S. 30. 


\section{London 1944: Formelkompromisse in der EAC}

Die Briten nutzten den Heimvorteil und die Nähe zu ihren Planungsbürokratien und ergriffen die Initiative. Ihr Memorandum „Alliierter Kontrollapparat in Deutschland während der Besatzungsphase“, das sie am 15. Januar 1944 der eben in London konstituierten EAC vorlegten und das auf frühe (im italienischen Kontext entwickelte) Überlegungen vom Juli 1943 zurückgriff, handelte jedoch - entgegen seinem Titel mehr von Europa als von Deutschland ${ }^{11}$. Dahinter stand die Erkenntnis, daß Großbritannien den Krieg gegen Deutschland militärisch gewonnen, wirtschaftlich aber zugunsten der USA verloren hatte. Infolge der Belastungen des neuerlichen Weltkriegs drohte das Land zu einer Macht zweiter Ordnung abzusinken und war aus seiner defensiven Position heraus bestrebt, Macht durch Einfluß zu ersetzen. Unter dem Druck der anhaltenden militärischen Kampfhandlungen und frei von den politischen Zwängen einer Friedenskonferenz wollte die britische Regierung die Verbündeten frühzeitig auf ihre Ziele verpflichten und sozusagen am Reißbrett das zukünftige multipolare Mächtesystem entwerfen ${ }^{12}$.

Seit 1941 war unübersehbar, daß die europäische Friedensordnung und das globale Mächtesystem künftig nicht mehr ohne die Sowjetunion gestaltet werden konnten. Die Nachkriegskooperation mit dieser wurde gesucht, nicht weil Churchill und Eden (wie Roosevelt auch) aus konvergenztheoretischer Naivität deren Wandel erwarteten, sondern weil sie das pragmatische Arrangement mit der kommenden Weltmacht für unvermeidlich hielten. Auch wenn eine künftige Zusammenarbeit keineswegs als gesichert oder gar als wahrscheinlich galt, so sollte doch die Sowjetunion durch die gemeinsame Kontrolle Deutschlands am Erhalt einer gesamteuropäischen Friedensund Gleichgewichtsordnung interessiert werden. Edens Zustimmung zu den territorialen Forderungen Moskaus im Dezember 1941 und seine Bemühungen, im Gegenzug dafür Stalins Einverständnis zu einer gemeinsamen Kontrolle Deutschlands durch einen Rat der Siegermächte zu gewinnen ${ }^{13}$, waren insofern komplementär. Im Foreign Office bestand daher die Hoffnung, der Erhalt eines relativ starken Deutschland werde die Sowjetunion regelrecht in eine solche Ordnung hineinzwingen - wie Frankreich, wie möglicherweise auch die USA. „Es gibt keinen Grund zu glauben, daß der Erhalt eines geeinten Deutschland notwendig zu einer russisch-deutschen Kombination führen würde. Wenn Deutschland vereint bleibt, wäre das wahrscheinliche Ergebnis, daß die Russen mehr geneigt sein würden, mit uns zusammenzuarbeiten, immer unter der Voraussetzung, daß wir stark bleiben und ein Alliierter, den es sich zu haben lohnt. Man kann sogar weiter gehen und behaupten, daß die Existenz eines geeinten Deutschland sich als ein Faktor von größter Bedeutung erweisen könnte, die Sowjetunion und uns zusammenzuhalten." ${ }^{14}$ Eine zweite Denkschule, die bei den Militärs stärkeren Rückhalt fand, entwickelte - wenngleich zögernd und eher widerwillig - Alternativen für den Fall, daß ein solches „Appeasement“ der Sowjetunion abermals das untaugliche Mittel sein würde, die Politik der konkurrierenden Großmächte durch rationalen Interessenausgleich zu beeinflussen. Als Alternative zur „balance of power“

11 FRUS, 1944/I, S. 154 ff. (EAC(44)3).

12 Kettenacker, Krieg, S. 13 ff.

13 Kettenacker, Kontrolle, S. 34.

14 PRO, FO 371/46871/C303 (FO, 24. 1. 1945, von Eden „Wahlkampfrede“ genannt). 
entstand seit 1943 die Vorstellung eines „Westblocks“, der die Teilung Europas und Deutschlands implizierte: nicht als anzustrebendes, aber als mögliches Ergebnis einer immer wahrscheinlicher werdenden Auseinandersetzung mit der Sowjetunion ${ }^{15}$. Die künftige Haltung gegenüber Deutschland war insofern frühzeitig von dem Verhältnis zur Sowjetunion abhängig. Das Dismemberment bzw. die „Teilung des früheren Deutschland in östliche und westliche Einflußsphären“ war nicht die primäre Option; und je länger der Krieg dauerte, um so mehr suchte Churchill, sich die Nachkriegsoptionen offenzuhalten ${ }^{16}$.

Eine europäische Einbettung der deutschen Frage mochte die Entscheidung über die Teilung hinauszögern. Umgekehrt mochte die Einheit Europas durch die Einheit Deutschlands - als Drohung, als Reparationslieferant, als Handelspartner - befördert werden. Daher sollte, das war der Ansatz des britischen Entwurfs vom 15. Januar 1944, die Kontrolle Deutschlands „einer zentralen Körperschaft, die sich mit den europäischen Angelegenheiten befaßt“, übertragen werden. Bereits in dem Aide-mémoire vom 1. Juli 1943, das sie der Moskauer Außenministerkonferenz vorgelegt hatten, war von den Briten die Bildung einer zivilen „Kommission für Europa“ der Vereinten Nationen angeregt worden. Dieser war die Aufgabe zugedacht, „als die Oberste Behörde der Vereinten Nationen in Europa die Tätigkeit der verschiedenen Waffenstillstandskommissionen, der Alliierten Oberbefehlshaber und der zivilen Behörden der Vereinten Nationen, die eventuell errichtet werden, zu steuern und zu koordinieren; und sich mit den laufenden militärischen, politischen und ökonomischen Problemen zu befassen, die sich aus der Aufrechterhaltung der Ordnung ergeben“. Der Kommission sollten alle europäischen Staaten sowie - um den britischen Einfluß zu stärken - alle Dominions angehören, „die bereit waren, sich an der Überwachung [policing] Europas zu beteiligen“; die eigentliche Macht würde einem „Lenkungsausschuß" vorbehalten bleiben (dem späteren Rat der Außenminister), in dem die vier Großmächte ihre Entscheidungen einstimmig faßten ${ }^{17}$.

Der europäischen Kontrollbehörde nachgeordnet war in den britischen Vorschlägen „ein weiterer Apparat zur Behandlung der deutschen Probleme vor Ort, [...] der als Vertreter des zentralen Gremiums handelt“. Die Länderkontrollbehörde würde wie die parallelen Organe in Italien, Österreich, Rumänien, Ungarn und Bulgarien nach einer Phase militärischer Besatzungsverwaltung von etwa 18 Monaten in eine zivile Alliierte Hochkommission umgewandelt werden, die während der militärischen Phase „embryonal“ bestand und ihren Tätigkeitsbereich in der „mittleren“ Besatzungsphase allmählich zu Lasten der Militärverwaltung ausdehnte. In dieser Zeit würde die oberste Gewalt ausschließlich bei den Oberkommandierenden liegen, „die

15 Amerikanische Beobachter erkannten früh, daß Englands Pläne für einen Westblock „would favor a policy toward Germany which would conserve a maximum of German strength“. BA, Z 45 F/OMGUS, POLAD-TS/34/1-3 (Kittredge, 25. 11. 1944). Der Verdacht bestand nicht zu Unrecht. PRO, BT 211/73 (ORC(45)1 2, 25. 7. 1945); FO 942/226 (APW(45)13, 26. 1. 1945; APW Committee, 1. 2. 1945). DBPO, I, 1, S. 234 ff., 868 ff., 873 ff. DBPO, I, 5, S. 4, 16, 175. Die Militärs wollten aufgrund ihrer Analyse der potentiellen Bedrohungskonstellation nach Kriegsende die Besatzungszonen zum Ausgangspunkt für einen „Westblock“ gegen die Sowjetunion machen. Das Foreign Office, in sich gespalten, hielt länger an der gesamteuropäischen Kooperationslösung fest. Young, Britain, S. 4 f., 38 f., 56, 60, 143. Deighton, Impossible Peace, S. 16-28.

16 DBPO, I, 1, S. 189. Churchill, Second World War, Bd. 6, S. 305 f.

17 FRUS, 1944/I, S. 154 ff. (EAC(44)3, 15. 1. 1944). FRUS, 1944/II, S. 614 ff. Kettenacker, Krieg, S. $217 \mathrm{ff}$ 
als ein Gremium zusammentreten“, dem zur Kontrolle der deutschen Regierung, „falls sie besteht“, „nachgeordnete politische, militärische, wirtschaftliche und Verwaltungsstäbe“ zur Verfügung standen; darunter befand sich ein zunächst nicht näher definiertes „Exekutivkomitee“, das spätere Koordinationskomitee. In der dritten Phase sollte die Hochkommission die deutsche Verwaltung kontrollieren, bei deren Fehlen selbst „erhebliche administrative Verantwortung“ übernehmen, die Ausführung der Waffenstillstandsbedingungen überwachen sowie den politischen und wirtschaftlichen Neuaufbau Deutschlands in die Wege leiten. Dazu wurde der Hochkommission die Aufsicht über die Besatzungsstreitkräfte, die regionalen Unterorgane der UN (UNRRA, ECITO, ECO) sowie über die deutsche Zivilverwaltung übertragen, soweit eine solche neben der Kontrollkommission bestand.

Insgesamt wies diese Konstruktion starke zentralistische Elemente auf. Die höchste Gewalt sollten die Zonenkommandeure nur bis zur Errichtung des Kontrollrats ausüben, die dann an diesen überging ${ }^{18}$. Den Oberkommandierenden wurde lediglich das Recht zuerkannt, bei Konfliktfällen innerhalb der Hochkommission an die eigene Regierung zu appellieren. Sie durften jedoch unter dem Notstandsvorbehalt jeden Teil der eigenen Zone dem Kriegsrecht unterwerfen, d. h. selbst die uneingeschränkte höchste Autorität außerbalb des Zugriffs der Hochkommission übernehmen. Mit diesen Klauseln suchte der Entwurf auf die Vorbehalte der Militärs Rücksicht zu nehmen, die mit der Entscheidung zugunsten einer zonalen Besatzung sowohl ihre Autonomie in der gemeinsamen Kontrollbehörde als auch strategische Sicherungen für den Fall eines Konflikts mit der Sowjetunion verankern wollten. Damit war ein Präjudiz für die Formen der Besatzungsverwaltung geschaffen. Das Prinzip der „indirekten Herrschaft“, mit geringem Aufwand größtmögliche Effizienz zu gewährleisten, war verankert, aber die Möglichkeit einer zonalen alliierten „Regierung“ statt einer zentralen „Kontrolle“ wurde frühzeitig nicht ausgeschlossen. Es war jedoch fraglich, ob die dezentralisierende Wirkung der Zoneneinteilung durch eine zentrale Kontrollkommission aufgefangen werden konnte; denn die Mischung von ziviler und militärischer Verantwortlichkeit blieb unübersichtlich und interpretationsfähig, ebenso das Verhältnis zwischen den Alliierten in den Kontrollratsorganen oder das Verhältnis zwischen Kontrollrat und Zonenbefehlshabern.

Die USA unterbreiteten der EAC ihre Gegenvorstellungen am 25. März $1944^{19}$. Auch diesen lag ein Kompromiß zwischen State Department und Militärs zugrunde, in dem letztere ihre Positionen stärker hatten verankern können. Aufgrund ihrer Erfahrungen mit der „zusammengesetzten“ Militärregierung in Italien und infolge der Reduktion der Planungen auf eine nach Monaten zu bemessende Übergangszeit befürworteten sie ein dezentralisiertes, „zonales Verwaltungssystem“20. Zu diesem Ansatz waren sie nicht durch strategische oder politische Überlegungen (Sicherheit durch Dismemberment bzw. Föderalisierung) bewogen worden; maßgeblich war allein das Bestreben, keine politische Verantwortung für Deutschland tragen und keine Begrenzung ihrer Handlungsfreiheit in Deutschland hinnehmen zu müssen. Darin ließen sie sich durch das weitsichtige britische Argument vom Mai 1944 nicht irritieren, eine

18 NA, RG 59/EAC, box 3, folder: 133 Germany (Remarks (Control Machinery), 11. 9. 1944).

19 FRUS, 1944/I, S. 185 ff. (WS-15c, 27. 1. 1944).

20 FRUS, 1944/I, S. 186. Vgl. Moskauer Konferenz 1943, S. 45, 254. Kettenacker, Krieg, S. 319 (1. 9. 1944). 
weit gefaßte zonale Autonomie werde es den Sowjets gestatten, Beschlüsse des Kontrollrats nach Belieben zu interpretieren, und durch unterschiedliche Verwaltungssysteme zur Spaltung Deutschlands beitragen. Diese Linie kam Roosevelts „Politik der Vertagung" von Grundsatzentscheidungen auf die Nachkriegszeit entgegen ${ }^{21}$, zumal das State Department bereit war, seine langfristige Perspektive zur Umgestaltung und Reintegration eines demokratischen Deutschland zunächst zurückzustellen.

Der Entwurf war als reines Organisationsstatut entsprechend allgemein gehalten und bezog sich ausschließlich auf die kurze Anfangsperiode, die in der britischen Vorlage als militärische Besatzungsverwaltung geplant war $^{22}$. „Ein zonales Verwaltungssystem scheint vielleicht die praktischste Lösung. [...] Jede Zone würde separat verwaltet, aber Vorkehrungen für die Repräsentanz jeder Regierung in jeder Zone zum Zwecke der Liaison würden getroffen werden." Wenn die Besatzungsverwaltungen ihre „Eigenständigkeit“ behielten und „in ihren jeweiligen Zonen getrennt tätig“ würden, dann brauchte der Kontrollrat nur in Groß-Berlin die „direkte lokale Verwaltung“ selbst zu übernehmen. Außerhalb Berlins würde er „keine Befehlsfunktionen haben“, sondern sich der zonalen Militärverwaltungen als "Vollstreckungsbehörden“ bedienen, die ansonsten allein den Anweisungen ihrer Regierungen unterworfen waren. Entsprechend schmal waren die dem Kontrollrat zugewiesenen Kompetenzen; „Empfehlungen hinsichtlich größerer Änderungen in der Politik würden im Rat formuliert und den drei Regierungen zur Beratung überwiesen werden." Der Kontrollrat und seine (ebenfalls als Drei-Mächte-Direktorium geplanten) „Unterorgane“ für Handel und Industrie, Banken und Geld, Demobilmachung, Transport usw. durften lediglich die Detailplanungen ausführen, „die zur Umsetzung der weitgefaßten Direktiven seitens der Regierungen nötig sind“, die zonalen Maßnahmen „koordinieren“ sowie die Regierungs- und Wirtschaftsbereiche überwachen, „die, sofern die Besatzungsbehörden so entscheiden, weiterhin auf nationaler Ebene im Interesse eines stabilen und geordneten Lebens in Deutschland funktionieren“. Wie in den britischen Entwürfen war ein Gremium der „Politischen Berater“ vorgesehen, das die JCS in „untergeordneter" Funktion belassen wollten, während das State Department dieses „mehr als ein Kabinett denn als Stab" neben den Militärkommandeuren zu etablieren wünschte. Die exekutive Verantwortlichkeit blieb den Militärs überlassen, die als Kontrollrat innerbalb der Obersten Alliierten Behörde „die politischen [policy-making] Organe der bestehenden deutschen Regierung ersetzen“; „der bestehende deutsche Verwaltungsapparat, aber nicht der politische [policy-making] Apparat, soll zur Ausführung der vereinbarten Politik und der Routineverwaltung Deutschlands genutzt werden “23.

21 Für Roosevelt war die EAC eine „drittrangige Ebene“ im Verhältnis der Großmächte. Sie war nur „beratend“; an ihre Empfehlungen würden die Regierungen nicht gebunden sein. FRUS, Malta and Yalta, S. 155, 158. TL, Oral History Collection, Riddleberger (1971), S. 14. Thomas, EAC, S. $28 \mathrm{ff}$.

22 NA, RG 107/McCloy, box 27, folder: 370.8 Germany (23. 11. 1944). Während das State Department von einer Besatzungszeit von 5-10 Jahren ausging (Hammond, Directives, S. 344 f.), wollten die Militärs diese Phase „brief“ bzw. „very short“ halten. BA, Z 45 F/OMGUS, 2/92-1/3. FRUS, 1945/III, S. 441. Am 29. 11. 1945 vertrat Patterson die Auffassung, der Übergang von der militärischen zur zivilen Phase werde „require negotiations with the other powers represented on the Control Council in Berlin and will no doubt require a modification of the present agreement on control machinery for Germany“. FRUS, 1946/I, S. $1129 \mathrm{f}$.

${ }^{23}$ FRUS, 1944/I, S. 185 ff. NA, RG 59/EAC, box 3 (7. 2., 5. und 16. 7. 1944; Draft, 19.6. 1944); RG 107/McCloy, box 26 (8. 5. 1944). 
Die Konzeption der USA war im Unterschied zu der britischen nicht zentralistisch, sondern dualistisch angelegt; die föderalen Elemente überwogen, während die zentralen durch enge Definition streng begrenzt waren. „Die Wahl hinsichtlich der Form des Verwaltungsapparats scheint zu sein zwischen“, wie dem Committee on Post-War Programs nicht verborgen geblieben war, „(a) einem vereinigten [unified] DreiMächte-System, (b) einer vollständig getrennten und unabhängigen Verwaltung in jeder der drei Zonen, und (c) einer Zwischenlösung.“ Die erste Variante, die die Briten favorisierten, stieß auf wenig Gegenliebe, da sie „die Aufgabe des Zonenkommandeurs vor allem darauf begrenzen würde, die administrativen Anordnungen des zentralen Drei-Mächte-Organs auszuführen“. Die zweite Variante verfiel der Ablehnung, weil sie zum ökonomischen und sozialen Kollaps Deutschlands führen müsse. Aber die konkrete Ausgestaltung der „Zwischenlösung“ blieb offen, nämlich „ob das DreiMächte-Organ in erster Linie beratend oder eine genuine gemeinsame Verwaltungsbehörde“ sei. Das Komitee, dem der amerikanische Entwurf zu „allgemein“ geblieben war, empfahl die „Errichtung einer Drei-Mächte-Organisation mit der Vollmacht, die einheitliche Verwaltung ganz Deutschlands anzuordnen"24. Doch der Entwurf, den die amerikanische Delegation am 11. September in der EAC zur Diskussion stellte, folgte dem Modell vom 27. Januar bzw. 26. Februar 1944: Der Kontrollrat solle die Aktivitäten der Alliierten „koordinieren“ und „jene zentralisierten Regierungsfunktionen und Wirtschaftsaktivitäten überwachen, die [...] für nötig gehalten werden“. Die Einheitlichkeit der Maßnahmen in den Zonen könne durch Liaisonoffiziere gewährleistet werden ${ }^{25}$.

Entsprechend unklar blieb die amerikanische Verhandlungsführung in der EAC. Einerseits bezeichnete Winant die amerikanische Konzeption als der sowjetischen weitgehend entsprechend, indem jeder Oberbefehlshaber in seiner Besatzungszone "die oberste Gewalt" sei $^{26}$; andererseits folgte seine Interpretation vom 20. September, „daß die oberste Gewalt im Zentrum liegen sollte, als der letzten Quelle der Autorität für Deutschland als Ganzes“, den Vorstellungen des State Department. Winant hatte die fundamentale Differenz zur Sowjetunion sehr wohl erkannt, die das Verhältnis der Zonen untereinander bzw. zum Kontrollrat sozusagen konföderativ definierte und die Souveränität entsprechend an der Peripherie ansiedelte. Er dagegen wollte dieses Verhältnis, wie sein Rekurs auf die amerikanische Verfassung nahelegen mag, in Anlehnung an die britische Position dahingehend uminterpretieren, daß im Sinne einer föderalistischen Konzeption die zonalen Militärregierungen über erhebliche Autonomie, aber nicht über „Souveränität“ verfügten. Winant war gleichwohl nicht bereit, die „staatsrechtliche“ Differenz bis zum offenen Dissens weiterzuverfolgen. Da der Zonenkommandeur in Personalunion dem einstimmig beschließenden Kontrollrat angehörte, schien es unerheblich, welcher Funktion er seine „Souveränität“ verdankte. Allerdings, das hatte er nicht bedacht, die politisch entscheidende "Lücke“ in dieser "Verfassungstheorie“ wurde erst offenbar, als der Konfliktfall nicht mehr als wenig wahrscheinliche Denkfigur hinwegdefiniert werden konnte.

24 FRUS, 1944/I, S. 317 (5. 8. 1944).

25 PRO, FO 371/40664/U7452 (Annex)

26 Roosevelts Vorstellungen gingen gleichfalls dahin, daß die Oberkommandierenden in ihrer jeweiligen Zone verantwortlich sein würden, während der Kontrollrat eher eine „zusätzliche“ Kommission „aus Militärs mit niedrigerem Rang“ war, der ein starkes ziviles Element beigesellt werden sollte. FRUS, 1944/I, S. 409. 
Mit diesen anglo-amerikanischen Entwürfen vom Januar 1944 waren die Umrisse des Kontrollapparats in Deutschland festgelegt. Es blieb der Sowjetunion vorbehalten, mit ihrem Entwurf vom 26. August 1944 die entscheidenden Akzente zu setzen ${ }^{27}$. Sie griff auf die amerikanische Vorlage zurück, deren dezentralisierende Elemente sie noch verschärfte. Ihr Vorschlag sah Regelungen ebenfalls nur für die erste, militärische Kontrollperiode vor. Da jede weitere Entwicklung in Deutschland nicht vorhersehbar sei, sollten für diese Phase nur die ,wichtigsten Prinzipien der Kontrolle“ festgelegt werden, d. h. politische Richtlinien, aber keine konkreten Einzelmaßnahmen. Die Erfüllung dieser Aufgaben müsse den zeitlichen Rahmen der Besatzung bestimmen; diese werde „eher länger“ dauern, etwa 12-18 Monate. In ihrer Konzeption verfügte der Zonenbefehlshaber über die „oberste Verantwortung und Gewalt in seiner Zone“, die drei Befehlshaber gemeinsam über die „oberste Gewalt für Deutschland“. Um die „Einheitlichkeit“ der „wichtigsten“ politischen und wirtschaftlichen Maßnahmen in den Zonen sicherzustellen und die deutsche „Regierung“ und ihre Organe zu kontrollieren, „werden die drei Oberbefehlshaber einen Kontrollrat bilden“, der grundsätzlich nur einstimmig beschließen durfte. Als zugleich ausführendes und die Entscheidungen vorbereitendes Organ war diesem ein Koordinationskomitee unterstellt. Direkte exekutive und administrative Funktionen sowie ein entsprechender Verwaltungsunterbau waren nicht vorgesehen, da nur Berlin (das „als eine besondere Zone betrachtet werden kann“28) von einer „Inter-Alliierten ,Regierungsbehörde“ (Komendatura)“ verwaltet werden sollte. Dem Koordinationskomitee sollten einige ausführende Beamte „zugeordnet“ werden, keine „Berater“, sondern ein „technischer Apparat und Experten“. Aus dieser Konstruktion war erkennbar, daß die Sowjetunion möglichst wenig Befugnisse an nachgeordnete Stellen des Kontrollapparats delegieren wollte, jedoch nicht im Sinne eines Systems der ,indirekten Herrschaft“, sondern im Interesse ihrer zonalen Autonomie. Die eigentliche Verwaltungstätigkeit sollte deutschen Stellen überlassen bleiben, die, sofern sie bei Kriegsende nicht bestanden, ,vielleicht vorübergehend“ neu ins Leben gerufen werden müßten. Es war aber nicht - das entsprach dem amerikanischen Plan - an eine deutsche Regierung, sondern lediglich an ein „Regierungsorgan“ zur Unterstützung der Alliierten gedacht, da diese die exekutive Tätigkeit nicht selbst vollständig übernehmen könnten. Das deutsche Exekutivorgan des Kontrollrats, gelegentlich gleichwohl „deutsche zentrale Regierung“ genannt, sollte ausdrücklich „keine lokale Vertretung“ haben. „Lokale Fragen“, das war der entscheidende Punkt, blieben den Zonenbefehlshabern vorbehalten. Da die Sowjetunion weder an ein Dismemberment noch an eine vollständige Besetzung ganz

27 Der Entwurf in: FRUS, 1944/I, S. 299 ff. (EAC(44)25). Zusätzlich berücksichtigt wurden die Erläuterungen Gousews in der EAC (meine Hervorhebungen).

28 AMAE, Y 692, Bl. 225 (Januar 1945: „zone berlinoise“). Der Vorschlag des Militärdirektorats, Berlin im Hinblick auf die Demobilisierung "as an additional zone under the control of the Komendatura“ zu behandeln, scheiterte am Widerstand Sokolowskis. BA, Z 45 F/OMGUS, 2/118-1/5-16 (CORC/ $\mathrm{P}(45) 114$ und 2nd Revise; DMIL/P(45)9, 27.9. 1945). Die CCG wollte durch die Trennung des FDGB-Berlin vom FDGB der SBZ „preserve the status of Berlin as a fifth zone“. PRO, FO 943/765 (22. 9. 1946). Am 17.6. 1947 wies die Deutsche Verwaltung für Handel und Versorgung der SBZ auf den „grundsätzlichen Irrtum“ hin, „Berlin zur sowjetischen Zone (SBZ) zu rechnen. Das GroßBerliner Wirtschaftsgebiet bildet gewissermaßen eine selbständige Zone und untersteht der Alliierten Kommandantur, also nicht der SMAD“. BAC, N-1/731, Bl. 31 (17.6. 1947). Vereinzelt wurde von einer polnischen Zone gesprochen. NA, RG 43/WWII\&PWConf, box 147, folder: State Department Briefs (Intelligence Research Report OCL-4252, 7. 1. 1947). Eine belgische Zone hatte die Sowjetunion abgelehnt. AMAE, Y 121, Bl. 58, $119 \mathrm{f}$. 
Deutschlands dachte, sondern (wie vorübergehend auch anglo-amerikanische Kreise) an „ausgewählten Schlüsselpunkten“ Besatzungstruppen stationieren wollte, brauchte der Kontrollrat keinen Unterbau und keine „lokalen Vertreter“ in den Zonen: Der Kontrollrat sollte kontrollieren, nicht regieren. Lediglich „politische Fragen, wirtschaftliche Fragen und Fragen der Entwaffnung und Entmilitarisierung" waren zentral vom Kontrollrat zu regeln. Entscheidend war der Vorbehalt, daß zentrale Entscheidungen ,in allen Zonen so ausgeführt würden, daß sie den Bedürfnissen der jeweiligen Zonenbefehlshaber entgegenkommen“. Gousew definierte die „staatsrechtliche“ Stellung des Kontrollrats, der Zonenkommandeur besitze keine eigene Autorität, sondern dürfe nur auf Anweisung der Regierungen tätig werden, für die er die Zustimmung im Kontrollrat suchen müsse; bei Nichteinigung seien die ungelösten Fragen an die Regierungen zurückzuverweisen. Die Zonengrenzen seien „nur“ für Besatzungszwecke und nicht als Staatsgrenzen gezogen worden und müßten, vor allem im wirtschaftlichen Bereich, durchlässig sein; insofern sei es Aufgabe der Zonenbefehlshaber, ihre Maßnahmen zu koordinieren, „nicht nur, soweit es seine Zone betrifft, sondern auch, soweit es Deutschland als Ganzes betrifft“. Zugleich legte Gousew in einem Maße Wert auf die Autonomie des Zonenbefehlshabers, daß die Zonengrenzen doch mehr als Demarkationslinien wurden: „Die eigentlichen Elemente der Kontrolle würden die Besatzungskräfte in jeder der drei Zonen sein. Das habe Vorrang. Die zentralen Behörden, die wir durch koordiniertes Handeln vom Zentrum her lenken, sind sekundär. Jeder Oberkommandierende würde für die Zustände in seiner Zone gegenüber seiner eigenen Regierung verantwortlich sein und nicht allen drei Regierungen zu-

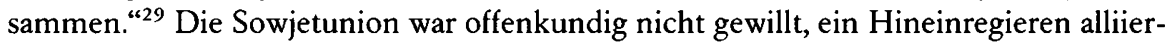
ter Kontrollratsorgane oder gar deutscher Zentralverwaltungen in ihre Zone hinzunehmen. Das deutete darauf hin, daß sie im Konfliktfalle bereit war, in ihrer Zone eigene Wege zu gehen; diese war Grundlage ihrer „souveränen“ Herrschaft in Deutschland $^{30}$. Ihr Zonenbefehlshaber war nicht Verwalter einer wie auch immer zu konstruierenden deutschen Souveränität, sondern Exponent der sowjetischen Souveränität, die er weder mit den Vertretern der Westmächte teilte, noch mit ihnen zusammen gemeinsam ausübte. Daher suchte die Sowjetunion alles zu vermeiden, was auch nur den Anschein des „staatsrechtlichen“ Primats des Kontrollrats gegenüber den Zonenkommandeuren hätte erwecken können.

In den Beratungen der EAC standen sich zwei Konzeptionen gegenüber: „die Idee der Drei-Mächte-Kontrolle Deutschlands und die Idee der obersten Gewalt in jeder Zone“. Politisch entscheidend für die Funktionsfähigkeit des zentralen Kontrollorgans, und damit für die Kompatibilität der Besatzungspraxis in den Zonen, war der Grad von Autonomie, der den Zonenbefehlshabern vorbehalten blieb, bzw. das Maß an exekutiver Gewalt, das dem Kontrollorgan zugebilligt wurde. Wenn die zonale Autonomie sehr weit interpretiert wurde, so war das vor allem auf die Forderungen der Sowjetunion zurückzuführen, denen die USA jedoch ohne Zögern zustimmten. Als die amerikanische Delegation das sowjetische Papier als „vielversprechend“ begrüß-

29 PRO, FO 371/40665/U7516 (20.9. 1944).

30 FRUS, 1944/I, S. 328, 391. Tjulpanow, Rolle, S. 243: „Die Souveränität der Militäradministrationen aller Besatzungszonen war [...] in allen ihren Tätigkeitsbereichen [...] durch die auf der Potsdamer Konferenz übernommenen völkerrechtlichen Verpflichtungen eingeschränkt." Daraus leitete die SMAD den Anspruch und die Verpflichtung ab, für deren Einhaltung in ganz Deutschland sorgen zu müssen. 
$\mathrm{te}^{31}$, war eine Vorentscheidung für die weiteren Verhandlungen gefallen. Nachdem am 12. September 1944 das Zonenprotokoll unterzeichnet worden war, konnte die Einigung rasch erzielt werden; Briten und Sowjets waren offenkundig bestrebt, alle Grundsatzfragen zu erledigen, ehe im November 1944 die französische Provisorische Regierung der EAC beitrat ${ }^{32}$. In nur vier Sitzungen im September 1944 gelang es, durch Angleichung der Entwürfe die endgültige Organisationsstruktur festzulegen ${ }^{33}$. Mit gewissem Zögern akzeptierte die Sowjetunion die von den USA geforderten „Unterorgane“, die späteren Direktorate, nachdem sie vergeblich versucht hatte, deren Errichtung vom „Bedarf“ abhängig zu machen; sie selbst hatte bezeichnenderweise besondere Organe nur für Reparationen und Kriegsgefangene vorgesehen ${ }^{34}$. Zurückgewiesen wurde das britische Bemühen, ein beratendes Gremium der kleineren europäischen Mächte ${ }^{35}$ und der Dominions beim Kontrollrat zu errichten. Aufgrund sowjetischer Vorbehalte, denen sich die USA anschlossen, wurden diesen nur militärische Verbindungsstäbe zugestanden, um ihnen eine einflußreichere Repräsentation vorzuenthalten. Maßgeblich für den schließlich gefundenen Kompromiß wurden die USA. Botschafter Winant, der mangels politischer Entscheidungen in Washington keine klaren Richtlinien erhalten hatte, suchte in der EAC möglichst viel von den bisher erreichten Kompromissen zu retten, ehe die Anfang August von Morgenthau ausgelöste Debatte diese wieder in Frage stellte ${ }^{36}$. In der vermeintlich rein "technischen“ Frage der Organisation des Kontrollrats war solches möglich, bei den inhaltlichen Zielen der Besatzungspolitik dagegen nicht. Da die amerikanische Position das Ergebnis eines prekären internen Kompromisses war, der inhaltliche Aspekte ausklammerte und selbst die technisch-organisatorischen Fragen ambivalent und interpretationsfähig gestaltete, konnte sie zwischen dem zentralistischen britischen Modell (alliierte Kontrolle einer deutschen zonenübergreifenden Verwaltung) und dem konföderativen sowjetischen Modell (zonale Selbstverwaltung mit zentraler alliierter Politikkoordination) den Mittelweg weisen: einerseits zentrale alliierte Politikentscheidung (in einigen Finanz- und Wirtschaftsbereichen auch alleinige Politikausübung) und andererseits zentral koordinierte, aber zonal exekutierte deutsch-alliierte Politikausübung.

Dieses de facto etablierte Mischmodell beruhte auf der Annahme optimaler Bedingungen, weil es interner Einigungsunfähigkeit entsprang; es sollte sich als fataler Trugschluß erweisen, daß in der kurzen Übergangszeit der rein militärischen Besatzungsverwaltung ein organisatorischer und politischer Status quo in Deutschland aufrechterhalten werden könne. Eine ausdrückliche Festlegung erfolgte jedoch in der EAC nicht. Angesichts des sowjetischen Widerstrebens wurde am 20. September auf einen formellen Beschluß verzichtet, aber nach britischer Interpretation bestand der vage Konsens, daß ,jeder Oberkommandierende in seiner Zone, soweit Fragen berührt sind, die ganz Deutschland betreffen, nicht gemäß Anweisungen handeln würde, die er vom Kontrollrat erhält, sondern auf der Grundlage von Beschlüssen von die-

31 FRUS, 1944/I, S. 331 (Moseley, 5. 9. 1944).

32 FRUS, 1944/I, S. 384, $391 \mathrm{f}$.

33 Eine Synopse der drei Papiere in: NA, RG 59/EAC, box 3 (11.9. 1944) und BA, Z 45 F/OMGUS, AGTS/104/25. Die britischen EAC-Protokolle in: PRO, FO 371/40664 und 40665; die amerikanischen in: NA, RG 59/EAC, box 19.

34 Thomas, EAC, S. 168.

35 Entsprechende Forderungen vom Frühjahr 1945 in: NA, RG 59/EAC, box 2; 740.00119 EAC/31745 (Report des Allied Consultative Committee der EAC).

36 Hammond, Directives, S. 338 ff., 351 f. Blum, Morgenthau Diaries, S. 375 ff. 
sem, denen er selbst in seiner anderen Eigenschaft zugestimmt haben würde“. Auch Winant interpretierte das Ergebnis dahingehend, „daß nach dieser Formulierung der

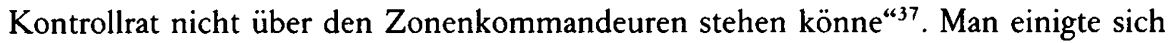
schließlich auf die Formulierung, die unverändert in das Potsdamer Abkommen übernommen wurde: „Die oberste Gewalt in Deutschland wird, auf der Grundlage von Instruktionen ihrer jeweiligen Regierungen, von den Oberbefehlshabern [...] ausgeübt werden, und zwar von jedem in seiner eigenen Besatzungszone, und auch gemeinsam in Angelegenheiten, die Deutschland als Ganzes betreffen, in ihrer Eigenschaft als Mitglieder des obersten Kontrollorgans, das gemäß dieser Vereinbarung konstituiert wird." ${ }^{38}$ Die Sowjetunion hatte einen folgenschweren Sieg errungen. Und die Westmächte akzeptierten diesen in Yalta in der vollen Erkenntnis seiner Tragweite. Wenn sie der Sowjetunion entgegenkamen, dann war das kaum naive Beflissenheit oder gar „Appeasement“, sondern Folge der Unsicherheit über den eigenen deutschlandpolitischen Kurs und mangelnder interner Einigungsfähigkeit. Bei den Westmächten mehrten sich die Stimmen, die Konflikte über die gemeinsame Verwaltung Deutschlands und die Rekonstruktion Europas erwarteten und die daher in einem dualistisch konstruierten Besatzungsregime das geeignete Mittel erblickten, im Falle der zu erwartenden Erschütterungen im Verhältnis der Großmächte untereinander sich eine unilaterale Handlungsfreiheit zu bewahren.

Am 14. November 1944 wurde die „Vereinbarung über den Kontrollapparat in Deutschland“ von den drei EAC-Delegationen unterzeichnet und zusammen mit dem Zonenprotokoll bis zur Konferenz von Yalta von den Regierungen gebilligt ${ }^{39}$. Frankreich, das im Januar 1945 noch gefürchtet hatte, nur auf Spitzen- und nicht auch auf der Arbeitsebene der Direktorate vertreten zu sein ${ }^{40}$, trat dem Protokoll offiziell am 1. Mai 1945 bei. In der EAC hatte die französische Delegation keine Änderungen gefordert, sondern sich im Gegenteil bemüht, „die Vier-Mächte-Einigung zu erleichtern “41. Paris konnte kein Interesse daran haben, seinen deutschlandpolitischen $\mathrm{Zu}$ griff schon im Vorfeld durch Obstruktion selbst zu gefährden, sondern brauchte zunächst die gesicherte Vetoposition als Voraussetzung für künftige Einflußnahme, solange es auf der Ebene der Regierungschefs nicht beteiligt war. Die endgültige Fas-

37 PRO, FO 371/40665/U7516 (20.9. 1944).

38 FRUS, Malta and Yalta, S. 124 ff. (meine Hervorhebung). Im Kommuniqué von Yalta hieß es: „Coordinated administration and control [...] through a central Control Commission"; ebenda, S. 970 (meine Hervorhebung).

39 FRUS, Malta and Yalta, S. 124, 958, 970. England bestätigte das Protokoll am 5. 12. 1944 und die USA am 23. 1. 1945, die Sowjetunion erst am 6. 2. 1945 während der Konferenz von Yalta, nachdem die Westmächte ihr Festhalten am Zonenprotokoll am Vortag bekräftigt hatten. Durch Festlegung der Zonen wollte sich die Sowjetunion offenkundig eine autonome Stellung in Deutschland sichern. Sie bestand daher auf einem formellen Protokoll über die Errichtung des Kontrollapparats, während die Westmächte sich mit einer informellen Absprache begnügt hätten.

40 AMAE, Y 692, B1. 225. In Yalta war überlegt worden, Frankreich eine Zone, aber keinen Sitz im Kontrollrat einzuräumen. Auch die Briten, die einen Kontrollratssitz für Frankreich befürworteten, wollten das Land nicht auf den Kriegskonferenzen der „Großen Drei“ vertreten sehen. Roosevelt änderte noch in Yalta seine Meinung und plädierte für eine Beteiligung der Franzosen am Kontrollrat. Stalin schloß sich an. Krim(Jalta)konferenz 1945, S. 60 ff., 92 f., 99 f., 107, 177. AMAE, Y 121, Bl. 181. Dafür versuchte die Sowjetunion, Polen und Jugoslawien an der Alliierten Reparationskommission zu beteiligen, aber Frankreich von dieser auszuschließen. FRUS, 1945/III, S. 1194 ff., 1205 , $1209 \mathrm{f} ., 1230 \mathrm{f}$.

41 NA, RG 59/CED, box 1, folder: General Policy (EAC, 12. 7. 1945). 
sung des Protokolls über den Kontrollapparat wurde von allen vier Mächten am 4. Mai 1945 bestätigt $^{42}$.

\section{Yalta 1945: Interpretation und Revision}

Mit der Festlegung des Organisationsaufbaus waren die eigentlichen Probleme nicht gelöst, geschweige denn offen angesprochen worden; es sollte sich jedoch erweisen, daß damit weitreichende Entscheidungen auch über Politikinhalte vorgegeben waren. Ungeklärt blieb das Verhältnis von Kontrollrat und Zonenkommandeuren, ebenso das von Kontrollrat und deutschen Behörden, also von Kontrolle und Verwaltung, von Aufgabenbereich und Status. Weder waren die „allgemeinen Prinzipien“ der Besatzungsherrschaft in groben Umrissen definiert, noch dem Kontrollrat durch die EAC Handlungsanweisungen in Form von Direktiven an die Hand gegeben, um die Einheitlichkeit der Maßnahmen in den Zonen zu gewährleisten. Offensichtlich waren die Regierungen (noch) nicht daran interessiert, sich bis in solche Details festzulegen. Gegen dieses Aufschieben der Entscheidungen waren die drängenden Planungsstäbe, vor allem in den jeweiligen Außenministerien, machtlos.

Die Zeit, in der das State Department seine Vorstellungen ungehindert hätte durchsetzen können, war ohnehin vorbei. Nach der Landung in der Normandie und dem überraschend schnellen Vorstoß der alliierten Truppen in Frankreich drängten die Militärs auf rasche Entscheidungen, da sie zunehmend von dem ungeliebten Fall ausgingen, daß Deutschland kollabieren und die Alliierten selbst die Verwaltung und die Versorgung würden übernehmen müssen. Während Eisenhower Mitte August 1944 versuchte, diese Last auf andere Schultern, notfalls die der Deutschen selbst, abzuwälzen, griff Morgenthau mit Erfolg in die Debatte ein. Roosevelt zog am 26. August die bisherigen Richtlinien für die Besatzungsverwaltung zurück und verhalf in der nachfolgenden internen Auseinandersetzung Morgenthaus Vorstellungen in der „Vorläufigen Direktive“ JCS 1067 vom 22./24. September zum Durchbruch. Weitsichtige Teilnehmer an dieser internen Debatte übersahen nicht, daß die Beschlüsse wertlos waren, wenn sie von den anderen Alliierten nicht akzeptiert wurden. Darauf setzte das State Department seine Hoffnungen; mit Erfolg, wie sich bald zeigte. Zudem blieb die Geltungsdauer der Direktive offen; je kürzer die militärische Besatzungsphase, desto eher konnte das State Department darauf rechnen, seine Vorstellungen doch noch durchzusetzen. Diese Gefahr erkannten auch Morgenthau und sein Vertrauensmann in London, Colonel Bernstein. Ihre Möglichkeit, die Taktik des State Department zu durchkreuzen, lag darin, die eigene Zone von äußerer Einflußnahme abzuschirmen, indem dem Kontrollrat möglichst wenig Einfluß auf die Verwaltung in den Zonen eingeräumt wurde ${ }^{43}$. Denn jede zentralistische Lösung mochte das Dismemberment Deutschlands negativ präjudizieren.

Das ging über die bisherigen Forderungen der Militärs noch hinaus. Diese griffen Ende Oktober Morgenthaus Kritik auf, um mit seiner Hilfe eine Revision des Kontrollabkommens durchzusetzen. Dessen „zentralistischer“ Ansatz widerspreche den

42 FRUS, 1945/III, S. 264 f.

13 Hammond, Directives, S. 348-76, 387. Blum, Morgenthau Diaries, S. 383 ff. FRUS, Malta and Yalta, S. $143 \mathrm{ff}$. 
Vorstellungen der Stabschefs, die „absolute Kontrolle“ und „volle Handlungsfreiheit“ des Oberbefehlshabers in seiner Zone und dessen „Unabhängigkeit von der Kontrolle des zentralen Kontrollrats“ gefordert hatten. Ohne das Abkommen aufzukündigen, müsse diese „Verlagerung“ zugunsten der Zentrale „durch andere Mittel“ korrigiert werden. Zwar sei, da der Kontrollrat einstimmig beschließe, der amerikanische Zonenkommandeur in der Lage, ,den Kontrollrat davon abzuhalten, sich übermäßig einzumischen, in Maßnahmen in seiner Zone einzugreifen oder die Überwachung von Fragen zu versuchen, die die Wirtschaftsdirektive, die JCS 1067 beigefügt ist, der nicht-nazistischen deutschen Initiative überlassen würde“; doch müsse der amerikanische Zonenbefehlshaber angewiesen werden, das Kontrollabkommen ,in U̇bereinstimmung mit der amerikanischen Auffassung seiner Bedeutung auszulegen und seine Zustimmung zu einstimmigen Beschlüssen zu verweigern, die nicht mit der amerikanischen Politik übereinstimmen“. Die Militärs drängten daher auf die Verabschiedung einer revidierten Fassung von JCS 1067 durch die EAC, die nicht mehr Direktive der JCS oder, das hatten die Briten bereits abgelehnt, der CCS, sondern gemeinsame Direktive der Regierungen an alle Oberbefehlshaber sein sollte. Das State Department gab diesem Druck nach und übersandte der EAC-Delegation am 2. November den Entwurf für eine solche gemeinsame Direktive, die die Gewichte nachträglich zugunsten der Zonenkommandeure verschoben hätte; der Kontrollrat sollte lediglich „über-

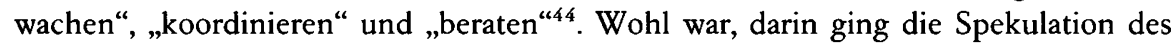
State Department auf, an eine Neuverhandlung des Abkommens nicht mehr zu denken; doch bestand die Gefahr, daß dann das Bestreben Morgenthaus und der Militärs nach unilateraler Handlungs- und Interpretationsfreiheit noch stärker wurde. In der Tat wurde die (nationale) Direktive JCS 1067 am 6. Januar 1945 formell an das Kontrollabkommen angepaßt, aber die Akzentverlagerung war deutlich zu erkennen: „Die vereinbarte Politik des Kontrollrats soll überall in den Zonen maßgeblich sein.“ Komme eine Einigung nicht zustande oder fielen einzelne Politik- und Wirtschaftsbereiche nicht in die Zuständigkeit des Kontrollrats, habe der Zonenkommandeur die „alleinige Verantwortlichkeit“ in seiner Zone, u. a. im Hinblick auf die ausschließliche Kontrolle der zonalen Abteilungen einer möglichen deutschen Zentralverwaltung; er müsse lediglich seine Militärverwaltung mit der der anderen Zonen über den Kontrollrat „koordinieren“, um die „Einheitlichkeit“ der Maßnahmen zu wahren ${ }^{45}$. Erneut hatte das State Department eingelenkt, obwohl es bereit war, „bis zu einem gewissen Grade“ die Begrenzung der zonalen Handlungsfreiheit zu akzeptieren, indem etwa einige Bereiche der Wirtschaft in der alleinigen Verantwortung des Kontrollrats verblieben; Ziel war es, ,jede der Besatzungsmächte daran zu hindern, in ihrer Besatzungszone nach eigenem Gutdünken zu verfahren“, damit in erster Linie die Sowjetunion, aber wohl auch die eigenen Militärs (und Morgenthau) meinend ${ }^{46}$. Insgesamt sah die

${ }^{44}$ FRUS, 1944/I, S. 374 ff. (28. 10./2. 11. 1944), 382 ff. (State Department, 4. 11. 1944). NA, RG 107/ McCloy, box 27, folder: 370.8 Germany (23. 11. 1944); RG 43/ACC, box 3, folder: Control Machinery (WS-228).

45 FRUS, 1945/III, S. 378 ff. (meine Hervorhebung). Vgl. NA, RG 107/McCloy, box 28 (The New Proposed German Directive, o.D.); RG 59/EAC, box 2 (Joint U.S. Advisors EAC, 10. 1. 1945): „The extent to which the Control Council might exercise supervision within the Zones can only be determined by a unanimous decision of the Control Council, namely the three Zone Commanders". BA, Z 45 F/OMGUS, USGCC/44-45/2/3 (22. 2. 1945; Hervorhebung im Original).

46 BA, Z 45 F/OMGUS, POLAD-TS/34/1-3. Roosevelt glaubte, daß die Sowjets in ihrer Zone „will do 
Direktive in ihrer Fassung von Anfang Januar 1945 ein duales System der Besatzungsverwaltung vor, das Kontrollrat und Zonenkommandeur formell gleichrangig stellte, doch verankerte das Vetorecht den Vorrang der Zonen. Als Ergebnis eines Kompromisses zwischen den verschiedenen Gruppen und Interessen innerhalb der amerikanischen Regierung blieb die Direktive auch in anderen Festlegungen schwammig und unentschieden. Ihre Gültigkeit wurde auf die „erste Phase nach dem Ende des organisierten Widerstands“ begrenzt; alle Anordnungen sollten „von kurzfristigem und militärischem Charakter sein, um keine Maßnahmen zu präjudizieren, die später beschlossen werden könnten“. Das sollte die Annahme des radikalen Zonenprinzips auch in der EAC erleichtern, die Militärs von politischen Querelen in einer interalliierten Besatzungsverwaltung entlasten und den Regierungen bzw. dem State Department frühzeitig einen autonomen Spielraum für die Neugestaltung Deutschlands eröffnen.

Mit dieser Vertagung der eigentlichen Entscheidung konnten alle beteiligten Regierungsstellen leben, zumal die unterschiedlichen inhaltlichen und organisatorischen Vorstellungen in drei Anhängen als politische, wirtschaftliche und finanzielle Direktive verankert waren. Diese Vertagung entsprach den Absichten Roosevelts ebenso wie den Hoffnungen des State Department, seine Vorstellung von der langfristigen Reintegration Deutschlands in Welthandel und Weltgemeinschaft später gegenüber Morgenthau doch noch durchsetzen zu können. Die Forderungen Winants oder der Briten nach einer Festlegung von konkreten Inhalten der Besatzungsziele vor Abschluß des Waffenstillstandes, solange der Einigungszwang noch groß war, mußten hinter dem institutionellen Interessenausgleich zurückstehen. Winant protestierte daher aus London heftig, wenngleich vergeblich, gegen die „beträchtliche“ Reinterpretation von JCS 1067 . Seine Kritik richtete sich vornehmlich dagegen, daß die neue Fassung „nicht im voraus die präzise Aufteilung der Verantwortlichkeiten zwischen dem Kontrollrat und den Zonen zu definieren“ versuche. Diese „doppeldeutige“ Haltung werde nicht nur bei den Alliierten für „Konfusion“ sorgen, sondern auch SHAEF bzw. USGCC legten die Direktive dahingehend aus, Ziel der amerikanischen Politik sei die Verwaltung der eigenen Zone „als separate Einheit“; der Kontrollrat werde „eher als ein beratendes denn als ein politische Entscheidungen treffendes Gremium“ aufgefaßt; das Vetorecht im Kontrollrat erlaube es, daß die „Militärregierung in jeder Zone nach eigenem Gutdünken vorgehen werde“ und „die Zonenbehörden es in ihr Belieben stellen werden, ob sie die gemeinsame Politik in der U.S.-Zone ausführen oder ob sie die Entscheidungen bzw., wie sie es formulieren, die Empfehlungen des Kontrollrats ignorieren werden“. Winant beschwor Regierung und Militärs, nicht fortwährend von der "freien Hand“ in der eigenen Zone zu reden, zumindest nicht öffentlich, wolle man nicht eine „sehr ernste“ Beeinträchtigung der sowjetischen Kooperationsbereitschaft provozieren. Denn er unterstellte der Sowjetunion ein Interesse am Erhalt zentralistischer Strukturen, damit Deutschland die ihm auferlegten (Reparations-)Forderungen erfüllen könne; gegenüber diesem Ziel sei für Moskau die Umgestaltung Deutschlands sekundär. Wenn daher JCS 1067 eine „wirtschaftliche Kontrolle in jeder der drei oder vier getrennten militärischen Zonen“"vorsehe, ohne Rück-

more or less what they wish“. FRUS, Malta and Yalta, S. 155. Gegen das Streben der Sowjetunion nach maximaler Autonomie in ihrer Zone „les Américains veulent faire de la Commission de Berlin un Gouvernement de l'Allemagne aux directives duquel les Commandements alliés se conformeraient strictement“. AMAE, B/Etats-Unis/170, Bl. 41 (28. 2. 1945). 
sicht auf Rohstoffverteilung oder Transportwege, seien „ernsthafte Friktionen“ mit den Alliierten absehbar ${ }^{47}$. SHAEF dementierte nach einer „Untersuchung“ die Vorwürfe, aber das State Department sekundierte: Treasury und War Department hätten seit Monaten „beinahe vollständige Handlungsfreiheit“ in einem Ausmaß verlangt, das den Sowjets (und vermutlich auch den Briten) als „faktische Zurückweisung“ der Vereinbarungen erscheinen müsse ${ }^{48}$.

Winants Forderung nach einer „Klärung“ - mit anderen Worten: nach einer Revision - der amerikanischen Position erhielt ihre Chance, als Roosevelt am 28. Februar 1945 das State Department mit der Umsetzung der Beschlüsse von Yalta beauftragte. Dieses legte am 8. März einen Entwurf vor, den der Präsident am 10./12. März billigte. Darin hatten die Diplomaten ihre zentralistischere Konzeption verankert: Der Kontrollrat werde die Stelle und die Funktion „einer" deutschen Zentralregierung einnehmen; seine Autorität solle in ganz Deutschland maßgeblich sein; die Besatzungszonen seien „Gebiete des Vollzugs [...], nicht Gebiete, in denen der Zonenkommandeur einen weiten Spielraum autonomer Machtbefugnisse besitzt“. Dazu werde ein deutscher Verwaltungsapparat benötigt; Zentralverwaltungen müßten eingesetzt oder, falls aufgelöst, neu geschaffen werden ${ }^{49}$. Zur Absicherung seiner zentralistischeren Konzeption, für die es bei den Briten Unterstützung erwarten konnte, drängte jetzt auch das State Department auf die Verabschiedung einer Generaldirektive an die Zonenbefehlshaber in der EAC, um nicht nur die Sowjetunion auf gemeinsame Ziele alliierter Besatzungsherrschaft festzulegen, sondern um auch durch alliierte Beschlüsse die zu erwartenden Angriffe der eigenen Militärs abwehren zu können.

Letztere gaben sich keineswegs geschlagen. Sie beharrten auf der Autonomie in ihrer eigenen Zone, ohne Rücksicht auf die Einheitlichkeit der Maßnahmen in den Besatzungsgebieten. Dabei führten sie als ein neues Argument in die Debatte ein, daß sie ihre Handlungsfähigkeit für den Fall wahren müßten, daß der Kontrollrat sich nicht auf eine gemeinsame Besatzungspolitik einigen könne. Abermals suchten und fanden sie Rückhalt bei Morgenthau, nach dessen Ansicht die neue Direktive die Politik aus der Zeit vor Yalta „vollständig umkehrte“. Auf mehreren Sitzungen zwischen dem 13. und 22. März kamen die Differenzen zwischen State, War und Navy Department sowie der Treasury über die Vereinbarungen von Yalta offen zum Austrag. McCloy, der bis dahin trotz einer gewissen „Konfusion“ keine erheblichen Konflikte zwischen Zentral- und Zonenverwaltung erwartet hatte, kritisierte nun: „Die bloße Tatsache, daß die Zonenkommandeure auch Mitglieder des [Kontroll-]Rats sein würden, erscheine nicht ausreichend, das notwendige Ausmaß regionaler Machtbefugnis zu ge-

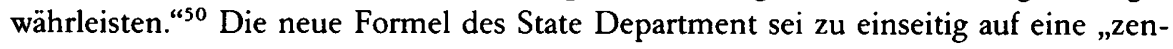
tralisierte Kontrolle“ ausgerichtet; die Armee, die „sich diesen vagen Ideen einer zentralen Verwaltung in Berlin“ nicht unterwerfen könne, bestehe auf einer starken Dezentralisierung: „Die Verwaltung würde [...] in den Zonen vom Zonenkommandeur durchgeführt werden, außer wenn bzw. bis der Kontrollrat anders entscheidet.“ Auch Stimson monierte, die Formel lege „erheblichen Nachdruck auf Zentralisierung

47 NA, RG 43/ACC, box 4, folder: General Order (Winant an Roosevelt, 28. 1. 1945). FRUS, 1945/III, S. 396 ff. (26. 1.), 405 ff. (Winant, 5. 2.), 429 ff. (24. 2. 1945).

48 FRUS, 1945/III, S. 457 f. (16. 3. 1945).

49 FRUS, 1945/III, S. 433 ff.

so NA, RG 59, 740.00119 EAC/3-1345 und /3-1445. 
[...], sowohl hinsichtlich der Formulierung von Politik als auch hinsichtlich deren Ausführung“. Es werde für die alliierte Gemeinsamkeit eher schädlich sein, wolle man die einheitliche Anwendung einer vereinbarten Politik „erzwingen“. Obwohl das State Department an seiner Auffassung festhielt, daß der Standpunkt der Militärs den Beschlüssen von Yalta widerspreche und seitens der Sowjets, aber auch der Briten als Aufkündigung des erzielten Konsenses aufgefaßt werden könnte, wich es vor dem Druck Morgenthaus und der Militärs ein weiteres Mal zurück: Auf Anregung Stimsons wurde die Formel von der zentralen Politikentscheidung und der dezentralen Politikausführung entwickelt, die Phase der Zentralisation zum kurzen Vorspiel für die zweite Phase von „Dezentralisierung und Teilung“ heruntergestuft und den Militärs „verwaltungsmäßiger Spielraum“ in den nationalen Direktiven zugesichert ${ }^{51}$. Das Ergebnis der Beratungen war eine abermalige „Reinterpretation“ der Entscheidung vom 10. März. Danach sollte „die Vollmacht des Kontrollrats, die Politik in allen Fragen zu formulieren, die Deutschland als Ganzes betreffen, übergeordnet sein“; zugleich wurde im Sinne der Militärs für den Fall einer Nichteinigung im Kontrollrat festgelegt - das sollte weitreichende Folgen haben -, daß „beim Fehlen solcher Beschlüsse [policies] und in Fragen, die ausschließlich seine Zone betreffen, jeder Zonenkommandeur seine Machtbefugnis in Übereinstimmung mit Anweisungen ausüben wird, die er von seiner eigenen Regierung erhält". Zudem sei eine zentrale Verwaltung durch den Kontrollrat keineswegs in allen Bereichen „wünschenswert“; langfristiges Ziel bleibe die Dezentralisierung von politischer Struktur und Wirtschaft in Deutschland $^{52}$. Auf Verlangen Morgenthaus wurde Eisenhower die Direktive mit dem Hinweis übersandt: Sollte er für diese im Kontrollrat keine Zustimmung finden, werde ihm, vor allem im wirtschaftlichen Bereich, vorsorglich die Freiheit eingeräumt, „direkt mit einem oder mehreren Kommandeuren in allen Fragen in Verbindung zu treten, die für diese Zonen von besonderer Bedeutung sind“ ${ }^{\text {“53 }}$.

Die Briten machten sich gleichfalls Gedanken über das Verhältnis von Zentrale und Zone, allerdings weniger auf alliierter als auf deutscher Ebene. Im Gegensatz zu den gelegentlich eher emotionalen Äußerungen oder gar Vereinbarungen der Staatsoberhäupter waren sich die Planungsstäbe frühzeitig einig, ein Dismemberment werde außer größerer „wirtschaftlicher Sicherheit“ nur Nachteile mit sich bringen: Es werde die Lieferung von Reparationen ebenso beeinträchtigen wie den deutschen Beitrag zur Rekonstruktion der europäischen Wirtschaft, Exportmärkte zerstören, zudem das Problem akut werden lassen, nach dem politischen auch das ökonomische Dismemberment gegen die deutschen Teilstaaten auf Dauer erzwingen zu müssen. Es stand in diesen Kreisen fast axiomatisch fest, daß im Falle eines politischen Dismemberment „irgendein Organ für die zentrale wirtschaftliche Verwaltung in Deutschland für eine gewisse Zeit nach dem Ende der Kampfhandlungen“ erhalten bleiben müsse ${ }^{54}$. Allein das ökonomische Argument führte seit dem Herbst 1944 in Verbindung mit der zunehmend sich verfestigenden Erwartung, in Deutschland werde es bei Kriegsende

51 FRUS, 1945/III, S. 438-78 passim (meine Hervorhebung).

52 FRUS, Potsdam I, S. 436 ff. Nübel, Reparationspolitik, S. 30.

53 FRUS, 1945/III, S. 484 ff. Thomas, EAC, S. 209. Clay ließ sich später von seinem Legal Advisor bestätigen, daß das Potsdamer Abkommen im Konfliktfall „Vorrang“" vor JCS 1067 habe. BA, Z 45 F/ OMGUS, AGTS/12/9 (3. 6. 1945); AGTS/9/1 (9. 8. 1945).

54 PRO, FO 371/39180 (PHP(44)62(Final), 25. 9. 1944); FO 942/66 (EIPS/P(44)30(Final), 4. 9. 1944; APW(45)40, 19. 3. 1945); FO 371/46871/C292 (23.1. 1945), C1017 (9.3. 1945). 
keine funktionierende zentrale Regierung mehr geben, zum Abrücken von allen Zerstückelungsplänen. Dismemberment hieß nun „Konföderation, Föderation und Dezentralisation“ bzw. „Aufbrechen der unitarischen Regierung“55, zumal sich die Planungsstäbe gegen den anfänglichen Widerstand der politischen Führungsebene seit April 1945 darauf einstellten, daß in Deutschland nach dem Ende der Feindseligkeiten nicht mit einem "absichtlichen“, aber doch mit einem „de facto Dismemberment" $\mathrm{zu}$ rechnen $\mathrm{se}^{56}$. Solche Überlegungen ließen Ende 1944 in zunehmendem Maße die Trennung von ökonomischer und politischer Einheit als einen möglichen Weg attraktiver erscheinen, um die zonale politische Autonomie der Besatzungsmächte einerseits und die nationale Wirtschaftsverflechtung und Leistungsfähigkeit Deutschlands andererseits miteinander zu vereinbaren. Damit war die Frage aufgeworfen, ob die Wirtschaftseinheit der politischen Einheit bedürfe.

Mitte April 1945 wurden angesichts der sowjetischen Polenpolitik die britischen Bedenken im Hinblick auf die Nachkriegskooperation immer ausgeprägter. Erstmals wurde die Möglichkeit eines Bruchs zwischen den Alliierten offen diskutiert; in der weder anzustrebenden noch durchsetzbaren Einheitlichkeit der (wirtschafts)politischen Maßnahmen in den Zonen schien ein elastischer Kompromißspielraum zu liegen. Die Auffassung der Stabschefs gewann Resonanz, nicht die Einheit, sondern die Teilung Deutschlands werde „eine Versicherung gegen eine feindliche UdSSR“ $\operatorname{sein}^{57}$. Am 11. April erwartete Kriegsminister Sir James Grigg, bei Kriegsende werde es keine akzeptable deutsche Regierung geben, nicht einmal eine zentrale Verwaltung. Das werde den britischen Zonenkommandeur zwingen, „vollständige Verantwortlichkeit“ in seiner Zone zu übernehmen, notfalls „ohne vereinbarte Anweisung seitens einer zentralen Alliierten Kontrollkommission“. Hinter diesen Gedankengängen stand weniger die Erwartung, daß die technischen Voraussetzungen für eine zentrale Kontrolle nicht gegeben seien, sondern die aus der Arbeit der EAC abgeleitete Erfahrung, „daß einstimmige Entscheidungen [...] schnell nicht zu erreichen sind, wenn sie überhaupt erzielt werden können“. Sollten „die Zonen unter getrennter nationaler Kontrolle auseinanderfallen“, würden allein die äußeren Rahmenbedingungen in der stark zerstörten, von Lebensmitteleinfuhren abhängigen britischen Zone den Oberkommandierenden zwingen, „zu Beginn und für einige Zeit darüber binaus“ in seiner Zone einseitige Vorkehrungen zu treffen „im Vorgriff auf eine allgemeine Politik, die später in der interalliierten Kontrollkommission auf einer gesamtdeutschen Grundlage vereinbart werden würde“58. Zwei Tage später wurde Grigg vor dem War Cabinet noch deutlicher: Das Fehlen einer deutschen Zentralregierung bei Kriegsende werde dazu führen, „daß die russische Zone zumindest dahin tendieren wird, separat verwaltet zu werden“. Man müsse sich auf den Extremfall einer separaten Verwaltung der eigenen Zone einrichten. „Es scheint daher, daß wir mit einem de facto Dismemberment konfrontiert sein könnten, ob wir das mögen oder nicht. [...] Es sollte beachtet werden, daß, selbst wenn es eine Fassade [!] zentraler Kontrolle geben sollte, es so lange dauern könnte, Entscheidungen herbeizuführen, und diese [Zentralinstanz] so in ihrer Arbeit

55 PRO, FO 371/46871/C313 (24. 1. 1945).

56 PRO, FO 371/46824/C1979 (APW(45)63, 3. 5. 1945; Hervorhebung im Original). FRUS, 1945/III, S. $471 \mathrm{f}$

57 Kettenacker, Kontrolle, S. 43 (9.9. 1944).

58 PRO, FO 371/46731/C2274 (WP(45)239, 11. 4. 1945; meine Hervorhebung). 
durch die Bedingungen in Deutschland behindert werden könnte, daß sie nicht effektiv wäre." Schatzkanzler Sir John Anderson und Sir William Strang erwarteten derartige "Störungen“ nicht nur von sowjetischer Seite. Obwohl sie von einer zumindest vorübergehenden Abschottung der einzelnen Zonen ausgingen, wollten sie an der zentralen, gemeinsamen Kontrolle festhalten, jedoch mit der Einschränkung, „daß es dennoch effektiver sein könnte, die Verwaltung bis zu einem gewissen Grade zu dezentralisieren“, d. h. Funktionen von der Zentrale auf die Zone zu verlagern ${ }^{59}$. Eine Stellungnahme des Foreign Office zu dem Memorandum von Sir John Grigg führte den Gedankengang noch weiter: „Wenn es sich als unmöglich erweisen sollte, eine effektive zentrale Vier-Mächte-Kontrolle in Deutschland einzuführen (entweder wegen des Fehlens eines deutschen zentralen Verwaltungsapparates oder aus irgendwelchen anderen Gründen), oder wenn andererseits eine zentrale Vier-Mächte-Kontrolle eingerichtet wird, aber sich als ineffektiv erweist und bald zusammenbricht, wird wahrscheinlich jede der Besatzungsmächte dazu übergehen, eine mehr oder minder autonome Kontrolle über die eigene Besatzungszone zu errichten. Es könnte eine stärkere oder schwächere Kooperation zwischen der britischen, amerikanischen und französischen Zone geben; aber es ist wahrscheinlich, daß es wenig Kontakt zwischen jeder von ihnen und der sowjetischen Zone geben wird.“ Die schlüssige Folgerung aus dieser nicht erwünschten, weil unbequemeren und kostspieligeren, aber immer wahrscheinlicher erscheinenden Konstellation war, die Autonomie des Zonenkommandeurs auf Kosten der Zentrale weiter zu stärken, diesen auf die Direktiven der britischen Regierung zu verweisen, ihm aber die Möglichkeit offenzuhalten, sich fallweise mit einzelnen Kollegen zur einheitlichen Handhabung gemeinsamer Probleme ins Benehmen zu setzen ${ }^{60}$.

Obwohl die Briten sich damit stark der amerikanischen Position genähert hatten, protestierte Strang in der EAC, als die USA dort ihren Sinneswandel offiziell vortrugen: Der Entwurf, den Winant am 6. April vorgelegt hatte, verstoße gegen die YaltaFormel und sei gegenüber dem Kontrollabkommen „weniger optimistisch“; ihm liege die Erwartung zugrunde, der Kontrollrat werde nicht einigungsfähig sein. Dieser Fall sei in den bisherigen Vereinbarungen lediglich „informell“ vorgesehen worden. Strang hatte die Tragweite der amerikanischen Formulierung richtig erfaßt, als er Winant fragte, ob die vorgeschlagene Formel ,jeder Regierung völlige Handlungsfreiheit in ihrer Zone gibt, wenn eine vereinbarte Politik fehlt, und ob jeder Zonenkommandeur dann in der Lage wäre, Vereinbarungen im Kontrollrat zu verhindern und auf diese Weise völlige Handlungsfreiheit in seiner Zone zu gewinnen“. Im britischen Gegenentwurf entfiel jede Erwähnung der zonalen Autonomie im Falle der Nichteinigung des Kontrollrats ${ }^{61}$. Doch die Perspektive einer reinen Zonenpolitik, die als Ergebnis einer solchen Auflösung des Einigungszwangs drohte, schien Churchill als „katastrophale Alternative“; denn, so Robertson später, die Formel „als allgemeine Regel zu ak-

59 PRO, FO 942/66 (APW Committee, 13.4. 1945; Hervorhebung im Original).

60 PRO, FO 371/46731/C2344 (ACAO/P(45)51, 18. 5. 1945).

6 PRO, FO 371/46824/C1979 (APW(45)63, 3. 5. 1945; EAC Summary No. 72, 4. 5. 1945). FRUS, 1945/III, S. 471 f. (amerikanischer Entwurf), 521 (britischer Entwurf). NA, RG 59, 740.00119 EAC/ 5-745. Lediglich die Passage: „in Fragen, die ausschließlich seine eigene Zone betreffen, wird jeder Oberkommandierende die oberste Gewalt in Übereinstimmung mit den Anweisungen ausüben, die er von seiner eigenen Regierung erhält", blieb erhalten. Das Foreign Office sprach sich am 16. 4. 1945 dafür aus, daß der Zonenkommandeur seine Weisungen nicht vom Kontrolirat, sondern von seiner Regierung empfange. PRO, FO 371/46731/C2274 (Kirkpatrick, 11. 4. 1945), C2275. 
zeptieren, würde bedeuten, einen Keil der Uneinigkeit in die gesamte Konzeption der Vier-Mächte-Kontrolle zu treiben" ${ }^{\text {"62 }}$. Ihre pessimistische Grunderwartung bewog die Briten zu dem Versuch, mit der Regierung Dönitz eine gesamtdeutsche Klammer zu erhalten. Einen zweiten, nicht minder verfehlten, weil das sowjetische Mißtrauen verstärkenden Anlauf, die Einheit doch noch zu erzwingen, unternahmen die Briten mit dem Versuch, den Rückzug auf die vereinbarten Zonengrenzen mit der Konstituierung des Kontrollrats zu verknüpfen ${ }^{63}$. Bis dahin sollten die Einrichtungen von SHAEF erhalten bleiben, um die koordinierte Verwaltung der drei Westzonen zu ermöglichen ${ }^{64}$. Doch beide Vorstöße scheiterten am Widerstand der USA.

Nur auf den ersten Blick mochte erstaunen, daß auch der französische Vertreter Massigli beklagte, der amerikanische Entwurf verpflichte die Zonenkommandeure nicht genügend auf Kompromiß und Gemeinsamkeit. Sollte eine Einigung im Kontrollrat sich als unmöglich erweisen, seien die Kommandeure zur Rückmeldung an ihre Regierungen zu veranlassen; erst wenn das erfolglos bleibe, dürfe die autonome Vorgehensweise in den Zonen ins Auge gefaßt werden: als letzter, nicht als erster Schritt. Abschließend brachte Massigli die Gefahr der amerikanischen Interpretation auf den Punkt: „Der amerikanische Entwurf, wie er vorliegt, läuft auf eine Einladung zur Spaltung und einseitigen Handlungsweise hinaus. “65 Diese Kritik hinderte die französische Regierung nicht, selbst in dieser Richtung (weiter) zu denken. In einer Aufzeichnung "Zonenpolitik oder Politik der Vier-Mächte-Kontrolle in Deutschland“ vom 20. Juni 1945 wurde dem Zonenkommandeur völlige Handlungsfreiheit zugebilligt, soweit seine Maßnahmen „nicht den gemeinsamen Direktiven, die vom Kontrollrat ausgearbeitet werden, widersprechen"66. Damit war ein weiter Interpretationsrahmen gegeben, der die Einigungspflicht nicht ausschloß, aber faktisch den amerikanischen Intentionen sehr entgegenkam. Interpretations- und Handlungsrecht wurden ins Belieben der Zone gestellt: „Infolgedessen wird dem Zonenkommandeur zwangsläufig eine große Handlungsfreiheit belassen; als Mitglied des Kontrollkomitees können wir daher immer in den Fällen, die uns besonders interessieren, die Entscheidungen, die uns behindern, scheitern lassen oder modifizieren, da jede Entscheidung einstimmig gefällt werden wird. Die Politik, die wir in unserer Zone betreiben möchten, wird daher weniger durch unseren guten Willen, an der Kontrolle teilzunehmen, behindert als durch unsere Neigung, nicht an diese zu glauben und zu handeln, als ob sie uns nichts anginge." Priorität hatte die Vier-Mächte-Kooperation, da die französische Zone wirtschaftlich und reparationspolitisch unbedeutend war und eine Einflußnahme auf die ökonomische Entwaffnung und Kontrolle in den anderen Zonen wichtiger erschien. Aber für den Fall eines Scheiterns sollte der Weg für eine reine Westlösung offenbleiben: „Wir müssen daher Partei ergreifen für eine Vier-Mächte-Politik bezüglich der Besetzung Deutschlands und, sollte diese ausbleiben, für eine Drei-Mächte-Entente, im Interesse der Stabilität unserer Lage in unserer Zone.“ Damit war faktisch der Primat der Zone etabliert; die Einstimmigkeitsklausel im Kontrollrat gab Frankreich die Chance zur Blockade einer gemeinsamen Deutschlandpolitik, sofern diese ihren In-

62 DBPO, I, 1, S. 4. PRO, FO 1049/247 (27.9. 1945).

63 PRO, FO 944/758 (War Office an Montgomery, 4.6. 1945).

${ }^{64}$ FRUS, 1945/III, S. 302 ff. Vgl. unten S. 80 mit Anm. 35.

65 PRO, FO 371/46824.

66 AMAE, Y 453, Bl. 63 ff. (meine Hervorhebung). 
teressen nicht entsprach. Zonale Autonomie und Vetorecht im Kontrollrat waren die „Zwei Vorteile des Vier-Mächte-Systems“, die Frankreich bis Anfang 1948 am Kontrollrat festhalten und ihn einer trizonalen Westlösung vorziehen ließen ${ }^{67}$.

Die sowjetische Haltung wurde nicht erkennbar. Lediglich aus der Beobachtung, daß Gousew sich an der Debatte „ziemlich betont" nicht beteiligt hatte, schloß Winant auf Zustimmung zur amerikanischen Position ${ }^{68}$. Aber offene Unterstützung erfuhr er von der Seite nicht. Zwar verhinderte die geschlossene Widerstandsfront ihrer Alliierten eine Festschreibung der amerikanischen Position, die Grundsatzfrage blieb jedoch ungelöst: „Die Mitglieder der Kommission [EAC] wünschten, die Situation offenzulassen. “69 In der endgültigen Vereinbarung über den Kontrollapparat vom 4. Mai 1945 wurde daher die Yalta-Formel bestätigt, aber die unterschiedlichen Interpretationsansätze ließen sich weder nachträglich wegdiskutieren, noch waren diese damit aufgegeben worden ${ }^{70}$.

\section{Potsdam 1945: Vertagung der Konflikte}

Auf der Potsdamer Konferenz wurde das Kontrollabkommen lediglich in nachgeordneten Komitees behandelt, da keine der beteiligten Mächte im Zeichen des aufbrechenden Mißtrauens an den Formulierungen der Vereinbarung rütteln wollte. Das bedeutete jedoch nicht den Verzicht auf neuerliche (Re-)Interpretationsversuche. Im Gegenteil. Bis zur Klärung der Fronten in Deutschland zogen es alle Mächte vor, stillschweigend im Sinne des Politikansatzes vorzugehen, den das State Department dem neuen Präsidenten Truman am 16. April 1945 zu dessen Amtsübernahme empfohlen hatte: „Unsere Politik ist es zu vermeiden, daß Fragen, in denen wir mit der Sowjetunion nicht übereinstimmen, die militärische Zusammenarbeit beeinträchtigen oder die Hoffnung auf die Nachkriegskooperation gefährden, ohne gleichzeitig irgendwelche Zugeständnisse zu machen, die die fundamentalen Prinzipien aufs Spiel setzen, auf denen unsere Außenpolitik beruht. ${ }^{\text {" } 11}$

Angesichts der Proteste ihrer Verbündeten in der EAC waren die USA offiziell zur Yalta-Formel zurückgekehrt, doch hinter den Kulissen schwelten die alten Konflikte weiter. Noch bei Konferenzbeginn bestand innerhalb der amerikanischen Delegation keine geschlossene Haltung. Die Frage, ob man eine „gemeinsame, einvernehmliche Politik oder eine unilaterale Politik in den jeweiligen Zonen" anstreben solle, war weiterhin nicht entschieden. „Das ist ein sehr fruchtbares Feld für zukünftige Konflikte, die wesentlich die zukünftige Einheit betreffen, und wird wahrscheinlich für einige Zeit eine kritische Situation sein, trotz allem, was getan werden kann. ${ }^{472}$ Das State Department, dessen Auffassungen die Verhandlungsrichtlinien des Präsidenten präg-

67 AN, 457 (Bidault) AP 15/Après CMAE London, Déc. 1947.

68 FRUS, 1945/III, S. 505.

69 BA, Z 45 F/OMGUS, 2/118-1/2-4 (Robertson, 27. 9. 1945).

70 Die Erklärung der vier Mächte vom 5.6. 1945 zum Kontrollapparat wiederholte die Formel im ersten Abschnitt. Der zweite Abschnitt relativierte dies jedoch: „The Control Council [...] will ensure appropriate uniformity of action by the Commanders-in-Chief in their respective zones of occupation and will reach agreed decisions on the chief questions affecting Germany as a whole." Documents on Germany under Occupation, S. 36 (meine Hervorhebung).

71 TL, Truman Papers, President's Secretary's File, Subject File. Cabinet, box 159, folder: Policy Manual, S. 53.

72 FRUS, Potsdam I, S. 213 (3. 7. 1945). 
ten, lehnte eine Aufteilung Deutschlands, „de facto oder de jure“, entschieden ab, sei es in „separate, integrierte deutsche Verwaltungs- und politische Einheiten, die mit den Besatzungszonen übereinstimmen“, sei es gar in „getrennte Staaten mit abweichender politischer Philosophie“. Daher fehlte auch der Passus, im Fall mangelnder Einigung im Kontrollrat habe jeder Zonenkommandeur unilaterale Handlungsfreiheit. Angesichts der Gefahr, daß eine „wirtschaftliche Mauer“ zwischen Ost- und Westdeutschland entstehen könnte, sei auf der Behandlung Deutschlands als Wirtschaftseinheit zu beharren, „soweit [!] Einigung zwischen den vier Regierungen und im Kontrollrat möglich ist“, allerdings nicht durch eine deutsche Regierung, sondern durch entsprechende zentrale Verwaltungen. Wenn dies nicht gelinge, sei der Rückgriff auf „Arrangements zwischen den westlichen Alliierten, in ihrer Anwendung auf Westdeutschland begrenzt“, unvermeidlich, ,wenn erste Übereinkommen, die die russische Zone einschließen, nicht schnell erreicht werden ${ }^{473}$. Doch Teile der Delegation, besonders Harriman und Pauley, erachteten angesichts der sowjetischen Ausplünderung der SBZ eine effektive Vier-Mächte-Verwaltung zunehmend als „unwahrscheinlich“, ja als unmöglich. In Anbetracht der unvereinbaren Standpunkte in der Reparations- und der Export-Import-Frage schienen Konflikte am ehesten durch pragmatischen Rückgriff auf den „zonalen Ansatz“ vermeidbar. Zwangsläufig wurde die autonome Handlungsfreiheit der Zonenbefehlshaber für den Fall der Nichteinigung im Kontrollrat und zugleich deren Vetorecht erneut hervorgehoben: Sie seien nur solchen Regelungen und Vereinbarungen unterworfen, „die sie im Kontrollrat zu finden wünschen [!] und [zu denen sie] in der Lage sein werden“. Insofern wurde für den Fall vorgesorgt, daß es vorübergehend zu einer separaten Verwaltung der Zonen zumindest in den umstrittenen Bereichen kam: „Wir planen daher auf einer zonalen Ebene, mit der Erwartung der gemeinsamen Durchführung und Finanzierung für die drei westlichen Zonen."74 Die Rückkehr zur Formel des Kontrollabkommens vom 12. November 1944 im Potsdamer Abkommen bedeutete unter diesen Vorzeichen nicht mehr sehr viel, kam auch deutlich zögernd. Briten und Amerikaner hatten inzwischen ihre „bis vor kurzem“ gültige „Hoffnung auf erfolgreiche Zusammenarbeit mit den Russen bei der Verwaltung Deutschlands als eine wirtschaftliche Einheit aufgegeben“, da die Sowjets eine Kooperation lediglich als ,abstraktes Prinzip“ akzeptierten; und für die Reparationen und den Export-Import-Plan galt auch das nicht einmal $\mathrm{mehr}^{75}$. Die USA scheuten sich daher nicht, ihre Interpretation des Kontrollabkommens offiziell zu wiederholen, daß jeder Oberkommandierende „das letzte Wort“ haben müsse und im Falle der Handlungsunfähigkeit des Kontrollrats berechtigt sei, ,in seiner eigenen Zone seine eigenen Ideen umzusetzen" ${ }^{\text {"76 }}$. Die wirtschaftliche Einheit Deutschlands, ganz zu schweigen von der politischen, war zur unverbindlichen Willenserklärung geworden.

Die Briten waren nach Wochen wachsender Skepsis in recht optimistischer Stimmung nach Potsdam angereist, obwohl in ihren Augen die Sowjetunion in der EAC nicht nur jede positive Vereinbarung über die politische Behandlung Deutschlands abgebremst, sondern auch immer wieder durch einseitige Maßnahmen Zweifel an ih-

73 FRUS, Potsdam I, S. 435 ff. (24. 5. 1945; Hervorhebung im Original).

71 FRUS, Potsdam II, S. 811-15 (23. 7. 1945).

75 DBPO, I, 1, S. 948, 1053.

76 DBPO, I, 1, S. $619(24.7 .1945)$ 
rer Kooperationsbereitschaft, ja ihrer Kooperationsfähigkeit provoziert hatte ${ }^{77}$ und obwohl sie in Osteuropa nur einige eher optische Zugeständnisse in den Kontrollorganen für Bulgarien, Rumänien und Ungarn sowie bei der Regierungsbildung in Polen gemacht hatte. Montgomery hatte bereits in London angefragt, ob es „Ein Deutschland oder zwei?" geben werde; mittlerweile sei eine "Mauer" zwischen der SBZ und den Westzonen errichtet worden ${ }^{78}$. Doch Eden hegte die Hoffnung, diese „Mauer“ in Potsdam wieder wegverhandeln und die Teilung Deutschlands und Europas im Kontrollrat verhindern zu können. Dazu war er bereit, nicht konsensfähige Themen vorläufig auszuklammern und im Vorfeld der Konferenz alles zu vermeiden, was den Sowjets den Eindruck vermitteln könnte, der Westen steuere den „endgültigen Bruch“ an. Angesichts des extremen Interesses der Sowjetunion an Reparationen glaubte man in London, im Hinblick auf die einheitliche Behandlung Deutschlands Moskau zum Kompromiß drängen, wenn nicht zwingen zu können ${ }^{79}$. Als aber in Potsdam die alten Konflikte mit der Sowjetunion erneut aufbrachen, erfolgte sehr rasch, wenngleich widerstrebend, die Rückkehr zu den „revisionistischen“ Positionen der Yalta-Zeit. Ähnlich wie die USA, in deren Schlepptau das Königreich auf der Konferenz zusehends geriet, war Großbritannien mit dem Ziel angetreten, die Einheit Deutschlands zu wahren bzw. wiederherzustellen. Doch die Amerikaner und, in ihrem Gefolge, die Briten taten angesichts erschöpfter Geduld, vorausgegangener Erfahrungen, innenpolitischen Erfolgszwangs und ausgereizter Verhandlungspositionen schließlich die entscheidenden Schritte, die diesem Ziel widersprachen. Die polnische Westgrenze, die Reparationen und die Export-Import-Frage waren die eng miteinander verwobenen Probleme, über die eine einvernehmliche Regelung nicht mehr zu erzielen war und die daher gemäß der sog. Byrnes-Formel nur noch durch die teilweise Aufhebung der Wirtschaftseinheit zu erledigen waren: Die Sowjetunion bediente sich vorwiegend aus ihrer Zone, wobei es ihr überlassen blieb, ob sie die Gebiete östlich von Oder und Neiße dazurechnete oder nicht. Obwohl die Briten überzeugt waren, daß Byrnes' Reparationsformel mit dem Prinzip der wirtschaftlichen Einheit unvereinbar sei und fast zwangsläufig zur Teilung führen werde, stimmten sie ihr zu, nachdem die USA und die Sowjetunion sich bilateral darauf geeinigt hatten und weil Bevin die Amerikaner nicht verprellen wollte. Doch für den Fall, daß sich infolge der Abtrennung der Gebiete östlich von Oder und Neiße die wirtschaftliche Lage ihrer Zone verschlechterte, war Vorsorge zu treffen ${ }^{80}$. Und diese konnte nach Lage der Dinge nur in der Sicherung ihrer zonalen Autonomie liegen. Das offizielle Festhalten am Kontrollabkommen bedeutete auch hier nicht sehr viel. Zwar konnten sich die Briten dem sowjetischen Argument schlecht entziehen, „daß man das Mißlingen der Einigung nicht in Betracht ziehen sollte", da Strang eben das Anfang Mai in der EAC selbst gefordert hatte; aber das Eingehen auf dieses Angebot war weniger Zeichen naiver Hoffnung als abwartender Skepsis: „Wir dürfen nicht vorschnell urteilen“, so hieß es am Tage vor Abschluß der Potsdamer Konferenz in Kreisen der britischen Delegation, „was geschehen wird, wenn es keine Einigung gibt oder [wenn wir] die Handlungsfreiheit

77 DBPO, I, 1, S. 140, 143.

78 DBPO, I, 1, S. $71 \mathrm{f}$.

79 DBPO, I, 1, S. 89, 215 (Eden, 12. 7. 1945), 259.

${ }^{80}$ DBPO, I, 1, S. 411 f. (Eden), 920 f., 1019 ff. (Bevin), 1050. 
unseres Oberkommandierenden beschneiden, aber wir sollten keinen Text haben, der das Scheitern der Einigung in Betracht zieht." ${ }^{\text {81 }}$

Die Sowjetunion zeigte in Potsdam eine schwankende Haltung. Einerseits befürchtete sie seit einiger Zeit, die Westmächte beabsichtigten die Spaltung Deutschlands und Europas, um dem Gestaltungsanspruch der „eigentlichen“ Siegermacht des Krieges zu begegnen. Die Furcht vor einem „Westblock“, der Westdeutschland einschloß, bewog Stalin, sich gegen ein Dismemberment des Reiches zu wenden ${ }^{82}$. Andererseits konnte das ausgeblutete Land seinen Gestaltungsanspruch auf Dauer nur durchsetzen, wenn es zugunsten der eigenen Rekonstruktion eine von den Westmächten unbeeinflußte Besatzungspolitik betrieb. Insofern demonstrierte die Sowjetunion unmißverständlich ihre Entschlossenheit, sich bei der Umsetzung ihrer Interessen nicht behindern zu lassen. Maßgeblich, so wiederholte auch sie ihre Position aus der EAC, sei der Zonenkommandeur; der Kontrollrat sei nur für die Deutschland als Ganzes betreffenden Fragen zuständig, vor allem für die Reparationen ${ }^{83}$. Deutschland, so forderte Molotow, „kann nicht sofort für alle Zwecke im gleichen Maße als eine wirtschaftliche Einheit behandelt werden“; er schlug statt dessen vor, „daß der Kontrollrat von Zeit zu Zeit detaillierte Instruktionen über das Ausmaß erläßt, in dem Deutschland als eine wirtschaftliche Einheit für spezifische Zwecke behandelt werden könnte“84. Indem die Sowjetunion am 30. Juli einen „Alliierten Rat“ für das Ruhrgebiet (ähnlich der Berliner Kommandantur) und deutsche Zentralverwaltungen im wirtschaftlichen Bereich forderte, untermauerte sie den ihr in Potsdam ausdrücklich zugesicherten Anspruch auf Reparationen aus dieser Region, dem nach ihrem Verständnis kein entsprechender Zugang der Westmächte zu Teilen ihrer Zone gegenüberstand ${ }^{85}$.

Als kurz vor Ende der Potsdamer Konferenz der Kontrollrat konstituiert wurde, war eine paradoxe Situation entstanden: Die Sowjets, die bislang durch ihr unbedingtes Beharren auf der zonalen Autonomie hervorgetreten waren, machten sich nun zum Advokaten einer durch deutsche Zentralverwaltungen (partiell) zentralistischeren Ausgestaltung des Kontrollrats, nachdem sie erkannt hatten, daß sie nur so ihren Reparationsansprüchen in den Westzonen Nachdruck verleihen konnten. Die AngloAmerikaner, die zunächst zentralistischere Organisationsvorstellungen vertreten hatten, befanden sich auf dem Rückzug zu einer zonalen oder doch westzonalen Teillösung, noch ehe die Franzosen die Chance erhielten, durch ihr Veto dieses Verhältnis zu komplizieren und die prinzipielle Unvereinbarkeit der Positionen zu überdecken. Der Kampf um Deutschland war entbrannt. Das Ergebnis war ein Formelkompromiß, der so kurz nach dem Ende des Krieges in Europa mehr den Zwang zur Konsensbildung zwischen den Siegern reflektierte als ungebrochene Illusionen über die Erfolgs-

81 DBPO, I, 1, S. 1124 (1.8. 1945).

${ }^{82}$ Krim(Jalta)konferenz 1945, S. 17 ff., $20 \mathrm{ff}$.

83 FRUS, Potsdam II, S. 141 (Maiski), 474 (Molotow). DBPO, I, 1, S. 219 ff., 256, 331

${ }^{84}$ DBPO, I, 1, S. 523.

${ }^{85}$ Vorstöße zur Internationalisierung der Ruhr hatten Maiski und Molotow seit dem 20. 7. 1945 unternommen. DBPO, I, 1, S. 445, 454, 580, 669. Potsdamer (Berliner) Konferenz 1945, S. $204,345$. FRUS, Potsdam II, S. 921. Frankreich forderte im Januar/Februar 1945 die Internationalisierung der Ruhr als Alternative zum Dismemberment, zunächst unter Einbeziehung der Sowjetunion; seit August 1945 galt das nicht mehr. PRO, FO 371/46729/C104. Im Februar 1946 schien Byrnes einer solchen Lösung nicht abgeneigt, als „un moyen de renforcer la solidarité alliée“. AMAE, Y 390, Bl. 74. Der britische EIPS sprach im Februar 1946 von einer „Seven-Power Kommandantura“. Die Ruhrfrage 1945/46, S. 483. Die Entscheidung gegen eine solche „Kommandantur“ fiel am 17.4. 1946. 
chancen einer langfristigen Kooperation. Das galt vor allem für die Expertengruppen in den Stäben und Planungsbürokratien, in denen der pragmatische Realismus notgedrungen ausgeprägter, zugleich der Zwang zur konkreten Problembewältigung größer war als auf der Ebene der Staatsoberhäupter. Was blieb, war im Hinblick auf Status und Funktion des Kontrollrats alles andere als befriedigend, da sich jede Seite in skeptischer, ja mißtrauischer Reserve die Optionen offenhalten wollte: Die Unklarheiten hinsichtlich der "staatsrechtlichen“ Definition des Kontrollrats aus den Zeiten der EAC wurden bewußt offengelassen; angesichts des Vetorechts war der Vorrang der Zonenkommandeure mit Billigung aller Mächte automatisch gegeben. Einheitlichkeit statt Einheit, Trennung von wirtschaftlicher und politischer Einheit, das waren die letzten Rettungsversuche; aber der Umweg über bi- oder trilaterale Arrangements zwischen den Zonenkommandeuren im Rabmen des Kontrollrats oder auch neben diesem war als Ersatz längst vorgesehen. Es wurde offenkundig, daß gesamtdeutsche Ansprüche sich gegen die anderen Besatzungsmächte richteten, als Druckmittel und Handelsobjekt unter dem Primat zonaler bzw. nationaler Interessen, daß sie aber nicht als Selbstverpflichtung gegenüber den Deutschen gemeint waren.

\section{Berlin 1945: Die Konstituierung}

Im November 1943, nach dem Ende der Moskauer Außenministerkonferenz, hatten die Briten mit der Errichtung ihrer „embryonalen“ Kontrollkommission für Deutschland, der CCG(BE), begonnen; doch erst im Juli 1944 begann die konkrete und detaillierte Planungsarbeit ${ }^{86}$. Am 9. August folgte gemäß Direktive JCS 923/1 vom 7. Juli 1944 die amerikanische Kontrollratsgruppe (USGCC) ${ }^{87}$. Beide Gruppen residierten in London, wobei die CCG trotz der Nähe zu den eigenen Ministerien, Behörden und Planungsstäben im Herbst 1944 mit 1380 Mitarbeitern doppelt so groß war wie die USGCC mit 680. Als beide Kontrollratsgruppen-,Kerne“ im Februar 1945 in die Nähe von Paris verlegt wurden, war die CCG in 9, später 10 Abteilungen gegliedert. Das Organisationsschema der USGCC mit 12 Abteilungen, dem sich schließlich die Briten anschlossen, nahm die spätere Direktoratseinteilung des Kontrollrats vorweg. Da der Vorschlag Eisenhowers ${ }^{88}$, die Westzonen auf einer (SHAEF entsprechenden) vereinten Basis zu verwalten, von seiner Regierung abgelehnt wurde, um den Eindruck einer "gemeinsamen Front“ gegenüber der Sowjetunion zu vermeiden, mußten nicht nur die britischen und amerikanischen Elemente in den SHAEF-Stabsgruppen G-4 und G-5 getrennt, sondern auch das komplizierte, in den einzelnen Bereichen unterschiedlich gestaltete Verhältnis zwischen SHAEF, CCG und USGCC neu geregelt werden ${ }^{89}$.

Vergeblich hatten die CCG und die USGCC seit dem Sommer 1944 in London auf die sowjetische Kontrollratsgruppe gewartet. Die Einsetzung eines embryonalen Kontrollrats als „Planungsgruppe“ hätte erhebliche Entlastung erbracht und dessen sofortigen Einsatz in Deutschland ermöglicht, falls das Reich früher als erwartet zusammenbrechen sollte. Obwohl die sowjetische Regierung am 25. Oktober 1944 offiziell

86 Donnison, Civil Affairs, S. 250 ff. PRO, FO 942/82.

87 Zur Frühgeschichte der USGCC vgl. BA, Z 45 F/OMGUS, 2/92-1/3; AG 45-46/62/2; USGCC 4445/12/4. NA, RG 59/EAC, box 2 (JCS 923/9, 31. 10. 1944).

88 Eisenhower, Crusade, S. 431.

89 CP, S. 4-12, 40. BA, Z 45 F/OMGUS, USGCC 44-45/12/4. 
ihre Bereitschaft angekündigt hatte, „in nächster Zukunft“ zur Erleichterung und Beschleunigung der Detailplanung einen „Stabskern“ ihrer Kontrollratsgruppe nach London zu entsenden, wurde diese Zusage nicht eingehalten ${ }^{90}$. Gousew ging im Dezember 1944 von dem baldigen Eintreffen der sowjetischen Kontrollratsgruppe aus, doch wurde dieses im Frühjahr 1945 trotz verschiedener Zusagen von der Sowjetunion erneut mit der Begründung verschoben, angesichts der militärischen Lage könne sie die erforderlichen 60 Offiziere nicht nach London abstellen ${ }^{91}$. Stalin war erst bereit, seine Kontrollratsgruppe „beschleunigt“ nach Deutschland zu senden, als angesichts des Verwirrspiels um Dönitz und des ausbleibenden Rückzugs der Westmächte aus Sachsen und Thüringen sein Mißtrauen wuchs ${ }^{92}$.

Auch die französische Kontrollratsgruppe wurde spät eingerichtet. Erst nach Yalta konnte die Provisorische Regierung davon ausgehen, nicht nur im Kontrollrat, sondern auch in seinen Unterorganen gleichberechtigt vertreten zu sein ${ }^{93}$. Hervorgehend aus dem am 10. Mai 1944 eingesetzten „Bureau für Waffenstillstands-Studien“ beim Generalstab war am 18. November 1944 die Militärmission für die deutschen Fragen (MMAA) beim Chef des Generalstabs eingerichtet worden, der unter Leitung von General Koeltz die organisatorische Vorbereitung und Personalrekrutierung übertragen wurde. Koeltz richtete sechs Sektionen ein (für Krieg, Marine, Luftwaffe, Wirtschaft und Finanzen, Politik und Repatriierung sowie eine Liaison- und eine Verwaltungsabteilung), in denen im Juli 1945500 Spezialisten aus Militär und Verwaltung tätig waren. Saint-Hardouin als Politischer Berater war bereits am 22. März bestellt worden, doch gab es erhebliche Einwände der Militärs gegen diese Institution, die sie auf die Zone begrenzen und vom Kontrollrat fernhalten wollten ${ }^{94}$. Nachdem der USGCC am 1. April Arbeitskontakte zu den französischen Kollegen in Paris gestattet worden waren, ernannte Koeltz Mitte des Monats die ersten Liaison-Offiziere; offiziell wurden die Verbindungen am 24. des Monats bei einem Besuch der französischen Abteilungsleiter im Hauptquartier der USGCC in Versailles hergestellt. Zu den Briten bestanden aus der Londoner Zeit „zahlreiche“ Kontakte, allerdings nur auf der militärischen Ebene, nicht im Bereich der Besatzungsplanung. Seit Ende Mai gab es Bemühungen, politisch wie personell Anschluß an SHAEF (G-5) zu gewinnen ${ }^{95}$. Die Spitzenbeamten der französischen Kontrollratsgruppe wurden erst zwischen dem 10. und 21. Juli ernannt. Die Folge war ein „Interregnum“, da sich die alte (Militär-)Verwaltung auflöste, noch ehe die neue funktionsfähig war. Angesichts zusätzlicher Konflikte zwischen

90 FRUS, 1944/I, S. 369 f., 390, 408, 414. Die Sowjetunion begann erst im September 1944, Offiziere auf die Besatzungsaufgaben in Deutschland vorzubereiten. Foitzik, SMAD, S. 13. Unter Berufung auf den Personalmangel weigerten sich die Sowjets, mehr als ein Thema zur gleichen Zeit in der EAC zu behandeln. NA, RG 59/EAC, box 3, folder: Control Machinery (Riddleberger an Matthews, 28. 8. 1944); RG 43/ACC, box 3 (War/Navy an State Department, 27. 12. 1944).

$91 \mathrm{BA}, \mathrm{Z} 45 \mathrm{~F} / \mathrm{OMGUS}$, POLAD/728/1 (21.3. 1945). NA, RG 43/ACC, box 4, folder: Yalta. Krim(Jalta)konferenz, S. $214 \mathrm{f}$.

92 Schukow, Erinnerungen, S. $636 \mathrm{ff}$. Den USA schien die sowjetische Kontrollratsgruppe „more or less improvised in Berlin“; im September 1945 waren noch nicht alle Stellen besetzt. NA, RG 59, 740.0019 Control(Germany)/8-1947.

93 AMAE, Y 121, Bl. 181, 205. Bis zur Konferenz von Yalta kannte die französische Regierung die Beratungen der EAC nur aus der Zeitung. Die Auskünfte, die sie seit dem 17.2. 1945 in London und Washington einzuholen begann, blieben unbefriedigend; ebenda, Bl. 146, $166 \mathrm{ff}$.

${ }^{94}$ AN, F 60/3034, doss. 2 (20.7. 1945); 457 (Bidault) AP 62 (10. 10. 1944). AMAE, Y 465, Bl. 9, 25, 49bis; Y 652, Bl. 371 ff.; Y 692, Bl. 371.

95 AO, Berlin/3276/1/2007. Das erste Protokoll der MMAA datiert vom 1. 5. 1945. 
den zivilen und militärischen Beamten in seiner Behörde hatte General Koenig Probleme, nach dem Ende des "Interregnums“ die Zügel in die Hand zu bekommen. Aufgrund fehlender Vorausplanungen orientierten sich die Franzosen stark an den britischen Überlegungen, konnten nur reagieren und waren häufig zu Improvisationen bei den Verhandlungen gezwungen ${ }^{96}$.

Als die USA nach der deutschen Kapitulation in der EAC auf die sofortige Konstituierung des Kontrollrats drängten, lehnte Gousew ab. Die alliierte Erklärung zur Übernahme der obersten Gewalt in Deutschland müsse dem vorausgehen ${ }^{97}$. Bereits zu diesem Zeitpunkt hofften die USA, durch die rasche Errichtung der Vier-Mächte-Verwaltung einseitige Maßnahmen der Sowjets in Berlin und ihrer Zone verhindern zu können. Die sowjetische Seite habe sich beharrlich jeder Kontaktaufnahme widersetzt und „keine Anzeichen des ernsthaften Willens" gezeigt, als „tatkräftiger Bestandteil“ des Kontrollrats tätig zu werden. Angesichts der „unendlichen Serie von faits accomplis“ drängte Clay seine Kollegen vergebens, wenigstens ein Alliiertes Sekretariat einzurichten, um die Konstituierung des Kontrollrats vorzubereiten ${ }^{98}$. Schließlich suchten die USA die Sowjets unter Druck zu setzen, indem sie am 11. Mai die Existenz ihrer USGCC bekanntgaben, dabei deren Organisation und Aufgaben erläuterten, ohne das Bestehen entsprechender Organisationen bei den anderen Westmächten zu erwähnen. Es war abzusehen, daß sich der pragmatische Ansatz, die politischen und wirtschaftlichen Stabsabteilungen von SHAEF (CRAB) als Übergangslösung zur VierMächte-Organisation auszubauen, kaum realisieren lassen würde ${ }^{99}$.

Nachdem alle Versuche zur raschen Konstituierung des Kontrollrats vor Ort gescheitert waren, drängte Truman über Harriman und Harry Hopkins Stalin persönlich zur sofortigen Ernennung seines Kontrollratsvertreters ${ }^{100}$. Als auch dies vergeblich blieb, übermittelte Truman am 26. April einen Briefentwurf an Churchill, den dieser, wie erbeten, sodann als Anfrage an Truman und Stalin richtete, den Kontrollrat bis zum 1. Juni zu aktivieren, um ihm als erste Aufgabe die Entflechtung der Truppen und deren Rückzug auf die vereinbarten Zonengrenzen zu übertragen. Würden die Sowjets auf dem sofortigen Rückzug ohne Konstituierung des Kontrollrats bestehen, so schlug das Foreign Office dem State Department am 24. Mai vor, dann müßten die Westmächte verlangen, daß die vier Oberkommandierenden ,in ihrer Eigenschaft als Mitglieder des Kontrollrats" weitere Punkte berieten: neben der Wirtschaftseinheit auch die politische Einheit Deutschlands und vor allem die Frage, „ob in Anbetracht der Zerstörungen Berlin noch geeignet sei als Sitz der Kontrollkommission und ob nicht ein anderer Sitz gewählt werden sollte“"101. Allein der Zusammenhang, in dem dieser Vorschlag vorgetragen wurde, verdeutlicht, daß es sich keineswegs um ein logi-

96 AMAE, Y 282, Bl. 173 ff.; Y 692, Bl. 376. AN, 457 (Bidault) AP 62 (SGAAA, Note sur la situation en ZFO, 6. 9. 1945). BA, Z 45 F/OMGUS, 2/92-1/3; POLAD/728/6.

${ }^{97}$ FRUS, 1945/III, S. 314 f. (29. 5. 1945).

98 BA, Z 45 F/OMGUS, USGCC 44-45/14/11; POLAD-TS/34/1-3 (Murphy, 25. 4. 1945). FRUS, $1945 / \mathrm{III}$, S. $175 \mathrm{ff}$.

99 FRUS, Potsdam I, S. 641. FRUS, 1945/III, S. $280 \mathrm{ff}$

100 FRUS, Potsdam I, S. 51. FRUS, 1945/III, S. 309, 318. BA, Z 45 F/OMGUS, POLAD/728/1 (State Department an Harriman, 14.3. 1945).

101 FRUS, 1945/III, S. 244 f., 304 f., 311 ff. PRO, FO 944/758. Nach britischen Vorstellungen kamen Halle oder Weimar in Frage, durch die dann die Demarkationslinie (gemäß dem Status quo) verlaufen würde, oder Leipzig. 
stisches Problem handelte, sondern daß „politische Einwände“ dahinterstanden ${ }^{102}$. Verlor Berlin durch Auslagerung des Kontrollrats einen Teil seiner Hauptstadtfunktion und -tradition, so war die gemeinsame Verwaltung der Stadt durch alle vier Mächte politisch weniger bedeutsam; damit würde der Zwang zum Rückzug aus Thüringen und Sachsen geringer. Im Foreign Office gab es erste Stimmen, die den Sowjets ein geringes Interesse an der sofortigen Einrichtung des Kontrollrats nachsagten und daher vorschlugen, statt mit einem umfangreichen Kontrollapparat zunächst nur mit einem kleinen Verbindungssekretariat zu beginnen ${ }^{103}$. Angesichts der Zweifel, ob eine Kooperation mit der Sowjetunion überhaupt möglich oder gar wünschenswert sei, lief dieser Vorschlag darauf hinaus, durch ein Hinauszögern die Vier-Mächte-Verwaltung entweder von vornherein scheitern zu lassen oder aber ihre Ausgestaltung nach westlichen Vorstellungen durchzusetzen. In jedem Fall hätten die westlichen Oberkommandierenden für eine längere Übergangszeit „freie Hand“ in ihren Zonen gewonnen.

Den USA war der Gedanke, Berlin nicht zum Sitz des Kontrollrats zu machen, keineswegs neu. Winant und das State Department, besonders Riddleberger, hatten sechs Monate eine Auseinandersetzung geführt, ob die Errichtung des Kontrollrats in Berlin, d. h. hinter den sowjetischen Linien, zweckmäßig sei. Die USGCC hatte, mit Unterstützung Murphys, Anfang Juni Alternativen vorgeschlagen, zum einen Leipzig, zum anderen das Drei-Zonen-Eck mit Sitz des Kontrollrats in Eisenach und Weimar (Thüringen) oder in Hann. Münden (Niedersachsen/Hessen). Bei der letzteren Lösung konnten die Kontrollratsgruppen auf die umliegenden Städte verteilt werden, so daß mit Ausnahme der Franzosen alle Mächte in ihrer eigenen Zone residiert hätten, ohne von komplizierten Zugangsregelungen wie im Falle Berlins abhängig zu sein ${ }^{104}$. Es war ein letzter Versuch, das Versäumnis beim Zuschnitt der Zonen zu korrigieren, sich einen Zugang nach Berlin zu sichern und aus der Abhängigkeit vom sowjetischen Plazet zum Einrücken in die alte Reichshauptstadt zu befreien ${ }^{105}$. Doch mit der Sowjetunion ließen sich, im Augenblick des Hochgefühls des Sieges, die Grundlagen der EAC-Vereinbarungen nicht neu verhandeln. Insofern setzte diese mühelos gegen die unentschlossenen Westmächte ihre Bedingung durch, die diese realistischerweise erwartet hatten: erst Verwirklichung des Zonenabkommens, dann Durchführung der Vereinbarung über den Kontrollapparat. Wollten die Westmächte eine Festlegung der Sowjetunion auf eine gemeinsame Besatzungspraxis durch den Kontrollrat noch vor Potsdam erreichen, mußten sie dieser abermals entgegenkommen. Alles andere hätte die sofortige Spaltung Deutschlands bedeutet.

${ }^{102}$ DBPO, I, 1, S. 216 f. (12./13. 7. 1945). PRO, FO 371/46697/C2691 (Mai 1945). Die Überlegungen setzten sich 1946 fort: Bei einem wiedervereinigten Deutschland könne die Lage der Hauptstadt nicht ohne Belang sein, vor allem wenn die Ostgrenze an Oder und Neiße verlaufe. Sollte die VierMächte-Kontrolle zusammenbrechen und eine westliche Drei-Zonen-Lösung zustandekommen, kämen Hannover, Göttingen oder Bonn als Hauptstadt in Frage. FO 371/55586/C1499 (FO, 8. 2. 1946). Auf französischer Seite befürwortete General Koenig im Juli 1946 eine duale Lösung: Berlin sollte Sitz des Kontrollrats bleiben, um Kontakt nach Osten zu halten; für die Hauptstadt eines Staatenbundes sei ein anderer Ort zu suchen, allerdings nicht Frankfurt, das historisch zu enge Bindungen zum Rheinland habe. AMAE, Y 286, Bl. 147.

103 Thies, Militärverwaltung, S. 34 (Steel, 12. 5. 1945).

104 TL, Oral History Collection, Riddleberger (1972), S. 30 f. BA, Z 45 F/OMGUS, AGTS/11/2 und AGTS/12/9 (ETOUSA, 4. 6. 1945). AMAE, Y 283, BI. 9 (9. 10. 1945).

$105 \mathrm{BA}, \mathrm{Z} 45$ F/OMGUS, AGTS/9/1 (in Vorbereitung für das Treffen der vier Oberkommandierenden in Berlin am 5.6. 1945). 
Daß nicht sie die Bedingungen stellten, sondern die Sowjetunion, mußten die Westmächte in einer für sie demütigenden Form am 5. Juni erfahren, als sie nach Berlin in das Hauptquartier Schukows mit der Erwartung anreisten, bei der Unterzeichnung der Alliierten Erklärung auch den Kontrollrat konstituieren zu können. Die amerikanischen und britischen Delegationen waren mit konkreten Themenkatalogen für diese Gespräche versehen. Erstere wollte neben einer Erklärung, daß die bisherigen Maßnahmen von SHAEF und SMAD in den jeweiligen Besatzungsgebieten in Kraft bleiben sollten, einen Beschluß herbeiführen, „wo, wann und wie“ der Kontrollrat errichtet werde, und dazu die Rechte klären, ,die sich auf den Gebrauch von Straßen, Eisenbahnen und Kommunikationsverbindungen zu dem vereinbarten Sitz der Regierung beziehen“, sowie die sofortige Einsetzung des Koordinationskomitees beschließen und „Zeit und Ort der nächsten Sitzung“ festlegen. Der („unvollständige“) Katalog der Briten umfaßte 86 Punkte „für eine frühzeitige Diskussion mit den Sowjets", von dem sich die ersten 20 auf die Errichtung des Kontrollrats, inkl. der „Boden-Transitrechte“ nach Berlin, bezogen ${ }^{106}$. Die Sowjetunion machte den Westmächten jedoch einen Strich durch die Rechnung. Ihr Mißtrauen war geweckt bzw. bestätigt worden, als diese Sachsen und Thüringen nicht freiwillig räumten. Nachdem die westlichen Delegationen Berlin erreicht hatten, ließ Schukow sie viereinhalb Stunden warten, da er angeblich in einem untergeordneten Punkt letzte Instruktionen aus Moskau abwartete. So blieb, ob beabsichtigt oder nicht, kaum Zeit, mehr als die Unterzeichnung der Alliierten Erklärung um 16.40 Uhr vorzunehmen, da Eisenhower und Montgomery am Abend nach Frankfurt zurückkehren wollten. Verhandlungen über die umfangreichen Forderungskataloge der Westmächte waren damit erledigt. In dem kurzen „ersten informellen Treffen der vier Mitglieder des Kontrollrats“ ${ }^{107}$, das sich an die Unterzeichnung der Erklärung anschloß, stellte Schukow trotz aller „freundlichen Herzlichkeit" unmißverständlich klar, daß man seiner Auffassung nach nur als Versammlung der Zonenkommandeure, nicht als Kontrollrat zusammensitze. Ohne Rückzug auf die vereinbarten Zonengrenzen werde die Konstituierung des Kontrollrats nicht erfolgen. Denn, so akzentuierte er den Primat der Zone gemäß der sowjetischen Interpretation des Kontrollabkommens, solange er nicht Herr in seiner Zone sei, könne er nicht an Beratungen über Deutschland im Kontrollrat teilnehmen. Bis dahin werde er nicht einmal technischen Vorgesprächen oder Vorbereitungen seitens der Stäbe oder der Stellvertreter zustimmen. Eisenhowers Widerspruch, mit der Unterzeichnung der Erklärung sei der Kontrollrat als konstituiert anzusehen, blieb ohne Resonanz. Als Eisenhower und Montgomery ihre Fragenkataloge vorbringen bzw. an die Stellvertreter verwiesen sehen wollten, zog sich Schukow auf die Position zurück, erst müßten die prinzipiellen Fragen durch die Oberbefehlshaber entschieden sein; doch entschuldigte er sich sofort für die nächsten Tage mit Verpflichtungen in Moskau. Er verweigerte selbst, weil offenbar ohne Instruktionen, den Verbleib der stellvertretenden Militärkommandeure oder westlicher Stabsabteilungen in Berlin zur Regelung logistischer Probleme bei der Truppenentflechtung ${ }^{108}$.

${ }_{106}$ PRO, FO 944/758. BA, Z 45 F/OMGUS, AGTS/12/9. Eisenhower Papers, Bd. VI, S. 132 f.

107 Das amerikanische Protokoll in: BA, Z 45 F/OMGUS, AG 44-45/66/1, das britische in: PRO, FO 944/758, das französische (als das ausführlichste) in: AMAE, Y 453, Bl. 30-45. Clay, Entscheidung, S. 35 ff. Eisenhower, Crusade, S. 435 ff. Montgomery, Memoirs, S. $376 \mathrm{ff}$.

108 FRUS, 1945/III, S. 314, 328 f. Schukow nimmt in seinen Erinnerungen (S. 636 f.) für sich in An- 
Zurück blieb bei den westlichen Vertretern Ratlosigkeit und Enttäuschung. Zwar wurde ein gewisses Verständnis für Schukows Forderung nach voller Kontrolle über seine eigene Zone geäußert, aber mehr als die „Hoffnung“, die Sowjetunion werde letztlich einer Vier-Mächte-Kontrolle in Berlin zustimmen, bestand nicht. Bezeichnend schnell kehrten Briten und Amerikaner zu ihrer Skepsis zurück, der Kontrollrat werde vielleicht „nur ein Beratungsorgan und in keiner Weise eine Gesamtregierung für Deutschland“ werden. Eisenhower hatte bereits am 16. Mai die Erwartung geäußert, der Kontrollrat werde nicht mehr als eine „Clearingstelle“ für dringende Probleme sein; selbst wenn der sowjetische Vertreter für jede Entscheidung Moskau konsultieren müsse, bleibe der Kontrollrat immerhin „ein Instrument rascher Kommunikation mit den russischen Behörden“. Aufgrund seiner pessimistischen Einschätzung empfahl Eisenhower am 6. Juni, „daß unsere Regierung jetzt die möglichen Alternativen zur Vier-Mächte-Kontrolle in ganz Deutschland überprüfen sollte [...]. Nach meiner Auffassung müssen wir, wenn die Vier-Mächte-Regierung Deutschland nicht als Ganzes behandelt, entweder eine Drei-Mächte-Kontrolle in Westdeutschland errichten, damit dieses als eine wirtschaftliche Einheit behandelt werden kann, ohne die damit berührten Implikationen zu übersehen; oder wir müssen sonst bereit sein, unsere Zone praktisch für sich zu regieren. Mir ist die Unerwünschtheit beider Alternativen bewußt, und ich hoffe, daß die Notwendigkeit, einer von beiden zu folgen, nicht eintreten wird. " ${ }^{109}$ In diesem Sinne waren Eisenhower, Clay und ihr Politischer Berater Murphy gewillt, „einen echten Versuch zu unternehmen, Deutschland als eine wirtschaftliche Einheit zu behandeln“110. Doch da sie für „viele“ bzw. für „ungefähr drei“ Monate eine weitgehend autonome Verwaltung der eigenen Zone erwarteten, schien zur Bewältigung der anstehenden Tagesprobleme eine „informelle“ Kooperation mit der britischen und der französischen Zone unumgänglich. Trotz aller Bedenken, der entsprechende Ausbau von SHAEF könne von den Sowjets als Bildung einer gegen sie gerichteten Front interpretiert werden, wurden Ende Juni beim Hauptquartier der USGCC in Hoechst britische und französische Liaison-Stellen errichtet. Ein informelles Gremium der Vereinten Stellvertretenden Militärgouverneure sollte die Zeit „Zwischen der Auflösung des Gemeinsamen Oberkommandos und der vollen Arbeitsfähigkeit des Vier-Mächte-Kontrollrats“ überbrücken, dessen Unterorgane (CRAB) über die formelle Auflösung von SHAEF am 14. Juli hinaus bis zum September tätig blieben. Das gewährleiste eine effektivere Kooperation der Westzonen, könne aber gegenüber den Sowjets als provisorische Notlösung für eine Übergangszeit ausgewiesen werden ${ }^{111}$. Zwar mochte man in dieser Übergangsphase durch Ausklammern und Vertagen aller kontroversen Fragen Vertrauensbildung betreiben, doch würde, das wußte auch Clay, trotz „Geduld und Verständnis“ irgendwann der Tag der Wahrheit kommen. „Ich hoffe, daß eine endgültige Entscheidung im Hinblick auf eine Drei-Mächte-Regierung in Westdeutschland niemals notwendig werden möge, indem wir die Vier-Mächte-Regierung arbeitsfähig machen“, so gab er Ende Juni seine Zweifel zu Protokoll. „Wir können jedoch in der amerikanischen Zone als

spruch, den Konnex zwischen Rückzug der Westmächte aus der SBZ und der Ubergabe der Westsektoren Berlins hergestellt zu haben. Die Westmächte waren von dieser Forderung keineswegs überrascht. PRO, FO 944/758. BA Z 45 F/OMGUS, AGTS/12/9.

109 FRUS, 1945/III, S. 302, 329.

110 DBPO, I, 1, S. 1258.

111 DBPO, I, 1, S. 13. Vgl. unten S. 80 mit Anm. 35. 
einer Einheit nicht leben ohne den Import vieler wichtiger Güter aus den USA, wenn wir nicht einige formelle bi- oder trizonale Arrangements etablieren, sollte die VierMächte-Regelung scheitern." ${ }^{112}$ Ohne die Westlösung aufzugeben, war der Weg für die Vier-Mächte-Kooperation offengehalten. Gegenüber seinem Kollegen Saint-Hardouin erklärte Murphy, die endgültige Politik lasse sich erst festlegen, wenn die sowjetische Linie absehbar sei. Um diese beeinflussen zu können, das wurde Murphys Strategie der nächsten Monate, brauche man den Kontrollrat: „Wir müssen das Maximum der Rechte ausschöpfen, die uns das Kontrollabkommen bietet.“113 Ganz ähnlich waren die Empfindungen und Empfehlungen Montgomerys ${ }^{114}$. Ebenso äußerten die französischen Vertreter "große Skepsis“, ob „die Vier-Mächte-Kontrolle bald und in jedem Fall wirksam arbeiten" werde ${ }^{115}$.

Der Kontrollrat war noch nicht konstituiert, da wurde er in der Enttäuschung angesichts erster Hindernisse bereits zur Totgeburt erklärt. Allerdings darf bei allem Verständnis für die Enttäuschung über die politisch bedingten Verzögerungen nicht übersehen werden, daß die Arbeitsaufnahme des Kontrollrats aus rein technischen Gründen kaum früher möglich gewesen wäre. Da die EAC bis zum 31. Mai über die endgültige Fassung der gemeinsamen Alliierten Erklärung verhandelte und alle alliierten Vertreter beim Kontrollrat von ihren Regierungen nicht vor dem 2. Juni offiziell ernannt wurden, da auch die Westmächte sich über das Procedere nicht einigen konnten, wäre ein Treffen in Berlin vor dem 5. Juni kaum zu arrangieren gewesen. Ebenso war der Umzug der USGCC nach Hoechst erst Mitte Juni abgeschlossen. Das französische Hauptquartier in Baden-Baden nahm seine Arbeit offiziell am 29. Juli auf ${ }^{116}$.

Immerhin konnten in London bei der EAC am 14. Juni Vorverhandlungen ,auf Sekretärsebene“ über die Errichtung eines Alliierten Sekretariats beim Kontrollrat begonnen werden ${ }^{117}$. Nach Schukows Rückkehr am 28. Juni aus Moskau begannen am nächsten Tag in Berlin die Verhandlungen über den Truppenrückzug. Nachdem dieser am 4. Juli abgeschlossen, die Westmächte endlich in Berlin präsent waren, willigten die Sowjets „während des einstweiligen Fehlens des Kontrollrats“ in Drei-MächteVerhandlungen ohne Frankreich ein. Diese führten am 7. Juli zu dem Beschluß, am 11. Juli in Berlin die Kommandantur (mit französischer Liaison) einzusetzen und am darauffolgenden Tag den jeweiligen Mächten die Kontrolle über die vereinbarten Sektoren zu übergeben. Die ihnen von der Sowjetunion kurzerhand auferlegte Pflicht zur Versorgung ihrer Sektoren mit Lebensmitteln und Brennstoffen aus den Westzonen wurde von den überrumpelten Anglo-Amerikanern mangels präziserer Instruktionen zunächst akzeptiert, in einer weiteren Verhandlungsrunde am 10. Juli aber auf Anweisung ihrer Regierungen unter den Vorbehalt gestellt, die Zusage gelte nur vorläufig

112 CP, S. 37 f. (29. 6. 1945). BA, Z 45 F/OMGUS, 3/410-2/13 (Clay an McCloy); 2/92-1/3 (USGCC, 10.6. 1945).

113 AN, 457 (Bidault) AP 61/III (15.7. 1945).

114 PRO, FO 944/758 (6. 6. 1945). Montgomery, Memoirs, S. 380 ff. Die Koordination der Politik für Deutschland als Ganzes, so auch das Foreign Office, könnte von einer Alliierten Kommission ,innerhalb oder außerhalb Deutschlands“ gesteuert werden, „vorzugsweise auf einer Vier-MächteEbene, aber, wenn die russische Zustimmung ausbleibt, auf einer anglo-amerikanisch-französischen Grundlage“. PRO, FO 371/46730/C4049.

115 AN, 457 (Bidault) AP 61/II (20.6. 1945).

116 Eisenhower Papers, Bd. VI, S. 112 f. Clay, Entscheidung, S. 20 ff., 24, 47 f. BA, Z 45 F/OMGUS, USGCC 44-45/14/11.

117 BA, Z 45 F/OMGUS, USGCC 44-45/14/11. 
bis zum endgültigen Zusammentritt des Kontrollrats bzw. bis zur Klärung durch die Potsdamer Konferenz. Erst in dieser zweiten Sitzung wurde ein westlicher Protest gegen die Ausklammerung der Gebiete östlich von Oder und Neiße aus dem Zugriffsbereich des Kontrollrats vorgetragen. Auch den wehrte Schukow unter Hinweis auf die bevorstehenden Beratungen der Regierungschefs als nicht in seine Zuständigkeit fallend $\mathrm{ab}^{118}$. Als die Westmächte in Potsdam mit Bevins Kompromißvorschlag nicht durchdrangen, daß die Gebiete östlich von Oder und Neiße zwar nicht Teil der sowjetischen Zone seien, aber gleichwohl dem Kontrollrat unterstanden, war die sowjetische Interpretation anerkannt, daß deren Abtretung de facto, wenngleich nicht völkerrechtlich in Yalta beschlossen worden sei ${ }^{119}$.

Vor der Sitzung vom 10. Juli hatte Clay ein Papier zur Errichtung des Kontrollrats und seiner zwölf Direktorate an Schukow übersandt, das der nach Moskau zur Genehmigung weiterleitete ${ }^{120}$. Am 11. Juli trat, sozusagen als Symbol einer schrittweisen Realisierung des Kontrollabkommens, die Kommandantur zur ersten Sitzung zusammen. Am gleichen Tag trafen sich Vertreter der USA, Großbritanniens und der Sowjetunion im Gebäude der Kommandantur, um die Errichtung des Alliierten Sekretariats beim Kontrollrat, die Organisation und die Aufgaben der Direktorate sowie die Unterbringung der Kontrollbehörde zu besprechen ${ }^{121}$. Zur Befriedigung Sokolowskis wurde festgestellt, daß angesichts einer fehlenden deutschen Zentralregierung nur das "Gerippe“ eines Stabs beim Kontrollrat bestehen sollte, „während die Hauptstäbe in den Zonen behalten werden“, d. h. „die Abteilungen in den Besatzungszonen die vollziehende Gewalt ausüben sollten“, mit der alleinigen Ausnahme der Währungsfragen und der Reichsbankkontrolle. Nachdem Schukow aus Moskau grünes Licht erhalten hatte, legten die stellvertretenden Militärgouverneure auf einer informellen Zusammenkunft den 30. Juli für die erste Sitzung des Kontrollrats fest, die auf sowjetischen Vorschlag im amerikanischen Hauptquartier unter dem Vorsitz Eisenhowers stattfand $^{122}$. Dort wurde das amerikanische Papier zur Aktivierung des Kontrollapparats beraten und an die stellvertretenden Militärgouverneure überwiesen. Während Pioniere das im amerikanischen Sektor gelegene, aus 546 Räumen bestehende, nur leicht zerstörte Gebäude des ehemaligen Reichskammergerichts in der Elsholtzstraße $32 \mathrm{im}$ Bezirk Schöneberg als Sitz der Kontrollbehörde herrichteten, hielten die Stellvertreter

118 Clay, Entscheidung, S. 38 ff., 42 ff. CP, S. 27 ff. (29.6. 1945), 49 ff. (9. 7. 1945). BA, Z 45 F/OMGUS, AG 45-46/66/1. FRUS, Potsdam I, S. 630 ff. DBPO, I, 1, S. 98 ff., 122 f., 219 ff.

119 DBPO, I, 1, S. 122, 173, 219 ff., 472, 494, 729, 941, 947 ff., 1020, 1095, 1187. Die Briten hatten intern die Oder-Neiße-Grenze nie akzeptiert. Kettenacker, Krieg, S. 468 ff. Aber spätestens hier war die faktische Anerkennung vollzogen. Potsdamer (Berliner) Konferenz 1945, S. 99 ff., 113 ff., 127 ff. Insofern hatte Molotow recht, daß die Grenze endgültig erst auf einer Friedenskonferenz beschlossen werden könne, aber nach dem Beschluß von Yalta und Potsdam zur Aussiedlung der Deutschen sei die Grenze „doch nicht provisorisch“. SAPMO, ZPA, NI 36/739, Bl. 8-11. Ausgeklammert wurde die Erstreckung der Befugnisse des Kontrollrats auf Ostpreußen und das an die Sowjetunion abzutretende Gebiet um Königsberg. Potsdamer (Berliner) Konferenz 1945, S. 136. DBPO, I, 1, S. 549 f. Am 12. 2. 1946 gliederte Frankreich das Saargebiet aus dem Kompetenzbereich des Kontrollrats aus. Schmidt, Saarpolitik, Bd. 2, S. 1 ff. Obwohl die Westmächte dies bis zur Moskauer Außenministerkonferenz 1947 nicht akzeptierten, gab es Aufweichungstendenzen. Im Juli 1946 wurde Clay autorisiert, die Zustimmung zur Ausgliederung der Saar gegen die französische Zustimmung zu "any arrangements for economic unity“ anzubieten. FRUS, 1946/V, S. $577 \mathrm{ff}$.

120 BA, Z 45 F/OMGUS, 2/108-3/1 (CONL/P(45)1).

121 BA, Z 45 F/OMGUS, AG 45-46/66/1; USGCC 44-45/14/11.

122 Clay, Entscheidung, S. 48 ff. BA, Z 45 F/OMGUS, AG 44-45/66/1; USGCC 44-45/15/2. Das französische Protokoll in: AMAE, Y 652, Bl. 22 ff. 
vier , inoffizielle“ Sitzungen $a^{123}$. Am 31. Juli legten sie Verfahrensempfehlungen vor, die die Oberkommandierenden bis zum 4. August im Umlaufverfahren billigten. Auf dieser Basis wurden die technischen Einzelheiten und die personelle Besetzung der Direktorate geregelt, die der Kontrollrat auf seiner zweiten Sitzung am 10. des Monats bestätigte. Die Kontrollbehörde konnte ihre Arbeit aufnehmen, auch wenn sie ihre Existenz den Deutschen und der Welt erst mit der Proklamation Nr. 1 am 30. August offiziell bekanntgab.

Versuche, nicht nur die Verfahrenstechniken und die Organisation der alliierten Besatzungsverwaltung festzulegen, sondern auch die Inhalte der Besatzungspolitik, hatte es gegeben, seitdem die Briten der EAC am 15. Januar 1944 einen 70 Artikel umfassenden Entwurf für einen Waffenstillstandsvertrag mit Deutschland vorgelegt hatten ${ }^{124}$. Doch da die USA, die britischen Militärs und die Sowjetunion eine rein militärische Kapitulationsurkunde wünschten, zeichnete sich Anfang März 1944 in einem amerikanischen Vorschlag als Kompromißlösung ab, daß die Kapitulation Deutschlands nach dem Vorbild Italiens in drei Dokumenten geregelt werden würde: in einer kurzen, militärischen Kapitulationsurkunde, einer einseitigen alliierten Proklamation der Oberbefehlshaber sowie einer Erklärung, die „zusätzliche Forderungen“ an Deutschland auf militärischem, wirtschaftlichem und politischem Gebiet enthielt $^{125}$. Am 22. Juni 1944 lag der EAC ein gemeinsamer Entwurf über die Kapitulationsbedingungen vor, der am 25. Juli gebilligt und mit geringen Änderungen Grundlage der alliierten Erklärung vom 5. Juni 1945 wurde $^{126}$. In Artikel 13 dieser Erklärung behielten sich die Alliierten, wie schon in Italien, das Recht vor, „zusätzliche Forderungen" an Deutschland zu stellen. Eine entsprechende Übereinkunft, von den Regierungen Anfang September gebilligt, wurde am 20. September als Proklamation Nr. 2 des Kontrollrats veröffentlicht ${ }^{127}$. Eine politische Generaldirektive war das gleichwohl nicht. Deren Zustandekommen hatte die Sowjetunion durch Hinhaltetaktik gezielt verhindert. Seit dem Sommer 1944 hatten die Westmächte die Sowjetunion zur Entsendung einer sowjetischen Kontrollratsgruppe gedrängt, um mit dieser in der räumlichen Nähe zur EAC gemeinsam die Inhalte der Besatzungspolitik zu erarbeiten ${ }^{128}$. Die Sowjetunion reagierte auf mehrfache Anfragen erst im Oktober 1944, nachdem die Beratungen über den Kontrollapparat abgeschlossen waren. Sie wollte zunächst die „zusätzlichen Forderungen“ beraten, die ihren spezifischen Interessen entsprachen: Repatriierung der Kriegsgefangenen und Displaced Persons, Entwaffnung und Entmilitarisierung, Abschaffung des Hitler-Regimes und Auslieferung der Kriegsverbrecher sowie Kontrolle der deutschen Wirtschaft.

Nach Erledigung dieser Punkte könne die EAC „weitere“ Befehle und Anordnungen an die Deutschen sowie Direktiven an die Oberbefehlshaber beraten. Da Briten und Amerikaner diesen Punkten ebenfalls Priorität beimaßen, wurden - mit Ausnahme des ersten - in der Abschlußerklärung von Yalta diese als die vorrangigen

123 Protokolle in: BA, Z 45 F/OMGUS, 2/118-1/2.

124 FRUS, 1944/I, S. 112 ff., 430 ff. Vgl. Kettenacker, Krieg, S. 250 ff.

125 FRUS, 1944/I, S. 193 f., 224 ff., 365 ff.

126 FRUS, 1944/I, S. 235, 252 ff., 338 f., 341. Die Erklärung vom 5. 6. 1945 in: Amtsblatt des Kontrollrats, Jg. 1945, Ergänzungsblatt Nr. 1, S. 7 ff.

127 FRUS, Potsdam II, S. 1006-23. DBPO, I, 1, S. 889 ff. Amtsblatt des Kontrollrats, Jg. 1945, S. 8.

128 FRUS, 1944/I, S. 217 ff., 241 ff., 350. Die Briten hatten der EAC insgesamt 46 Entwürfe vorgelegt. FRUS, 1945/III, S. 444 f. Die amerikanischen Direktivenentwürfe in: ebenda, S. 370 f., 402. 
Ziele der Alliierten in Deutschland benannt ${ }^{129}$. Nachdem es den USA im Frühjahr 1945 nicht gelungen war, ihre Direktive JCS 1067 in der EAC zur gemeinsamen Richtlinie für das Besatzungsregime durchzusetzen, konnte es nicht überraschen, daß in Potsdam ein erneuter Vorstoß ebenfalls scheiterte, verbindliche inhaltliche Vorgaben für den Kontrollrat festzulegen ${ }^{130}$. Statt dessen formulierte die Konferenz im Potsdamer Abkommen, wie Briten und Sowjets übereinstimmend als ausreichend erachteten, „politische und wirtschaftliche Prinzipien für die Behandlung Deutschlands in der ersten Kontrollphase“, die Richtlinien enthielten, aber klare Anweisungen vermieden. Angesichts dieser Erfahrungen war kaum mehr zu erwarten, daß es den Oberbefehlshabern im Kontrollrat gelingen könnte, auf der Grundlage der Potsdamer Formelkompromisse verbindliche „Direktiven“ nachträglich zu entwickeln, nachdem dies ihren Regierungen nicht möglich gewesen war. Es traten nun vier nationale Direktiven in Kraft, die den Primat der zonalen Autonomie weiter verfestigten - zumal nachdem die Sowjetunion durch ihren Befehl Nr. 2 vom 10. Juni 1945, mit dem sie die Zulassung von Parteien und Gewerkschaften in ihrer Zone verkündete, ihre Bereitschaft zum zonalen Alleingang nachdrücklich demonstriert hatte.

\section{Organisation, Personal und Arbeitsweise}

\section{a. Die Organe}

Oberstes Organ der Alliierten Kontrollbehörde (Allied Control Authority), wie sie trotz schwankenden Sprachgebrauchs ${ }^{131}$ seit dem 5. Juni 1945 offiziell hieß, war der Alliierte Kontrollrat (Allied Control Council), der aus den vier Oberbefehlshabern bestand. Er trat in der Regel alle zehn Tage unter monatlich wechselndem Vorsitz zusammen, bis zum 20. März 1948 zu 82 Sitzungen, und traf seine Entscheidungen (wie alle Unterorgane) einstimmig ${ }^{132}$. Obwohl der Kontrollrat die eigentlich entscheidungsbefugte Instanz war, sind doch nur wenige Entscheidungen in diesem Gremium gefallen. Herzstück der Kontrollbehörde wurde das Koordinationskomitee, das aus den stellvertretenden Militärgouverneuren bestand. Von Beginn an delegierten die

129 FRUS, 1944/I, S. 369 f., 393 f., 404, 408, 423. FRUS, Malta und Yalta, S. 970.

130 FRUS, Potsdam II, S. 238, 283 ff., $804 \mathrm{ff}$.

131 Seit den ersten britischen Vorlagen war der "Control Council“ nur das Gremium der Oberbefehlshaber. Als ihm durch die Vorschläge der USA ein Unterbau zugeordnet wurde, wurde der Sprachgebrauch schwammiger. Die Briten nannten die Gesamtinstitution "Control Commission", die USA „Supreme Allied Authority“, die Sowjets „Control Machinery“. Seit der alliierten Erklärung vom 5. 6. 1945 hieß die gesamte Behörde „Allied Control Authority“. Murphy registrierte entsetzt, daß „Control Council“ im Russischen "Control Soviet“ (kontrol'nyi sovet) hieß. Die Briten blieben mit dem Namen unzufrieden, doch wurde ihre Version „Control Commission“ von den Sowjets „abgelehnt“ und von den USA „nicht unterstützt“. Sie boten daher als Kompromiß „Allied Control Authority“ an, auch wenn das War Office dagegen, das Foreign Office nicht begeistert war; letzteres lenkte ein, um neue „internationale Verhandlungen“ zu vermeiden. BA, Z 45 F/OMGUS, AG 45$46 / 66 / 1$; 2/92-1/10. PRO, FO 371/40664/U7455; FO 1049/134 (17. 7. 1945). FRUS, 1945/III, S. 332 .

132 In den letzten Wochen seiner Existenz wurde die Arbeit noch einmal gestrafft, indem er auf Vorschlag Clays vom 20.1. 1948 zur Beratung der Währungsreform sowohl „öffentlich“ in der tradierten Form als auch „geheim“ mit nur vier bis sechs Mitgliedern pro Delegation in „executive session“ (FRUS, 1948/II, S. 870, 873) bzw. als „comité secret“ tagte. AN, 457 (Bidault) AP 15/Allemagne (22. 1. und 12. 2. 1948). Die Protokolle der „executive sessions“ sind in BA, Z 45 F/ OMGUS, 2/108-3/5 nicht enthalten. 
Oberkommandierenden nicht nur die Arbeit, sondern auch die Entscheidungsbefugnis. Bereits um die Jahreswende 1945/46 agierten die Stellvertretenden Militärgouverneure hauptverantwortlich im Kontrollrat wie im Koordinationskomitee. Nachdem Sokolowski zum Oberkommandierenden aufgerückt war, nahm er zunächst, wohl um die Beratung des Industrieniveauplans in der Hand zu behalten, beide Funktionen selbst wahr. Am 8. März 1946 einigten sich die vier Stellvertreter im Kontrollrat in wenigen Minuten über die Stahlproduktion, nachdem sie selbst am Vortag als Koordinationskomitee in erbitterter Diskussion einen Kompromiß nicht erzielt hatten. In dieser Sitzung des Kontrollrats erteilten sich die Stellvertreter zur Beschleunigung des bürokratischen Verfahrens selbst inoffizielle Aufträge als Mitglieder des Koordinationskomitees für das weitere Vorgehen. Nachdem das Koordinationskomitee 1946/47 zunehmend Beschluß- und Exekutivkompetenz gewonnen hatte, verschoben sich die Gewichte wieder zugunsten des Kontrollrats, als die Stellvertreter der ersten Monate, d. h. Sokolowski, Clay und Robertson, 1946/47 selbst als Oberkommandierende in diesen aufgerückt waren.

Das Koordinationskomitee traf sich zu 153 Sitzungen, meist unmittelbar vor und nach denen des Kontrollrats. Es bereitete die Beratungen des Kontrollrats vor, leitete dessen Beschlüsse an die nachgeordneten Instanzen des Kontrollstabs und die Berliner Kommandantur weiter und überwachte deren Ausführung. Die Tagungshäufigkeit ließ seit dem Scheitern der Moskauer Außenministerkonferenz im Frühjahr 1947 deutlich nach. Die Abstände zwischen den Sitzungen wuchsen auf eine oder gar zwei Wochen; die Tagesordnungen wurden immer kürzer, die Tagesordnungspunkte belangloser ${ }^{133}$. Die Ursachen lagen sowohl in der Abkühlung des politischen Klimas als auch in dem allgemeinen Funktionsverlust, da mangels Einigungsfähigkeit die wichtigen Fragen zurückgestellt, an die Außenminister verwiesen oder außerhalb des Kontrollrats zwischen den Oberkommandierenden geregelt wurden.

Die Tätigkeit von Kontrollrat und Koordinationskomitee gestaltete sich mit der Zeit derart umfangreich und vielfältig, daß die (stellvertretenden) Kommandeure zunehmend von ihren Apparaten abhängig wurden. Offenbar nur in den Anfangsmonaten nahmen die (stellvertretenden) Militärgouverneure die Möglichkeit wahr, und das auch nur im Ausnahmefall, neben ihrem Politischen Berater ${ }^{134}$ und ihrem Stab zusätzlich die Abteilungsleiter bzw. Direktoratsvertreter an den Sitzungen des Koordinationskomitees teilnehmen zu lassen oder den amtierenden Direktoratsvorsitzenden als „Rapporteur“ um mündliche Stellungnahmen zu bitten. Fortan erarbeiteten das Alliierte Sekretariat und die nationalen Sekretariate entsprechende Materialzusammenstellungen; die Direktorate oder deren nationale Elemente stellten monatliche Zustandsberichte über die erledigten bzw. noch offenen Fragen zusammen, die die Konfliktpunkte und die verschiedenen Standorte der Delegationen in synoptischer Form aufbereiteten. Für die Chefs wurden in allen drei westlichen Kontrollratsgruppen von den Abteilungsleitern für jeden Tagesordnungspunkt und jedes Papier Zu-

133 BA, Z 45 F/OMGUS, 2/118-2/1 bis $2 / 118-3 / 21$.

134 Die Politischen Berater hatten als Repräsentanten der Außenministerien einen Sonderstatus; der amerikanische verfügte im Januar 1948 über einen Apparat von ca. 200 Personen. BA, Z 45 F/ OMGUS, POLAD/471/50. Clay, Entscheidung, S. 72, 74. Murphy, Diplomat, S. 282. Bei den Briten war es Aufgabe des Politischen Beraters, die Mitarbeiter der CCG auf dem nationalen Politikkurs zu halten und ihren Blick über die Lösung technischer Probleme hinaus für den Gesamtzusammenhang zu schärfen. PRO, FO 1049/281 (6. 11. 1945). 
sammenfassungen (,briefs“) von einer Seite erstellt, die bei OMGUS 24 Stunden vor den Sitzungen vorliegen mußten. Diese Zusammenfassungen enthielten sowohl die Substanz des zur Diskussion stehenden Papiers als auch die amerikanische Position. Nach den Sitzungen wurden, da die offiziellen Protokolle innerhalb von 48 Stunden nicht zur Verfügung standen, vom amerikanischen Element des Alliierten Sekretariats informelle Informationspapiere direkt an die zuständigen amerikanischen Vertreter der betroffenen Direktorate vorab übermittelt. Bis zum darauffolgenden Nachmittag hatten die Abteilungsleiter von OMGUS dem stellvertretenden Militärgouverneur zu melden, welches Vorgehen sie in der amerikanischen Zone bzw. im Direktorat für angebracht hielten, entweder fernmündlich oder durch einen Memorandenentwurf ${ }^{135}$.

Die konkrete Sacharbeit des Kontrollrats wurde in zwölf, später zehn Direktoraten erledigt, die ihrerseits wieder Ausschüsse, Unterausschüsse, Arbeitsgruppen oder ad hoc-Ausschüsse einsetzten. Es waren dies die Direktorate für Heer, Marine, Luftfahrt (im Januar 1947 zusammengefaßt im Vereinigten Militärdirektorat), Transport, Post und Telekommunikation, Politisches, Wirtschaft, Finanzen, Recht, Kriegsgefangene und Zivilverschleppte, Arbeit, Inneres und Nachrichtenmittel sowie Reparationen, Gegenlieferungen und Restitutionen. Ein weiteres, von den USA vorgeschlagenes Direktorat für Informationskontrolle kam nicht zustande; die einschlägigen Aufgaben wurden statt dessen einem Ausschuß des Politischen Direktorats übertragen ${ }^{136}$.

Bis zum 30. August 1945 hatten die zwölf Direktorate 35 Ausschüsse und sechs Unterausschüsse eingesetzt. Angesichts des erforderlichen Arbeitsaufwands wurden im September drei weitere Ausschüsse und acht Unterausschüsse sowie eine unbekannte Zahl von ständigen oder ad hoc-Arbeitsgruppen eingerichtet; andere waren inzwischen bereits wieder aufgelöst worden ${ }^{137}$. Bis zum Januar 1947 war die Zahl der Ausschüsse auf 55, die der Unterausschüsse auf 23 angewachsen ${ }^{138}$. Anfang 1948 bestanden zehn Direktorate, 49 Ausschüsse, 21 Unterausschüsse, 32 Arbeitsgruppen sowie diverse, nicht näher bezeichnete Arbeitsorgane. Dazu kamen 21 Gremien der Berliner Kommandantur, so daß die Kontrollbehörde, inkl. der Kommission für den deutschen Auslandsbesitz (GEPC), aus mindestens 140 Gliederungen bestand. Rechnet man die Sekretariate der Komitees oder die technischen Stäbe hinzu, so wurde die Zahl von 175 Unterorganen, die Clay angibt, ohne weiteres erreicht ${ }^{139}$.

Die technische Organisation oblag dem zunächst nicht vorgesehenen, dann aber auf amerikanisches Drängen als erstes eingerichteten und als letztes (im August 1948) aufgelösten Kontrollratsorgan, dem Alliierten Sekretariat ${ }^{140}$. Es bestand aus zwei Abteilungen. Die Protokollabteilung war für die Außenbeziehungen zuständig, vor allem für die Liaison zu den akkreditierten Militärmissionen. Die Verwaltungsabteilung, in

135 BA, Z 45 F/OMGUS, USGCC/44-45/2/3.

136 NA, RG 59, 740.00119 Control(Germany)/11-1045 (Murphy).

137 Im Finanzdirektorat bestanden Ende Oktober 1945 fünf Ausschüsse sowie ein gemeinsamer Ausschuß mit dem Transportdirektorat; zwei davon waren erst im Oktober eingerichtet, eine Arbeitsgruppe wieder aufgelöst worden. BA, Z 45 F/OMGUS, 2/121-2/5-9 (DFIN/Memo(45)21, 30. 10. 1945). Von September 1945 bis Januar 1946 bestanden im Innendirektorat je nach Bedarf 7-8 Ausschüsse, 4-8 Unterausschüsse und 4-9 Arbeitsgruppen, darunter ein spezielles Komitee der Stellvertreter und ein Gemeinsames Komitee zusammen mit dem Rechtsdirektorat. 2/103-1/3.

138 FRUS, 1947/II, S. 835 ff.

139 NA, RG 43/ACC, box 6 (1. 4. 1948). Clay, Entscheidung, S. 62. Keiderling, Kommandantur, S. $575 \mathrm{ff}$.

140 FRUS, 1947/II, S. 839. 
der die USA mit 45 zivilen und militärischen Mitarbeitern am stärksten vertreten waren, führte die zentralen Akten, organisierte die Übersetzungsdienste, standardisierte die Begrifflichkeiten, entwarf Formulare u.ä.m. Sie erarbeitete die Vorlagen und Protokolle auf Vorschlag des geschäftsführenden Sekretärs des jeweiligen Kontrollratsorgans, kontrollierte die Sekretariate der Unterorgane und stellte das Material für Beschlußvorlagen in Kontrollrat und Koordinationskomitee zusammen. Über das Alliierte Sekretariat wurden zudem die Befehle, Erlasse und Gesetze ausgetauscht, die in den einzelnen Zonen auf der Grundlage von Beschlüssen des Kontrollrats ergangen waren ${ }^{141}$. Versuche der Westmächte, im Alliierten Sekretariat einen Ständigen Sekretär für ein Jahr, so die Angelsachsen, oder doch zumindest für drei bis sechs Monate, so Frankreich, einzusetzen, um eine höhere Kontinuität in der Verwaltungsarbeit herzustellen, scheiterten am sowjetischen Widerstand, so daß auch im Alliierten Sekretariat der Vorsitz monatlich rotierte ${ }^{142}$. Trotz derartiger politischer und organisatorischer Behinderungen erlangte das Alliierte Sekretariat eine allseits anerkannte Effizienz, nachdem die USA im August 1945, als sie erstmals den Vorsitz innehatten, mit hohem Personalaufwand die Maßstäbe gesetzt hatten, denen die anderen Mächte mit ähnlich immensem Einsatz nacheiferten. Als bestgeführte Kontrollratsgruppe galt die der Briten, die - wie schon in der EAC - mit ihren Verwaltungspraktiken prägend wurden. Das wurde dadurch begünstigt, daß Amerikaner und Briten, durch lange Kooperation aufeinander eingespielt, in den beiden ersten Monaten die Geschäfte führten und damit die Usancen prägten. Frankreich, das im Oktober als dritte Macht die Geschäfte führte, paßte sich dem an. Hatte man auf westlicher Seite anfangs erwartet, daß die Sowjetunion völlig neue, ja "fremde" Methoden einführen würde, so daß man sie erst „erziehen“ müsse, so erwies sich diese Befürchtung als grundlos. Insgesamt war das Alliierte Sekretariat, nachdem es anfangs in einem „freundlichen, aber vielleicht etwas zufälligen" Stil gearbeitet hatte, nach Ende der Eingewöhnungsphase zu einem effizienten Instrument geworden, das die "große und ausgesprochen verworrene“ Kontrollbehörde zusammenhielt ${ }^{143}$.

Zur Effizienz trug bei, daß alle Direktorate über ein eigenes Sekretariat verfügten. Diese bereiteten die Berichte, Vorlagen und Protokolle für das Alliierte Sekretariat vor. Indem sie über die Sekretariate der vier Kontrollratsgruppen den engen Informationsaustausch zu den nationalen Repräsentanten in den anderen Direktoraten herstellten, konnten sie die bürokratische Schwerfälligkeit des Apparats etwas abmildern, nachdem die Sowjetunion durch ihr Veto verhindert hatte, daß die Direktorate unter Umgehung des Koordinationskomitees direkt in offiziellen Kontakt miteinander treten durften, was allein angesichts der zahlreichen, ungeklärten Kompetenzüberschneidungen angebracht gewesen wäre. Im Oktober 1945 hatte das Koordinationskomitee

141 BA, Z 45 F/OMGUS, POLAD/728/11. Mit der Begründung, die „Einheitlichkeit“ der Maßnahmen in den jeweiligen Zonen zu wahren, hatte Clay dies angeregt. 2/118-1/2-4 (CORC/M(45)7, 12. 9. 1945, mit CORC/P(45)57).

$142 \mathrm{BA}, \mathrm{Z} 45$ F/OMGUS, 2/118-1/2-4 (CORC/M(45)19, 6. 11. 1945). Britische Überlegungen, aus Ersparnisgründen nur die Spitze des Kontrollrats mit Vertretern aller drei bzw. vier Nationen, die Stäbe aber gemischt zu besetzen, wurden auch von den USA für die Bereiche abgelehnt, in denen "high policy is formulated or directed“. PRO, FO 942/82 (30.6. 1944). NA, RG 59/EAC, box 3 (19.6. 1944). Gleichwohl scheint es gemischte Elemente von Briten und Amerikanern im Alliierten Sekretariat gegeben zu haben. AMAE, Y 286, Bl. 29 (4. 6. 1946).

143 PRO, FO 1049/281 (27. 10. 1945). DBPO, I, 5, S. 293 ff. Ratchford/Ross, Reparations, S. 55. 
auf Anfrage des Wirtschaftsdirektorats vorgeschlagen, diesem Vollmacht zur eigenständigen, aber nicht unkontrollierten Ausübung seiner Tätigkeit zu übertragen. Während die Anglo-Amerikaner diese Regelung uneingeschränkt befürworteten, die Franzosen immerhin für die Übertragung „eines gewissen Teils unserer Gewalt“ votierten, lehnte Schukow das mit dem Argument ab, es gebe keine deutschen Zentralverwaltungen, denen das Wirtschaftsdirektorat Anweisungen erteilen könne ${ }^{144}$.

Dies hatte zur Folge, daß ein sehr rigide festgelegter Dienstweg eingehalten werden mußte, der zwangsläufig zu einem schwerfälligen Entscheidungsfindungsprozeß führte. Gleichrangige Unterorgane durften in der Regel nicht direkt miteinander in Verbindung treten, sondern mußten jeweils über die nächsthöhere Instanz gehen. Um die Tätigkeit verschiedener Direktorate besser koordinieren zu können, waren im Herbst 1945 Versuche unternommen worden, gemeinsame Sitzungen abzuhalten. Das bewährte sich nach Auffassung der Beteiligten nicht, da es zu Kompetenzstreitigkeiten und neuen Verzögerungen kam. Allerdings wurde der Ausweg, Mitglieder anderer Direktorate als Gäste oder „Berater“ einzuladen, nicht häufig in Anspruch genommen. Immerhin mußten (und durften) sich auf Vorschlag des Alliierten Sekretariats seit April 1946 die Direktorate direkt mit anderen interessierten oder betroffenen Direktoraten abstimmen, ehe sie dem Koordinationskomitee Vorlagen unterbreiteten, um mangelhaft vorbereitete Diskussionen, Vertagungen, Rückfragen usw. zu vermeiden. Nachdem das Koordinationskomitee die Teilnahme der Direktoratsvertreter an seinen Sitzungen aufgegeben und das Verfahren auf die Erstellung schriftlicher Kurzvorlagen beschränkt hatte, begannen auch die Unterorgane, sich bürokratisch abzukapseln. Die Direktorate versuchten zunehmend, ihre Unterorgane an die kurze Leine zu nehmen, indem aufgrund negativer Erfahrungen diesen die Arbeitsaufträge mit sehr detaillierten Vorgaben überwiesen wurden. Eine Ausdehnung gewisser Freiheiten auf die Unterorgane, die zumeist mit strenger Terminvorgabe arbeiten mußten, scheiterte mit wenigen Ausnahmen; nur bei besonderer Dringlichkeit durften sie in genau definierten Fällen direkten Kontakt aufnehmen. Insgesamt war es Praxis, fast jede Frage nach kurzer Vorberatung an das nächstniedrigere Organ abzuschieben und sich von diesem Vorlagen erarbeiten zu lassen. Es war insofern gar nicht immer nötig, ein offizielles Veto einzulegen. Es reichte, ein Problem auf die Reise durch die Instanzen zu schicken, um eine Verschiebung ad calendas graecas zu bewirken.

Wenn das Koordinationskomitee oder die Direktorate ihre Arbeit abgeschlossen hatten, ergaben sich neue Verzögerungen im Rechtsdirektorat, das alle Rechtstexte in eine juristisch entsprechende Form in den drei Amtssprachen brachte. Im April 1947 schob das Direktorat 50 Aufträge vor sich her, doch wurde ein britischer Vorstoß zur Beschleunigung des Verfahrens von Franzosen und Sowjets abgelehnt. Nach einer Neuauflage der Debatte vom Frühjahr 1946 über eine Reform des Alliierten Sekretariats unternahmen Briten und Amerikaner Anfang 1947 einen abermaligen Vorstoß zur Änderung des Verfahrens, indem sie eine unbürokratische, nicht hierarchisch kontrollierende, direkte Kommunikation zwischen allen Unterorganen forderten, freilich - um den Sowjets entgegenzukommen - unter Information aller denkbaren zuständi- 
gen höheren Stellen. Der sowjetische Vertreter begrüßte das prinzipiell, aber doch mit so deutlicher Zurückhaltung, daß grundlegende Änderungen nicht eintraten ${ }^{145}$.

Die Anglo-Amerikaner, in geringerem Maße auch die französischen Vertreter, hatten aufgrund des ihnen zugebilligten Ermessensspielraums noch am ehesten die Möglichkeit, auf der jeweils nächsthöheren Ebene des Kontrollrats Zugeständnisse zu machen und Positionen der unteren Ebene zu korrigieren. Koenig und Koeltz waren durch Instruktionen eng gebunden, wenngleich anfangs die Rückkoppelung nach $\mathrm{Pa}$ ris „sehr schlecht“ war $^{146}$. Zumindest Koeltz zeigte sich recht flexibel, manchmal wohl für seinen Stab zu flexibel, und wurde durch General Noiret abgelöst. Auch bei den Sowjets wurden nachgeordnete Instanzen häufig korrigiert, da ihre Vertreter keineswegs immer mit engen Instruktionen in die Verhandlungen gingen, von denen sie nicht abweichen durften. Doch wenn nachgeordnete Beamte auf mittlerer oder unterer Ebene sich zu sehr von den Sachzwängen beeindrucken ließen, revidierten die Vorgesetzten Entscheidungen, meist unter übergeordneten politischen Vorzeichen oder auf Anweisung aus Moskau ${ }^{147}$. Nur selten war zu beobachten, daß Schukow oder Sokolowski in Kontrollrat oder Koordinationskomitee wichtige Entscheidungen gegen ihren Stab und ohne Rückfrage in Moskau fällten, obwohl die Westmächte anfangs bei beiden Generälen den Eindruck hatten, daß sie einen für sowjetische Verhältnisse ungewöhnlich großen Entscheidungsspielraum hatten bzw. wahrnahmen ${ }^{148}$. Stalin hatte seine Militärs dagegen frühzeitig in Verdacht, zu besatzungspragmatisch zu handeln, „oft politisch genarrt“" zu werden, wenngleich von den Deutschen, so daß sie an eindeutige Direktiven gebunden werden müßten ${ }^{149}$.

Allgemein ließ sich der Trend beobachten, daß mit zunehmender Belastung der Kontrollratsarbeit durch politische Vorgaben bei allen Mächten die Entscheidungen nur noch auf höchster Ebene möglich waren und immer enger an die Instruktionen der Regierungen gebunden wurden. In den USA waren die kurzlebigen und informellen Planungsinstanzen, zuletzt das interministerielle IPCOG, mit Kriegsende aufgelöst worden; das State-War-Navy Coordinating Committee (SWNCC) war angesichts seiner sehr viel weiter gefaßten Aufgaben kein adäquater Ersatz, sorgte aber für eine gewisse Beruhigung, indem der Einfluß Morgenthaus auf die Deutschlandpolitik erheblich reduziert wurde. Zugleich entstand ein neuer Dualismus: Am 30. August 1945 ordnete Truman an, daß das State Department die Deutschlandpolitik formulierte, das

145 FRUS, 1946/V, S. 563 f. PRO, FO 1049/922 (ASEC(47)116). BA, Z 45 F/OMGUS, 2/118-2/8 (CORC/P(45)2, 19. 8. 1945; CORC/P(46)121, 28. 3. 1946; ASEC(45)136, 26. 11. 1945; DIAC/ Memo(46) 438 und $\mathrm{P}(46) 349) ; 2 / 118-3 / 10-21$ (CORC/P(47)85 und 131).

146 AN, 457 (Bidault) AP 62 (SGAAA, 6. 9. 1945). Die GFCC beschwerte sich über „widersprüchliche“ und „offensichtlich ungenügende" Instruktionen. AO, Berlin/3269/1/2701 (11.7. 1946); 3270/1/ 2132 (15. 5. 1946); 3276/1/2007 (MMAA, 15. 6. 1945).

$147 \mathrm{Zu}$ den Klagen eines SMAD-Offiziers vgl. AO, Berlin/3273/3/2731, I (25. 8. 1945). BA, Z 45 F/ OMGUS, 2/111-1/5-6 (DFIN, 23. 7. 1947). Die unterschiedliche Praxis des Informationsflusses innerhalb der einzelnen Delegationen läßt sich u. a. an der Zahl der Kopien ablesen, die für die offiziellen Protokolle der diversen Organe verlangt wurden. Im Wirtschafts- bzw. Arbeitsdirektorat bestellten die USA im Dezember $1945160(100)$, die Briten $110(50)$, die Franzosen $150(30)$ und die Sowjets $10(3)$.

148 PRO, FO 1049/281 (6. 11. 1945); CAB 21/2302 (1. CONL, 12. 8. 1945). DBPO, I, 5, S. 14. Bokow, Frühjahr, S. 406, $427 \mathrm{f}$.

149 FRUS, Potsdam I, S. 51 (28. 5. 1945, gegenüber Harry Hopkins). Vgl. die Äußerung Kowals gegenüber den Präsidenten der SBZ-Zentralverwaltungen am 24. 1. 1947: „Unsere Wünsche, dass unsere Arbeit die bessere ist, werden nicht von Hintergedanken diktiert. Jeder Oberbefehlshaber einer Zone will, dass es in seiner Zone klappt.“ SAPMO, ZPA, Nl 90/314, Bl. 48. 
War Department diese auszuführen hatte, da am militärischen Charakter der Besatzungsverwaltung nicht gerührt werden konnte und sollte ${ }^{150}$. Daraus ergab sich ein anhaltender Streit zwischen State und War Department um den Übergang der Verantwortung und vor allem der Kosten der Besatzungsverwaltung in zivile Hände, der auch durch die 1947 erfolgte Einsetzung des Assistant Secretary of State for Occupied Areas im State Department nicht gemildert wurde. Vielmehr eröffnete diese Konstellation Clay die Möglichkeit, starken Einfluß weniger auf die Formulierung als auf die Umsetzung der Politik zu nehmen. Ihm kam zugute, daß er Außenminister Byrnes aus der Kriegszeit kannte und daher im Zweifelsfalle, z. B. bei der Anwendung der Direktive JCS 1067, den direkten Weg zu diesem suchte; und dieser löste für Clay die Probleme beim Präsidenten „auf dem kurzen Dienstweg“. Die Stellung des Politischen Beraters Murphy wurde derart systematisch ausgehöhlt ${ }^{151}$.

Ähnlich waren die Probleme in Großbritannien. Die Militärverwaltung unterstand dem Kriegsministerium bzw. dessen Abteilung für Zivilangelegenheiten. Bis zum September 1945 waren das Hauptquartier der 21. Armee und die CCG vereinigt. Nach der Trennung wurden sie durch den Oberkommandierenden zusammengehalten, doch unterstand dieser als Chef der Militärverwaltung ziviler Kontrolle, als Oberbefehlshaber dem War Office. Montgomery umging diese Probleme, indem er aufgrund seines Ausnahmestatus sich direkt an den Premierminister wandte, während Robertson später Clays „allmächtige“ Position als Vorbild für seinen Kampf gegen den ministeriellen Dschungel in London diente ${ }^{152}$. Da das Foreign Office nicht bereit war, sofort die volle und alleinige Verantwortung zu übernehmen, wurde im Oktober 1945 das Control Office for Germany and Austria (COGA) gegründet, das sich zu einer schlagkräftigen Behörde entwickelte. Erst im März 1947, als Hynd durch Lord Pakenham abgelöst wurde, kam es zur stärkeren Einbindung in das Foreign Office, die mit einer engeren personellen Verflechtung auf der mittleren Verwaltungsebene verbunden war. Dahinter stand Bevins Absicht, im Kabinett seinen Einfluß auf die Deutschlandpolitik zu verstärken, um im Vorfeld der Moskauer Außenministerkonferenz einen härteren Kurs gegenüber der Sowjetunion durchsetzen zu können ${ }^{153}$.

In Frankreich wurde die Deutschlandpolitik koordiniert von dem am 7. Juli 1945 (nach dem Vorbild von IPCOG) gegründeten Comité Interministériel pour les Affaires Allemandes et Autrichiennes, in dem die Ministerien für ̈̈ußeres, Krieg, Wirtschaft, Wiederaufbau, Öffentliche Arbeiten, Transport und Industrielle Produktion vertreten waren und das unter dem beherrschenden Vorsitz von de Gaulle tagte ${ }^{154}$. Gedacht als „Drehscheibe“ zwischen dem (dem Staatspräsidenten der Provisorischen Regierung unterstellten) Oberkommando in Baden-Baden und den beteiligten Ministerien, waren das Komitee bzw. sein Generalsekretär doch politisch zu schwach, um diese Funktion auszufüllen. Dem konnte die Aufwertung zum „Generalkommissariat“ nicht abhelfen, da das Amt ohne Kabinettsrang zu wenig Einfluß besaß. Das CGAAA wurde, in An-

150 NA, 740.00119 Control(Germany)/1-246.

151 TL, Oral History Collection, Clay. Peterson, Occupation, S. 59 ff. Murphy sah seine Stellung dadurch geschwächt. Kindleberger, Letters, S. 30, 37.

152 Thies, Militärverwaltung, S. 40, $42 \mathrm{f}$., 50.

153 Reusch, Londoner Institutionen, S. 318 ff. Thies, Militärverwaltung, S. 42 ff. DBPO, I, 5, S. $301 \mathrm{ff}$. Deighton, Impossible Peace, S. $129 \mathrm{f}$.

154 AMAE, Y 465, Bl. 84; Y 650, Bl. 2, 19 ff. AN, F 60/3034, doss. 2. Journal Officiel, 25. 7. 1945. Hillel, Occupation, S. $160 \mathrm{ff}$. 
passung an die angelsächsischen Länder, am 20. August 1946, unmittelbar nach dem Scheitern der Pariser Außenministerkonferenz, zu einem Staatssekretariat aufgewertet, das im Außenministerium ressortierte ${ }^{155}$. Da Bidault, Couve de Murville und General Koenig enge Gefolgsleute de Gaulles waren, blieb - trotz aller Revisionsbemühungen aus den Apparaten von Außenministerium und Militärregierung - auch nach dessen Rücktritt Anfang 1946 eine Deutschlandpolitik in seinem Sinne gewährleistet ${ }^{156}$.

Lediglich in Moskau gab es kein spezielles Organ, das die SMAD anleitete. Ein dem Ministerrat unterstelltes Sonderkomitee vermochte die divergierenden Interessen der beteiligten Ministerien nicht zu bändigen, die sich direkte Drähte nach Deutschland geschaffen hatten. Bei grundsätzlichen Fragen gab es Anweisungen „direkt vom Politbüro, dem Rat der Volkskommissare und der Politischen Hauptverwaltung“; Schukow wurde auch von Stalin direkt telefonisch angewiesen, ebenso von seinen Stellvertretern Molotow und Mikojan oder den ZK-Sekretären Schdanow und Malenkow ${ }^{157}$. Derart direkte Befehlsstränge waren den Westmächten unbekannt; doch erwies sich das sowjetische Führungssystem weniger als eine "duale integrative“ Befehlsstruktur, wie sie auch die Westmächte kannten, sondern als ein „polykratisches Chaos“, in dem bis Ende 1947 weder die Eigenmächtigkeiten der regionalen SMAs noch die Rivalitäten zwischen staatlichen, parteiamtlichen und militärischen Instanzen effektiv zu unterbinden waren. Insofern scheint es hier die größten Reibungsverluste gegeben zu haben, nicht zuletzt, da sich die SMAD selbst bis Anfang 1946 in einer permanenten Umstrukturierung befand und ihre Kompetenzen von Sonderorganen eingeschränkt wurden, die Moskau direkt unterstellt waren. Zu den zahlreichen Spezialbehörden gehörte der „Gehilfe des Obersten Chefs für ökonomische Fragen“, der sowohl für die Reparationen als auch für die deutsche Wirtschaft verantwortlich war und über entsprechende Untergliederungen für Industrie, Landwirtschaft oder Handel und Versorgung verfügte. Die Spitzen der SMAD-Abteilungen oder Fachverwaltungen waren vom Rat der Volkskommissare ernannt und erhielten z.T. ihre Anweisungen direkt aus Moskau ${ }^{158}$. Ursache dieser internen Reibungsverluste waren in der Regel die Machtkämpfe in Moskau, die sich in vielfältigen Reorganisationen der Instanzen, der Zuständigkeiten und der Befehlsstränge sowie im Austausch des Personals niederschlugen ${ }^{159}$. Daraus erklären sich das Schwanken und die Unberechenbarkeit der sowjetischen Kontrollratspolitik, deren nachträgliche Revisionsund Reinterpretationsversuche den Westmächten Anlaß und Vorwand boten, ihre eigenen Wege zu gehen.

155 AN, 457 (Bidault) AP 65/Organisation.

156 Chauvel, Commentaire, S. $111 \mathrm{ff}$. Hillel, Occupation, S. $162 \mathrm{ff}$.

157 Bokow, Frühjahr, S. 427 f. Slusser, Soviet Economic Policy. Unklar ist, wie weit der Handlungsspielraum durch den am 28.6. 1945 auf Anordnung des Staatlichen Verteidigungskomitees als „kollektives Organ“ gegründeten (bis Januar 1947 bestehenden) Kriegs- bzw. Militärrat eingeengt wurde. Foitzik, SMAD, S. 19, 39. Im Juni 1947 empfahl die SMAD aufgrund wachsender Probleme, „vom militärischen System zu einem flexibleren System überzugehen, das einer zivilen Verwaltung näher steht“, und im Außenministerium „einen speziellen stellvertretenden Minister zu ernennen, dem direkt die Leitung der Sowjetischen Militäradministration in Deutschland unterstehen würde“, also das westliche Organisationsmodell zu kopieren. Archiv für Außenpolitik der Russischen Föderation, 7/12/19/231, Bl. 41-54 (Smirnow an Molotow, 25. 6. 1947; Hinweis und Übersetzung durch J. Laufer).

158 Slusser, Soviet Economic Policy, S. 18 ff. Foitzik, SMAD, S. 16 ff. Karlsch, Reparationsleistungen, S. 44, 47, $55 \mathrm{ff}$.

159 Foitzik, SMAD, S. $37 \mathrm{ff}$. 
Anders als die SMAD standen die Westmächte vor dem zusätzlichen Problem, angesichts der räumlichen Trennung die Koordination zwischen Kontrollratsgruppe und zonaler Militärregierung zu gewährleisten. Nachdem Clay die Vereinigung von USGCC und USFET zu OMGUS durchgesetzt hatte, wurden die Abteilungschefs der Militärregierung zumeist auch als Direktoratsvertreter benannt, so daß neben dem Zonenkommandeur auch die meisten seiner Spitzenbeamten wöchentlich zwischen Berlin und dem Zonenhauptquartier pendelten. „Stabskonferenzen“ 160 dienten zur Koordination zwischen den Abteilungen sowie zwischen Kontrollratsgruppe und zonaler Militärregierung. Auf diesen Stabskonferenzen mußten die zuständigen Abteilungsleiter prinzipielle Entscheidungen suchen, ehe Vorlagen für die Direktoratsarbeit entworfen wurden; in "offenen“ Sitzungen bestand periodisch die Gelegenheit, Grundsatzfragen der Besatzungs- und Deutschlandpolitik zur Debatte zu stellen ${ }^{161}$. Die Briten folgten dem amerikanischen Beispiel weitgehend. Mit Hilfe regelmäßiger Konsultationen und „Politikkonferenzen“ wurden die Londoner Direktiven und die Richtlinien des Oberbefehlshabers bis auf die unterste Ebene strikt eingehalten und eine koordinierte Aufgabenverteilung gewährleistet ${ }^{162}$. Frankreich hatte dagegen Zonenhauptquartier und Kontrollratsgruppe zunächst bewußt getrennt gehalten; beide waren gleichrangig und Paris unmittelbar unterstellt; die Koordination zwischen beiden erfolgte im wesentlichen durch den Politischen und den Wirtschaftlichen Berater. Weil General Koenig so selten wie möglich nach Berlin kam, blieb der dortige Stab klein und zweitrangig, so daß die französische Kontrollratsgruppe wenig effizient arbeiten konnte. Da Paris zudem häufig nicht in der Lage war, politische Richtlinien oder Anweisungen zu erteilen, da auch der wechselseitige Informationsfluß zu wünschen übrig ließ, blieben vielfältige Freiräume für personelle Konkurrenzen und institutionellen Kompetenzenwirrwarr mit den entsprechenden Reibungsverlusten ${ }^{163}$. Auch die Franzosen begannen daher seit 1946, wenngleich in größeren Abständen, in Berlin Konferenzen zwischen Militärregierung und Kontrollratsgruppe abzuhalten ${ }^{164}$. Maßgeblich dafür war der Finanzmangel, der einerseits zu einem starken Personalabbau führte und andererseits Laffons Forderung nach einer Verwaltungsreform Nachdruck verlieh, nach anglo-amerikanischem Vorbild Kompetenzen an die Deutschen zu übertragen und die Militärverwaltung auf die reine Kontrollfunktion zu reduzieren. Wenn nach dem Scheitern der Moskauer Außenministerkonferenz ein weiterer Abbau vorgesehen wurde, so war das per se kein Ausdruck für den sinkenden Stellenwert des Kontrollrats, sondern Koenig befürwortete jetzt die Zusammenlegung von zonaler Militärverwaltung und Berliner Dienststellen zur Straffung seiner eigenen militärischen Befehlsstränge ${ }^{165}$. Diese Auseinandersetzungen bildeten u. a. den Hintergrund der spektakulären Entlassung Laffons und erledigten sich schließlich durch das Ende des Kontrollrats Anfang 1948.

160 NA, RG 260/CAD.

161 BA, Z 45 F/OMGUS, 3/153-1/7.

$162 \mathrm{AO}$, Berlin/3270/1/2132. PRO, FO 1049/281.

163 AN, F 60/3034, doss. 2; 457 (Bidault) AP 62 (Note sur l'administration française en Allemagne, 8. 8. 1945). Hudemann, Sozialpolitik, S. 145 f. Balfour, Vier-Mächte-Kontrolle, S. 163. Lattard, Gewerkschaften, S. $15 \mathrm{ff}$.

164 Die Protokolle in: AO, Berlin/219/3 und 4.

165 Lattard, Zielkonflikte. 


\section{b. Das Personal}

Die räumliche Trennung der Kontrollratsgruppen in Berlin von ihren zonalen Hauptquartieren sowie die politische Aufgabenverteilung zwischen Kontrollratsgruppen und Zonenverwaltungen machten für die Westmächte die Unterhaltung eines recht umfangreichen Apparates am Sitz des Kontrollrats erforderlich.

Den größten Personalaufwand betrieben die Briten. Von den 26.000 Angehörigen der britischen Militärverwaltung waren, inkl. der Mitglieder von Sondereinheiten, 1946 ca. 2700 bei Hauptquartier und Kontrollrat tätig; Anfang 1947 waren es ca. 2400 von $20.000^{166}$. Seit dem Frühjahr 1946 waren die Angehörigen der Kontrollratsgruppe wie der Militärregierung mehrheitlich Zivilisten, etwa im Verhältnis 2:1; jeweils zwei Drittel des Personals entfielen auf Büro- und sonstige Hilfskräfte. Mit der fortschreitenden Demobilisierung nahm die Qualität des Personals stark ab, so daß Montgomery Ende März 1946 forderte, mit dem britischen Prinzip der ,indirekten Herrschaft“ Ernst zu machen und die wichtigsten Aufgaben, inkl. exekutiver Rechte, an deutsche Stellen zu übertragen und die Aufgaben der Besatzungsverwaltung auf „Überwachung und Anregung“ zu reduzieren ${ }^{167}$. Da OMGUS mit weniger als der Hälfte des Personals auskam, schlug das Foreign Office vor, geschultes Personal aus dem Ministry of Supply oder aus industriellen Organisationen anzuwerben, um die Effizienz der CCG zu steigern; doch mag dieser Unterschied zwischen CCG und OMGUS vor allem darin zu suchen sein, daß die USA auch wenn das intern nicht unumstritten war - in stärkerem Maße deutsches Personal einsetzten ${ }^{168}$. Die USGCC bzw. OMGUS umfaßte im Juli 19455265 Personen, davon 1383 Offiziere und 275 Zivilbeamte. Unter den 6459 Angehörigen im August 1946 waren nur noch 2000 Militärs ${ }^{169}$.

Die GFCC hatte, bei einer Gesamtstärke der französischen Besatzungsverwaltung von ca. 20.500 Personen im Dezember 1945, einen Personalbestand von 1758 im Oktober, von 1903 im November und von 1865 im Dezember 1945, darunter 576 Offiziere bzw. gleichgestellte Zivilbeamte. Von den 996 Personen, die im Dezember in den Unterorganen arbeiteten, gehörten $\mathbf{4 0 2}$ den militärischen und 359 den wirtschaftlich-finanziellen Abteilungen (inkl. Reparationen) sowie 119 der für innere Angelegenheiten an. Mit 39 Mitgliedern war z. B. die Finanzabteilung deutlich kleiner als die der Briten (286) oder der Amerikaner (184) und arbeitete entsprechend weniger effizient; dafür setzten die Franzosen 1550 Personen in der Transportkontrolle ein, während die britische und amerikanische Zone mit 200 bzw. 78 auskamen ${ }^{170}$. In fünf Schritten wurde bis Ende 1947 das Personal stark reduziert.

Das Personal der SMAD wird auf 30-32.000 im Jahre 1945 und 15-20.000 im Jahr 1948 geschätzt, davon arbeiteten aber wohl nur 2000 in der eigentlichen Militärregierung in Karlshorst. Diese relativ niedrigen Zahlen waren u. a. dadurch möglich, daß

166 PRO, FO 936/232 und 245; FO 1035/4; FO 371/64422.

167 PRO, FO 800/466/Ger/46/11 (25.3. 1946).

168 PRO, FO $371 / 55577$ (August 1946). Zink, United States, S. 30. Kindleberger, Letters, S. 53. Zu den innenpolitischen Auseinandersetzungen um die Personalpolitik der CCG vgl. Thies, Militärverwaltung, $\mathrm{S} .4 \mathrm{f}$.

${ }^{169}$ Clay, Entscheidung, S. 82. Ratchford/Ross, Reparations, S. 56. Kindleberger, Letters, S. 53. FRUS, 1946/V, S. 618. Zur Gliederung von OMGUS vgl. OMGUS-Handbuch, S. 90-130, zu Personalübersichten ebenda, S. 30 ff. (Oktober 1945), 46 ff. (Dezember 1946), 54 ff. (September 1947).

170 AMAE, Y 651, Bl. 41 (SGAAA, 12. 12. 1945). AN, 457 (Bidault) AP 65/ Organisation (Tableau synoptique, 1. 9. 1947). AO, Berlin/3276/5/2019D (GFCC, 15. 10. 1947, Annexe J). 
die Sowjets sich wohl am frühesten und stärksten auf deutsche Verwaltungsstellen stützten. Doch sind zu den Angaben für die eigentliche Militärregierung die rund 70.000 Ingenieure und Ministerialbürokraten hinzuzurechnen, die 1945/46 autonom und unter direkter Steuerung aus Moskau für die Demontagen und Reparationen zuständig waren ${ }^{171}$.

Die Personalrekrutierung und der häufige Personalwechsel waren ein Problem für alle Kontrollratsgruppen. Das betraf weniger die Spitzenebene als den Apparat. Die hohe Fluktuation war zunächst eine Folge der Demobilmachung, die völlig ungeregelt zum Austausch von langjährig ausgebildeten Spezialisten durch kurzfristig angeworbene Kräfte ohne praktische Erfahrung führte; bei den Sowjets kamen ideologische Kriterien hinzu. So hatte die Finanzabteilung von OMGUS im November 194563 Mitglieder, von denen 17 ihre baldige Entlassung anstrebten; 16 wollten unbegrenzt bleiben, z.T. in zivilem Status; die anderen, mit regulären Entlassungsterminen bis zum Herbst 1946, hatten sich noch nicht entschlossen ${ }^{172}$. Erst im April 1946 war die Rekrutierung des Personals dieser Abteilung einigermaßen abgeschlossen, das zunächst aus dem Bureau of the Budget, der Treasury und dem Federal Reserve Board stammte, später zunehmend durch Personal aus Privatbanken ersetzt bzw. ergänzt wurde. Nach verschiedenen Schilderungen dauerte es etwa zwei Monate, geeignete Kandidaten zu finden, zwei Monate, um sie von der Militärverwaltung bewilligt zu bekommen, und weitere zwei Monate, um sie einzuarbeiten und nach Deutschland zu bringen. Wenn es zwischen vier und sechs Monaten dauerte, bis geeigneter Ersatz effizient einzusetzen war, so lag das in dieser Abteilung zum einen an dem sehr sorgfältigen und kritischen Auswahlprozeß, zum anderen aber an den schlechten Vertragsbedingungen ${ }^{173}$. Die hohe Fluktuation wurde auch durch interne Richtungskämpfe ausgelöst, die bei OMGUS zum Ausscheiden ganzer „Fraktionen“ führten ${ }^{174}$. Jedoch kannten selbst viele „Spitzenbeamte der Militärregierung“ weder die Direktive JCS 1067 noch das Potsdamer Abkommen. Die Meinungen in OMGUS über das Potsdamer Abkommen waren geteilt. Manche vertraten extremere Forderungen; viele standen dagegen „durch Herkunft, Ausbildung oder Tradition, vielleicht sogar aufgrund geschäftlicher oder persönlicher Interessen“ der Zerstörung des Industriepotentials oder Beschränkung des Geschäftslebens eher ablehnend gegenüber ${ }^{175}$.

171 Foitzik, SMAD, S. 13 ff. Matschke, Entwicklung, S. 112. Bokow, Frühjahr, S. 419. Scherstjanoi/Laufer, Erste Schritte, S. 173 f. Weber, Transformationsprozeß, S. 17 ff.

172 TL, Fox Papers, boxes 7 und 8, mit detaillierten Einblicken in die Probleme, inkl. Lebensläufen und Beurteilungen. NA, RG 59, 740.00119 Control(Germany)/7-3145.

173 Bei OMGUS wurden Verträge für ein bis zwei Jahre vergeben; bei den Briten waren drei bis sieben Jahre üblich. Murphy, Diplomat, S. 282. Balfour, Vier-Mächte-Kontrolle, S. 156 ff. Kindleberger, Letters, S. 53.

174 Beispiel hierfür ist die OMGUS-Manpower Division; Fichter, Besatzungsmacht, S. 67 ff., $289 \mathrm{ff}$. Zur Decartelization Branch von OMGUS, die zunächst von den „trust-busters“ und „Morgenthau boys“ beherrscht wurde und die ebenfalls resigniert den Rückzug antraten, Martin, All Honorable Men. Stokes, Recovery, S. 79 f. Die „Morgenthau boys“ in der Finanzabteilung um Colonel Bernstein hatten bereits im Sommer 1945 ihren Einfluß verloren. Hammond, Directives, S. 349, 387, 396, $405 \mathrm{f}$.

175 TL, Fox Papers, box 8, folder: Notes on Military Government (4. 1. 1946). Die Ablehnung radikaler Forderungen im Sinne Morgenthaus hatte seit 1944 neben Teilen des State Department vor allem Stimson vertreten. Hammond, Directives, S. 355, 365 f. Im September 1945 warnte Murphy, ein „whole-sale transfer of German plants to liberated areas“ sowie „illconsidered de-industrialization of Germany may well have the effect of creating and extending chaos in Europe." NA, RG 59, 740.00119 Control(Germany)/9-3045. Draper befürwortete den Wiederaufbau von Vorkriegsindustrien; eine „balanced economy“ in Deutschland werde Kernstück des Wiederaufbaus Europas sein. 
Amerikaner (und Briten) griffen nach Möglichkeit auf Personen zurück, die in den heimatlichen Kriegswirtschaftsorganisationen einschlägige Erfahrungen gesammelt hatten, zumindest durch Berufsausbildung, Verbandstätigkeit u.ä.m. über entsprechende Vorkenntnisse verfügten. Angesichts der traditionell engen Verflechtung von Industrie, Hochfinanz und Regierung, die im Zuge der Kriegswirtschaft noch weiter verstärkt worden war, mußte gelegentlich eine Kollision mit zivilen bzw. beruflichen Interessen in Kauf genommen werden. So war General Draper, Vertreter im Wirtschaftsdirektorat, vormals bei der Dillon, Reed \& Co. Bank tätig, zu deren leitendem Personal auch Marineminister Forrestal gehört hatte. Sein Nachfolger Szymczak war beurlaubtes Mitglied der Federal Reserve Bank. Dodge, der maßgeblich die Pläne zur Währungsreform ausarbeitete, war ebenfalls Bankier, der in und nach dem Krieg zwischen Bank und Regierungsämtern in den USA, Deutschland und Japan pendelte. Sehr viel enger fiel die Interessenverknüpfung, selbst für Mitglieder von OMGUS in anstößiger Form, auf weniger exponierten Posten aus: Der Leiter der Metallabteilung bei OMGUS war Präsident einer Stahlgesellschaft und verfügte, dank persönlicher Freundschaft mit Clay, innerhalb des OMGUS über eine Art Monopol in allen Stahlfragen. Der Chef der Maschinenabteilung war ein (früherer) Mitarbeiter des Maschinenbaukonzerns Westinghouse ${ }^{176}$. Der Vizepräsident von ITT, die aus der Vorkriegszeit über erhebliche Interessen in Deutschland verfügte, verhandelte im Juni 1945 mit OMGUS und der Luftwaffe über eine Inspektionsreise in die amerikanische Zone. Sein Angebot, für eine Wiederaufnahme der Produktion in der dortigen Nachrichtenindustrie zu sorgen, wurde als Versuch interpretiert, „Männer seiner Wahl mit der Leitung der Betriebe in der Zeit der Militärregierung zu betrauen, in der Vertreter der Privatindustrie nicht als solche tätig werden können" ${ }^{177}$. Bei den Briten gab es vergleichbare Probleme. Die Chemical Branch wurde von einem Topmanager des Chemiekonzerns ICI geleitet, der seine Stellung dazu benutzt haben soll, durch Produktionsverbote etc. die deutsche Konkurrenz vom Markt zu verdrängen bzw. auf die Zulieferung von Halbprodukten zu beschränken. Entsprechende Klagen gab es über den Einfluß von Unilever auf die Unterabteilung für Speisefette ${ }^{178}$. Zwar bemühte sich OMGUS, mit Hilfe des Trading with the Enemy Act und des von Clay im Kontrollrat durchgesetzten Investitionsmoratoriums die deutsche Industrie vor einem Ausverkauf zu schützen ${ }^{179}$ und eine derartige Verknüpfung von Geschäft und Amt zu verhindern; doch die anhaltenden Klagen und Gerüchte, die wiederholten Verbote legen nahe, daß die Bestimmungen immer wieder umgangen wurden ${ }^{180}$. Wollte man derartige Unzuträglichkeiten vermeiden, soweit mit zunehmender Normalisierung des heimischen Wirtschaftslebens diese Personen nicht den Dienst quittierten, blieb nur der Rückgriff auf freigesetzte Frontoffiziere, die anders nicht unterzubringen waren, aber von Verwaltung und Wirtschaft nichts verstanden. Die überforderten Veteranen

Eisenhower Papers, Bd. VI, S. 440. Ähnlich äußerte sich Clay im Mai 1945. Nübel, Reparationspolitik, S. 30, 160.

176 Ratchford/Ross, Reparations, S. 111, 170. Über die zahllosen Verflechtungen vgl. Martin, All Honorable Men, wenngleich z.T. sehr verbittert und denunziatorisch.

177 NA, RG 107/McCloy, box 28 (Clayton an Hilldring, 23. 6. 1945).

${ }_{178}$ PRO, FO 943/201 (28.9. 1946). An zentralen Stellen arbeiteten auch führende Angestellte von Dunlop (Robertson war dort Manager) und Shell. Stokes, Recovery, S. 104, 119 ff. Thies, Militärverwaltung, S. $40 \mathrm{ff}$.

179 Vgl. unten S. $223 \mathrm{ff}$.

180 NA, RG 165/014(Germany)/7-246 (Clay an War Department). 
zogen zumeist keine ihnen überlegenen Experten, sondern entsprechend inkompetente Mitarbeiter gleicher Herkunft heran und versteckten ihre Hilflosigkeit hinter Kommißgehabe, kleinlicher Auslegung von Vorschriften und Formalismus ${ }^{181}$. Da auf Spezialisten nicht verzichtet werden konnte, blieb häufig als letzter Ausweg nur der Rückgriff auf Berufsanfänger, gescheiterte Existenzen, Glücksritter, eine „Art administrativer Fremdenlegion“ ${ }^{182}$; insofern handelte es sich trotz aller intensiven Bemühungen vielfach um Personen „von häufig zweitklassigem Format“ ${ }^{\text {(183, }}$, die von ihren Betrieben oder Verwaltungen eben deshalb freigestellt wurden.

Da die Sowjetunion mit der Schulung von Offizieren für Besatzungsaufgaben im kleineren Maßstab im September 1944 begonnen hatte ${ }^{184}$, setzte der eigentliche personelle Aufbau ihrer Militärverwaltung erst unmittelbar nach Kriegsende ein. Während einerseits verschiedene Generäle mit den geforderten Fachkenntnissen mit einem kleinen Stab nach Berlin gebracht und Verwaltungsfachleute aus Moskau in Marsch gesetzt wurden, mußten andererseits die niederen Ebenen zumeist mit Offizieren aus Einheiten der Roten Armee besetzt werden, die in der Nähe von Berlin stationiert waren und angeblich in ihren Stammeinheiten zusätzlich normalen Dienst verrichteten. Noch im September 1945 waren nicht alle Stellen besetzt, so daß manche Offiziere Dienst in mehreren Organen leisteten und dementsprechend inhaltlich wie arbeitsmäßig völlig überfordert waren. In den Monaten, in denen die Sowjets den Vorsitz in den Kontrollratsorganen hatten, holten sie zusätzliches Personal aus Moskau heran. Die obersten Ränge galten als kompetent, während die mittleren und unteren als eifrig, aber unfähig charakterisiert wurden; das förderte den Zentralismus des sowjetischen Verwaltungsapparats, das ständige Suchen nach Rückversicherung, Verantwortungsscheu und Verzögerung der Beratungen bzw. der Entscheidungsfindung $^{185}$. Mehrfach tauschten die Sowjets das Personal ganzer Abteilungen aus ${ }^{186}$, weil sie fachlich und/oder politisch nicht als kompetent angesehen wurden. Die ersten sowjetischen Vertreter im Industrieniveaukomitee des Kontrollrats, nach amerikanischen Angaben inkompetente und schlecht instruierte Frontoffiziere, wurden im Dezember 1945 in der entscheidenden Verhandlungsphase von aus Moskau eingeflogenen Experten der Planungsbehörden abgelöst. Diese waren derart auf ihre vom Plan vorgegebenen Daten fixiert, daß Kompromisse äußerst schwierig wurden ${ }^{187}$. Im Sommer 1946, als nach dem Scheitern der Pariser Außenministerkonferenz eine neue Demontagewelle einsetzte, fand ein abermaliger Austausch statt, von dem auch die SMAD überrascht wurde, obwohl sie durch Inkorporierung des Sonderkomitees für Reparationen zum Gewinner der Reorganisation wurde ${ }^{188}$. Im Sommer 1947 führte

181 PRO, FO 936/236.

182 Lattard, Zielkonflikte, S. 2 ff.

183 Ratchford/Ross, Reparations, S. 45; ebenda, S. 36, 96 ff. Thies, Militärverwaltung, S. 40.

184 Foitzik, SMAD, S. 13.

185 NA, RG 59, 740.00119 Control(Germany)/8-1947 (Anhang, ca. Anfang 1947).

186 So wurde Maiski durch Nowikow ersetzt, weil er durch Tatenlosigkeit das Scheitern der Alliierten Reparationskommission in Moskau provoziert hatte. AN, 457 (Bidault) AP 63/Conférence des Réparations (Rueff, 11. 8. 1945). Byrnes, Speaking, S. $84 \mathrm{f}$.

187 AO, Berlin/3275/4/704 (Rapport, S. 29). Ratchford/Ross, Reparations, S. 95 f. DBPO, I, 5, S. 527 f.

188 PRO, FO 943/308 (nach einem Bericht Skrzypczynskis über ein Telefongespräch Kowals mit Moskau, 29. 8. 1946). Im September 1946 konnte den Stellen der SBZ kein Organisationsplan übergeben werden, ,weil zurzeit die organisatorischen Verhältnisse in Karlshorst noch nicht vollständig feststehen“. BAP, G-2/1044, Bl. 129. 
die SMAD selbst ihre „nicht immer [...] einheitliche“ Politik auf den Personalaustausch, mangelnde Koordination der Dienststellen und personelle Defizite zurück ${ }^{189}$.

Durch Übergang von der direkten zur indirekten Herrschaft suchten sich die Westmächte aus diesem Dilemma zu befreien, gerieten dadurch aber zunehmend in Abhängigkeit von den deutschen Länderregierungen und Behörden. Insofern war die Bedeutung, die alle vier Mächte der Errichtung deutscher zentraler Hilfsorgane beimaßen, keineswegs nur auf politisch-taktische Überlegungen, sondern nicht minder auf praktische Bedürfnisse der Besatzungsverwaltung zurückzuführen. Doch war angesichts der ungelösten Zentralverwaltungsfrage im Herbst 1945 ein Vorstoß der Briten gescheitert, eine „Zentrale Deutsche Beratende Arbeitsbehörde“ einzusetzen, deren „technische Instruktionsentwürfe zur Umsetzung von politischen Entscheidungen“ seitens des Kontrollrats den deutschen Zonenbehörden über die zonalen Militärbehörden zugeleitet werden sollten. Als die Briten im Januar 1946 erneut den Einsatz deutscher Spezialisten bei der Vorbereitung der Direktoratsarbeiten vorschlugen, waren alle Mächte einverstanden, die Sowjets wehrten sich jedoch gegen deren Organisation auf Dauer ${ }^{190}$. Sie und die Franzosen beharrten auf dem Standpunkt, jede Besatzungsmacht könne Experten ihrer Zone heranziehen, ohne sie beim Kontrollrat formell zusammenzufassen ${ }^{191}$. Trotz der politischen Vorbehalte ihrer Regierung gegenüber deutschen Zentralverwaltungen waren verantwortliche Offiziere der GFCC frühzeitig geneigt, zumindest indirekt deutsche Experten heranzuziehen, weil ohne sie die Verwaltungstätigkeit ebensowenig wie die politische Planung angemessen zu gestalten war. Spätestens im Juli 1947 wurde die Lage kritisch, als die „rapide Verringerung“ des Personals sich nachteilig auf die Arbeit der zonalen Militärregierung wie der Kontrollratsgruppe auszuwirken begann. Die Komitees konnten nicht mehr beschickt und die bilateralen Beziehungen zu den anderen Alliierten nicht mehr adäquat aufrechterhalten werden. Da man sich von Beförderungen und Gehaltsaufbesserungen wenig Rekrutierungserfolge versprach, wurde der Ruf nach deutschem Ersatz laut bzw. der Widerstand gegen die Übertragung wichtiger Aufgaben auf deutsche Dienststellen geringer. Anfang 1948 dachte man nicht ungern über Personalverschiebungen von Berlin nach Baden-Baden nach, weil in Berlin „die Vier-Mächte-Aktivitäten dieses Personals offenkundig sehr reduziert sind“" ${ }^{192}$.

189 Archiv für Außenpolitik der Russischen Föderation, 7/12/19/231, Bl. 41-54 (Smirnow an Molotow, 25. 6. 1947; Hinweis und Übersetzung durch J. Laufer).

$190 \mathrm{BA}, \mathrm{Z} 45 \mathrm{~F} / \mathrm{OMGUS}, 2 / 113-3 / 13$. Nur zweimal wurden auf unterster Ebene deutsche Experten in Sitzungen von Kontrollratsorganen gehört, in der Arbeitsgruppe für Volkszählung des Innendirektorats und im Zivilverwaltungskomitee anläßlich der Einrichtung des Vermißtenbüros.

191 BA, Z 45 F/OMGUS, 2/114-1/7; 2/126-1/7-14 (DMAN/P(45)35). Die USA griffen Vorschläge ihres „Beraters“ Hermann Brill auf, der zur Jahreswende 1945/46 eine Denkschrift „zur Vorlage beim Kontrollrat" verfaßt hatte; doch wurde dieser Ansatz darauf reduziert, einen deutschen Beirat aus Vertretern der Länder-Arbeitsministerien bei der OMGUS-Manpower Division in Berlin (nicht beim Länderrat in Stuttgart!) einzusetzen. Im März 1946 kam es zu einer gemeinsamen Tagung der deutschen OMGUS-Berater. BA, Nl Brill/98, Bl. 8 ff., 43 ff., 48 ff., 63 f., 71 ff. Anfang 1946 verlangten die Finanzminister der amerikanischen Zone, OMGUS möge beim Kontrollrat erwirken, daß sie bei der Erarbeitung der Steuergesetze „zu den Sitzungen des Kontrollrats“ zugezogen würden. Die Ministerpräsidenten milderten dies dahingehend ab, daß sie „angehört und informiert“ würden. OMGUS trug dem insoweit Rechnung, als seine Finanzabteilung bei neuen Maßnahmen die Minister anhörte. AVBRD, Bd. 1, S. 260 (5. 2. 1946). Die Deutschen in der britischen Zonen wollten "gehört" werden; ebenda, S. 310 (1.3. 1946).

192 AO, Berlin/3276/1/2007 (GFCC, 23. 1. 1948); 2007-A (GFCC, 18. 7. 1947). AN, 457 (Bidault) AP 65/Organisation. Zum Hintergrund vgl. AMAE, Y 333, Bl. 187 ff. (22. 4. 1948). 
Vor diesem Hintergrund wird man den Wunsch aller Mächte nach Reduzierung der Organe des Kontrollrats und der Kommandantur sehen müssen. Nach französischen Berichten hatten die Kollegen der britischen und amerikanischen Kontrollratsgruppen bereits im August 1947 bezweifelt, „daß der Kontrollrat fortbestehen könne. Seine Tätigkeit im wirtschaftlichen und finanziellen Bereich sei jedenfalls sehr eingeschränkt, da es ja keine gemeinsamen Probleme mehr zwischen Westdeutschland und Ostdeutschland gäbe, und meine Kollegen beabsichtigen, eine regelrechte deutsche Regierung in der Bizone zu errichten." In dem Falle würden sie konsequenterweise die Schwerpunkte ihrer Besatzungsverwaltungen von Berlin nach Frankfurt verlegen und „in Berlin nicht mehr, als ein Feldbett und eine Stallwache beibehalten. Das Verschwinden der anglo-amerikanischen ,Sektoren“ in Berlin würde überdies den Abzug der angelsächsischen Dienststellen bei der Kommandantur nach sich ziehen“"193! Anfang März 1948 kündigten schließlich die Sowjets im Komitee für Informationskontrolle an, sie würden wegen Personalmangels die Arbeit in einigen Arbeitsgruppen und Unterkomitees einstellen ${ }^{194}$, und beantragten, in drei weiteren Direktoraten diverse Komitees, Unterkomitees und Arbeitsgruppen abzuschaffen. Sie bestritten alle Anschuldigungen, das verrate „vermindertes Interesse an der Vier-Mächte-Arbeit“; man solle keine falschen Schlüsse ziehen, sondern es gehe lediglich um eine Konzentration der Arbeit. Als daraufhin die USA die Streichung von vier Arbeitsgruppen im Wirtschaftsdirektorat verlangten, waren die Sowjets überrascht, stimmten aber kommentarlos zu. Die Briten waren nun überzeugt, daß dieses Verhalten nicht auf einen Rückzug der Sowjets hindeutete, zumal sie gleichzeitig die Einrichtung neuer Komitees im Rechtsdirektorat verlangten, dessen Überlastung ein wesentlicher Grund für die Verzögerungen in der Kontrollratsarbeit war. Anfang April 1948 setzte sich die Straffung des Verwaltungsapparats in der Berliner Kommandantur fort, als auf sowjetischen Vorschlag einige Komitees abgeschafft werden sollten. Die Verhandlungen, in denen die Sowjets eine "geschäftsmäßige und verständige Haltung" an den Tag legten, endeten mit dem Beschluß, sechs Komitees aufzulösen; sie stimmten der Beibehaltung eines siebten zu, während ein Komitee umstritten blieb. „Meinungsunterschiede im Hinblick auf die Komitees, die die Arbeit übernehmen sollten, wurden problemlos überwunden.“195 Selbst wenn man, obwohl manches dagegen spricht, allen Mächte zugute halten will, daß das nicht als schleichende Abwertung der gemeinsamen Besatzungsverantwortung gemeint gewesen sei, so war doch die Tatsache, daß der Arbeitsanfall in Kontrollrat und Kommandantur sich deutlich reduziert hatte, ein markantes Indiz für deren realen Bedeutungsverlust und die Gewichtsverlagerung zugunsten der Zonen ${ }^{196}$.

193 AMAE, Y 295, Bl. 297 (Leroy-Beaulieu an Noiret, 9. 8. 1947; Hervorhebung im Original).

194 NA, RG 59, 740.00119 Control(Germany)/3-948. Im Mai 1948 kündigte Sokolowski den Finanzministern der SBZ und der Finanzverwaltung der DWK an, daß „Arbeiten, die bisher von der SMAD geleistet wurden, in zunehmendem Maße in deutsche Hände gelegt werden“ sollten. BAC, N-1/2079-1, Bl. 2. Im September 1945 hatte die SMAD aus ähnlichen Gründen auf die Errichtung der Zentralverwaltungen gedrängt. BAP, L-1/996, Bl. 5 ff. (12. 9. 1945); G-2/1044, Bl. 144 (Kowal, 18. 10. 1946).

195 PRO, FO 1049/1289. NA, RG 59, 740.00119 Control(Germany)/4-948.

196 Balfour, Vier-Mächte-Kontrolle, S. 144 ff. passim, 162. Robertson hatte bereits im Juli 1946 erwartet, daß die Bizone „die Gestalt eines Zwei-Mächte-Gegenstücks zum Koordinationskomitee und den Direktoraten des Alliierten Kontrollrats annehmen könnte, obwohl kleiner in ihrem Umfang“. FRUS, $1946 /$ V, S. 619. 


\section{c. Das Arbeitsklima}

Von Beginn an hatte sich als eines der wesentlichsten Hindernisse für eine effektive Arbeit die buchstäbliche Sprachlosigkeit zwischen Ost und West erwiesen. Allein infolge der gemeinsamen Sprache und Kultur war die Zusammenarbeit zwischen Briten und Amerikanern reibungslos und unkompliziert. Da viele der Franzosen immerhin über gewisse englische Sprachkenntnisse verfügten, war eine Verständigung in der Regel möglich, auch wenn die Franzosen aus Prestigegründen nur in ihrer eigenen Sprache verhandelten, wenn sie in den Gremien den Vorsitz innehatten. All dies galt für das Verhältnis zu den Sowjets nicht ${ }^{197}$. Die vollständige Fremdheit in Lebens- und Arbeitsrhythmus, kultureller Prägung und politischen Auffassungen, in Verhandlungsstil und technischen Begrifflichkeiten ließ ein vertrauensvolles und effektives Arbeitsklima nicht entstehen. Die gewachsene, selbstverständliche Vertrautheit zwischen den Westmächten hielt das sowjetische Mißtrauen wach, das schon in Potsdam geweckt worden war. Als Churchill gegenüber Truman Wendungen gebrauchte wie „Wir waren uns einig“ oder „Wir haben besprochen“, hatten „Molotow und Stalin bedeutsame Blicke ausgetauscht, als Stalin offensichtlich erschrocken aufblickte“. Nach Auffassung eines amerikanischen Teilnehmers habe die Sowjetunion daraufhin versucht „herauszufinden, ob sie es noch mit Verbündeten zu tun hatte oder ob wir die feindselige Linie der Briten verfolgten wie in San Francisco“. Die Reparationen waren für die Sowjets der „Test auf unseren Treu und Glauben, ob wir zu den Yalta-Vereinbarungen stehen würden“. Wischinski äußerte dementsprechend sein Unverständnis, „warum Ihre Leute sich weigern, das Abkommen als im Prinzip fair anzuerkennen, das wir in Yalta erarbeitet haben“" ${ }^{198}$. „Die Engländer und Amerikaner wollen uns knebeln“, sagte Stalin zu seiner Delegation in Potsdam. „Aber keine Angst - wir haben den Bürgerkrieg durchgestanden, wir werden auch das überstehen. “199

Angesichts dieses grundsätzlichen Mißtrauens und dieser kulturellen Fremdheit hatte der Kontrollrat wenig Chancen, durch eine erfolgreiche Arbeit sich sozusagen immanent das Umfeld und Binnenklima zu erarbeiten, das es ihm ermöglicht hätte, die Deutschlandpolitik der vier Alliierten nicht nur zu exekutieren, sondern von sich aus positiv zu gestalten. Daran änderte die personelle Kontinuität bei den Militärs (Clay, Sokolowski, Robertson, Koenig) wie bei den Diplomaten (Murphy, Strang, Saint-Hardouin, Semjonow) wenig, auch wenn sie bis zu einem gewissen Maße dazu beigetragen hat, den wechselseitigen Respekt und z.T. die Freundschaftlichkeit ${ }^{200}$ der Beziehungen als ein ausgleichendes Moment gegenüber den Instruktionen aus den jeweiligen Hauptstädten und gegenüber der Klimaverschlechterung im internationalen Umfeld wirksam werden zu lassen. Die fast täglichen Arbeitskontakte über Monate und Jahre hinweg, die informellen Gespräche im Casino des Kontrollrats oder im Anschluß an die Sitzungen begründeten eine Umgänglichkeit, wie sie in internationalen

197 Ein bitterer, durch andere Angaben bestätigter Bericht in DBPO, I, 5, S. 527 ff.

198 Library of Congress, Papers of Joseph E. Davies, box 19 (Juli 1945). Erste Ansätze zu derartigen Vorwürfen waren auf der Londoner Außenministerkonferenz vom September 1945 zu bemerken. DBPO, I, 2, S. 347 f., $492 \mathrm{ff}$.

${ }^{199}$ Gromyko, Erinnerungen, S. 129 f., 156 f., 161.

200 Beispielhaft war der Glaube Eisenhowers an seine Freundschaft mit Schukow. EL, DDE, Pre-Presidential Papers, Principal File, box 24. Eisenhower, Crusade, S. 438, 462 f. Ebenso Clay (Entscheidung, S. 126, 152 f.) über sein Verhältnis zu Sokolowski. 
Organisationen ohne Beispiel gewesen sein dürfte, die aber die grundsätzliche Kluft gleichwohl nicht dauerhaft zu überbrücken vermochte ${ }^{201}$. Auf westlicher Seite war das „anfängliche Mißtrauen“ bis zum Jahreswechsel 1945/46 einem fast euphorischen Optimismus gewichen: Es finde ein „stetiger Fortschritt zu größerem gegenseitigen Vertrauen“ statt, vor allem „auf den unteren Ebenen“; entgegen allen Gerüchten gestalteten sich die amerikanisch-sowjetischen Beziehungen „besonders gut “202. Auch wenn die sowjetischen Kollegen gelegentlich als „stur“ oder „halsstarrig“ bezeichnet wurden ${ }^{203}$, nicht zuletzt aufgrund ihrer engen Bindung an Instruktionen bzw. ihres Mangels an Ermessens- und (Ver)Handlungsspielraum, so schienen sie doch persönlich umgänglich, kooperationsbereit und guten Willens; das Verhältnis war entsprechend „herzlich“, „freundschaftlich“, „sympathisch“, „harmonisch“204. Ende 1945 verfestigte sich bei den Briten der Eindruck, daß ihre sowjetischen Kollegen persönlich „sehr gesellig“ waren, aber durch eine „Politik der Non-Fraternisierung“ an engeren sozialen Kontakten gehindert wurden ${ }^{205}$. In der Tat wurden auf sowjetischer Seite diese westlichen Annäherungsversuche zurückhaltend beurteilt: Einige „jüngere“ Offiziere der SMAD, die zu „vertrauensselig“ gewesen und den westlichen Kollegen „auf den Leim“ gegangen seien, wurden vom Kontrollrat abgezogen. Zu Beginn, als der Kontrollrat „vielversprechende“ Beschlüsse im Sinne des Potsdamer Abkommens faßte, sei von ihnen die Gefahr seitens des Westens als „noch nicht so akut“ empfunden worden, so daß Schukow frühzeitig seine Offiziere warnen mußte, die Westmächte würden sich an das Abkommen, „unseren diplomatischen Sieg“, auf Dauer nicht halten $^{206}$. Doch ungeachtet aller Probleme hatten die westlichen Vertreter den Eindruck, daß ihre sowjetischen Kollegen gelegentlich nur ungern und widerstrebend ihren Instruktionen nachkamen. Vor allem die Militärs schienen lange der Auffassung Schukows zuzuneigen, „daß wir so lange eine Menge erreichen werden, wie die Politiker sich heraushalten“, daß trotz aller von außen hereingetragenen Belastungen auf der persönlichen Ebene ein arbeitsfähiges Arrangement möglich sein werde ${ }^{207}$.

Angesichts erster Stockungen in der inhaltlichen Arbeit und erster kontroverser Debatten verflüchtigte sich diese Anfangseuphorie allmählich im Oktober 1945. Aber dieser Klima-Umschwung war weniger Folge der französischen Blockadepolitik in der Frage der deutschen Zentralverwaltungen, sondern Ausdruck der beginnenden Ent-

201 Berichte dazu bei Clay, Entscheidung, S. 49, 128. PRO, FO 1049/281 (Strang, 6. 11. 1945). Balfour, Vier-Mächte-Kontrolle, S. 148.

202 NA, RG 59/CED, box 3, folder: Current Political Developments (1. 2. 1946).

203 Aufgrund seiner Unbeweglichkeit und seiner Sturheit besonders gefürchtet war General Dratwin, der Sokolowski im Sommer 1946 im Koordinationskomitee ablöste - wie manch anderer sowjetischer Vertreter in den Unterorganen ebenfalls. PRO, FO $371 / 64338$ (31. 1. 1947); 55680 (14. 2. 1946). Offenbar galt Dratwin auch bei seinen Vorgesetzten als keine glückliche Wahl; nach britischer Einschätzung hatten die Sowjets „so wenig Zutrauen in General Dratwins Fähigkeiten, daß er praktisch überhaupt keine Handlungsfreiheit erhält“. FO 371/55425/C5570 (18. 5. 1946). Er wurde bald von dem harten, aber flexibleren Kurotschkin abgelöst, kehrte jedoch im Mai 1947 in das (inzwischen bedeutungsloser gewordene) Koordinationskomitee zurück.

204 PRO, FO 371/55699-55701; 55423-55430; 64161-64164; 64408-64416. Dazu Einzelhinweise aus verschiedenen Provenienzen. Die französischen Berichte bis Juni 1946 (AO, Berlin/3269/1/2201) geben meist nur allgemeine Einschätzungen wieder: Die Debatte sei schwierig, aber effektiv, die

205 DBPO, I, 5, S. $527 \mathrm{f}$.

206 Tjulpanow, Deutschland, S. 19 f., 50, 56. Gniffke, Jahre, S. 173.

207 Schukow, Erinnerungen, S. 639. Donnison, Civil Affairs, S. 274. BA, Z 45 F/OMGUS, 2/100-1/11 (International Developments, 8. 10. 1945, S. 10). Murphy, Diplomat, S. 287. 
fremdung nach der ernüchternden Londoner Konferenz der vier Außenminister ${ }^{208}$. Die GFCC berichtete, daß nur noch bei den Verhandlungen über die Liquidation der deutschen Bedrohungspotentiale und bei Routinefragen keine Spannungen auftraten, wohl aber bei allen Tagesordnungspunkten, die Neugestaltung und Wiederaufbau betrafen $^{209}$. Besonders die Beobachtung der Entwicklung in Berlin bzw. im Ostsektor der Stadt ließ den lange verdrängten Argwohn gegenüber den Kommunisten und die Befürchtung einer schleichenden Revolutionierung neu aufflammen. In seinem Bericht vom November 1945 meldete der französische Politische Berater Saint-Hardouin, es entwickele sich in der Kommandantur „eine Spannung, die schließlich Rückwirkungen auf das gesamte Deutschlandproblem haben könnte" ${ }^{\text {210 }}$, da die Sowjetunion Schritt für Schritt ihre Position zu Lasten des Westens ausbaue. Frankreich war insofern frühzeitig bereit, durch seine Blockadepolitik eine Klimaverschlechterung im Kontrollrat zu provozieren, um den westlichen Alliierten die Augen zu öffnen - und aus dieser Konstellation Legitimation für die eigene Verweigerungsstrategie zu gewinnen ${ }^{211}$. Die Anglo-Amerikaner waren allerdings keineswegs blind für diese Entwicklungen. Robertson sah im Oktober 1945 den Kontrollrat „kurz vor dem toten Punkt", aber noch streute er die Verantwortlichkeiten breit. Der erste Grund liege in der französischen Weigerung, deutschen Zentralverwaltungen zuzustimmen; der zweite sei in dem „Eisernen Vorhang“ zu suchen, hinter dem die Sowjetunion ihre Zone dem Kontrollrat bzw. dem Westen entziehe; als dritten Grund benannte er die Intransigenz Clays und die mangelnde Perspektive der amerikanischen Politik in Deutschland ${ }^{212}$. Clay schien Ende 1945 entschlossen, mit den Russen auszukommen, verhielt sich aber „übertrieben mißtrauisch“ und „sehr voreingenommen“ gegenüber den Briten, deren Unnachgiebigkeit den Ausgleich mit der Sowjetunion verhindere. Das Verhältnis zwischen Briten und Amerikanern in Berlin galt Anfang 1946 als „schlecht“, die Kooperation beider Delegationen als „praktisch nicht existent“213.

Briten und Franzosen wiesen übereinstimmend Clay erhebliche Mitschuld an der Vergiftung des Klimas im Kontrollrat zu. Das mochte zunächst darauf zurückzuführen sein, daß dieser - von Beginn an die dominierende Persönlichkeit - infolge der französischen Blockadepolitik und der indirekten britischen Unterstützung für diesen Kurs die Chancen schwinden sah, das gute Arbeitsverhältnis zu der immer mißtrauischer werdenden Sowjetunion aufrechtzuerhalten ${ }^{214}$. Bei den vor allem gescholtenen Franzosen mochte es verständlich sein, daß sie Clays Drängen als „Enttäuschung“ und

208 NA, RG 59, 740.00119 Control(Germany)/8-1947 (Annex, ca. Ende 1945). DBPO, I, 2, S. 316 f., 492 ff., 501. Nach britischem Eindruck schien Moskau von dieser Entwicklung überrascht.

$209 \mathrm{AO}$, Berlin/90/1.

210 AMAE, Y 283, Bl. $109 \mathrm{ff}$.

211 Vgl. die Berichte Murphys aus Berlin in: FRUS, 1945/III, S. 1035 ff. passim. Am 19. 2. 1946 fiel in der Kommandantur auf amerikanischer Seite erstmals das Wort „Nazi-Methoden“ im Hinblick auf die Politik des Berliner FDGB, damit das sowjetische Vorgehen in der Gewerkschaftsfrage meinend. PRO, FO 1051/1020. Vgl. NA, RG 59/CED, box 3, folder: Current Political Developments (1. 4. 1946, S. 3). Bevin benutzte aufgrund persönlicher Antipathie gegen Molotow diesem gegenüber die Hitler-Analogie bereits im September 1945. Deighton, Impossible Peace, S. $47 \mathrm{f}$.

212 DBPO, I, 5, S. 178 ff. (5. 10. 1945). Schneider, Deutschland- und Besatzungspolitik, S. 96 f. (12. 10. 1945), 102 (27. 10. 1945).

213 NA, RG 59/OWEA, Misc. German Files, box 2, folder: Murphy (7. 3. 1946). Zu der zwiespältigen Beurteilung im OMGUS vgl. Kindleberger, Letters, S. 73. Eine eher milde Einschätzung bei Backer, Clay, S. 16 f., 163. Peterson, Occupation, S. 59 ff. Müller, Sicherheit, S. 75.

214 BA, Z 45 F/OMGUS, 2/100-1/11 (8. 10. 1945). 
„Bitterkeit“ über die geringen Fortschritte interpretierten, die ihn zu „Taktlosigkeit“ und „kindischem Verhalten“ verleiteten, als „Nervosität“, da er seine Vorstellungen und seine Anweisungen nicht rasch verwirklichen konnte ${ }^{215}$. Der britische Politische Berater Strang bestätigte die französischen Berichte. Auf die endlosen Debatten reagiere Clay nur noch mit „dem Ausdruck schärfster Erbitterung“ oder mit „Schulterzucken“, „um anzudeuten, daß er nicht verstehen könne, warum die anderen Delegationen ihr [der amerikanischen Position] nicht folgen“216. Die Briten führten das zunächst auf „Überarbeitung“ oder ein „Magengeschwür“ zurück; doch zunehmend schien es ihnen eher ein Problem seiner "Persönlichkeit und Position“ zu sein ${ }^{217}$. Seine Unbeherrschtheit, seine cholerischen Ausbrüche, seine herablassende Intransigenz rückten zunehmend in den Vordergrund der Berichte; schließlich war es Strang schon der Erwähnung wert, wenn der „Autokrat“, der „Tyrann aus Frankfurt“, der "Großinquisitor" seine Kollegen nicht in verletzender Form attackierte. Mit Schadenfreude sahen sie im Frühjahr 1946 das Ende des amerikanisch-sowjetischen „honeymoon" gekommen. Murphy hat diese Kritik anfangs auszugleichen versucht; intern gestand er freilich ein, daß Clays „herrisches Verhalten“ und sein Ehrgeiz, „einen Erfolg aus seinem Job zu machen“, ihn zu dem Verhalten verleiteten. Im Februar 1947 machte Clay bei der Beratung des Kontrollratsberichts an die Moskauer Außenministerkonferenz „eine große Show totaler Indifferenz“ und scheute dabei nicht davor zurück, sein Desinteresse an den Ausführungen seiner Kollegen zu demonstrieren, ,indem er eine Melodie pfiff“. Nachdem er aber aus Washington die Anweisung erhalten hatte, daß der Bericht erwünscht sei, spornte er seine Kollegen „unbarmherzig“ an und gab sich „so mürrisch und gereizt, wie er es nur konnte“, als es nicht sofort nach seinen Vorstellungen voranging ${ }^{218}$. Das wiederum registrierten die Franzosen mit Schadenfreude (und Erleichterung): „Die gesamten Debatten hinterlassen einen mühsamen Eindruck wegen Clays Charakter, der diesmal seine Galle über seinen BizonenKollegen ausgeschüttet hat. Robertson hat seinen Zorn [ulcération] nicht verborgen“, „wütend, in einem so raschen Tempo angetrieben zu werden" ${ }^{219}$.

Gleichwohl war es auf westlicher Seite immer wieder Clay, der sich gegen alle Warnungen seiner Berater bemühte, der Klimaverschlechterung im internationalen Umfeld gegenzusteuern. Am 1. Juni 1946 gab er die Weisung aus, alle Anstrengungen zu unternehmen, um zu dem guten Verhältnis der ersten Wochen und Monate zurückzukehren. „In den vergangenen Monaten hat ein erheblicher Wandel in der Haltung der amerikanischen Öffentlichkeit gegenüber den Russen stattgefunden, und wir hatten hier unsere Probleme, Einigung zu erzielen. Wir haben nicht mehr ein so freundschaftliches Verhältnis wie bisher. Jetzt, da die internationalen Beziehungen vor dem nächsten Treffen der Außenminister belastet sind, ist es notwendig, ungeachtet

215 AMAE, Y 283, Bl. 4 ff., 281; Y 284 (5. 3. 1946); Y 454, Bl. 81. Seydoux, Erinnerungen, S. 97. Rollet, Vétos, S. 102. Decouvrierend für das Verhältnis der Franzosen zu Clay war eine Äußerung Bérards, Frankreich habe Zugeständnisse in Deutschland weniger aus Überzeugung gemacht, sondern „after four years of the Clay treatment they were willing to agree to anything“. NA, RG 59/Secretary's Daily Meetings (25. 4. 1949).

${ }^{216}$ PRO, FO 1049/281 (6.11. 1945).

217 PRO, FO 371/65052 (9. 4. 1947).

218 PRO, FO 371/64409 und 64410. Ähnlich AMAE, Y 456, Bl. 88 f. (5. 3. 1947).

219 AMAE, Y 185, Bl. 71 f. So die ursprüngliche Version, die im offiziellen Bericht erheblich abgemildert wurde; ebenda, Bl. $96 \mathrm{f}$. 
unserer offiziellen Differenzen, daß unsere Beziehungen gut sind, und General Clay drängte jeden, mit den Russen engen Kontakt, auch offiziell, zu halten und die freundlichen Beziehungen wiederzubeleben, die vor einigen Monaten bestanden." 220 Noch Ende Juli 1946 sah Clay, der persönlich Kennans „langes Telegramm“ vom Februar „entschieden“ mißbilligte, die Lage als „durchaus noch nicht hoffnungslos“, verkannte aber nicht, daß angesichts der herrschenden Stimmung in Washington seine Bemühungen um ein pragmatisches Arbeitsverhältnis mit den Sowjets nicht erfolgreich sein konnten: „Wenn es so weitergeht, ist ein Bruch mit den Russen unvermeidlich.“221 Er war realistisch genug, gegenüber Noiret einzugestehen, es werde dem Kontrollrat „zweifellos nicht gelingen, das gestellte Problem zu lösen“; gleichwohl hielt er an der Hoffnung fest, dieser werde weiterhin zumindest als „Forum“ gegen eine konfrontative Sprachlosigkeit dienen ${ }^{222}$.

Eine weitere deutliche Verschlechterung im Arbeitsklima und im Umgangston trat im Frühjahr 1946 ein, noch deutlich vor Clays Reparationsstopp. Churchills Fulton$\operatorname{Rede}^{223}$ vom 5. März 1946 wurde von den Sowjets, die Zwangsvereinigung von KPD und SPD von den Westmächten als Kampfansage aufgefaßt. Während Nowikow, der sowjetische Vertreter bei der Reparationskommission, im Februar 1946 noch keinen bösen Willen bei den Westmächten erkennen wollte, als sich Industrieniveauplan und Reparationslieferungen verzögerten, gab es bald erste offene Vorwürfe, die Westmächte hielten sich nicht an die Potsdamer Vereinbarungen ${ }^{224}$. Ende Mai 1946 beschwerte sich Semjonow, die USA versuchten zu „diktieren“, in Deutschland, aber auch in „verschiedenen Gebieten der Welt“. Daß die Amerikaner ihre Ansichten zunächst mit den Briten abstimmten, werde von der Sowjetunion mit ,natürlichem Mißtrauen und einigem Unmut“ wahrgenommen. Sie trügen ihre Vorschläge vor und erwarteten „sofortige Entscheidungen, ohne der Sowjetunion angemessene Gelegenheit zu geben, die Frage zu studieren. Die UdSSR könne so nicht arbeiten. [...] Er sei jedoch nicht pessimistisch über die Möglichkeit, einige der anstehenden Probleme zu lösen. [...] Er denke, daß Fortschritte in der deutschen Frage erzielt werden könnten, aber die USA müßten größere Anstrengungen unternehmen, die Auffassung der UdSSR zu verstehen. “225 Ebenfalls Ende Mai 1946 bedauerte der sowjetische Vertreter im Politischen Direktorat, Iwanow, daß im Koordinationskomitee beim geringsten Widerstand sofort alle Anträge zurückgezogen würden. Wenn sich Ähnliches auch in den Direktoraten fortsetze, werde das der Anfang vom Ende des Kontrollrats sein. Der Kontrollapparat ,sehe mehrere verschiedene Ebenen von gestufter Bedeutung für Beratung und Entscheidung in allen Fragen vor, und er erachte es als einen Fehler, die

220 NA, RG 260/CAD, box 77. Die Franzosen führten im Juni 1946 den Stillstand in der Kontrollratsarbeit auf die bevorstehende zweite Verhandlungsrunde der Pariser Außenministerkonferenz zurück, deren Ausgang alle Kontrollratsgruppen abwarteten. Trotz des Scheiterns der Konferenz registrierten sie eine Belebung der Arbeit und eine spürbare Auflockerung des Klimas. AMAE, Y 287, Bl. $159 \mathrm{f}$.

221 Zitiert nach: Backer, Clay, S. 177.

222 AN, 457 (Bidault) AP 61/V (Saint-Hardouin, 21. 7. 1946).

$223 \mathrm{PRO}, \mathrm{FO} 800 / 501 / \mathrm{SU} / 46 / 6,10,11,42$, 46. In diesem Sinne berichtete Kennan aus Moskau. FRUS, 1946/VI, S. 712. Auch Tjulpanow (Deutschland, S. 19 f., 50, 56) bezeichnet die Fulton-Rede als Wendepunkt.

224 PRO, FO $371 / 55379$.

225 FRUS, 1946/V, S. 561. 
Möglichkeiten ihres Einsatzes zu mißachten“226. Offenkundig waren die Sowjets zu dieser Zeit intensiv bemüht, die Stockungen in der Arbeit des Kontrollrats nicht zum Ausgangspunkt eines vertieften Bruchs werden zu lassen. Ende Juni unternahm Iwanow daher einen neuen Vorstoß. Die Spannungen zwischen den USA und der Sowjetunion seien zweifellos noch überwindbar; Großbritannien versuche dagegen, einen „Block“ gegen die UdSSR zu errichten. Wenn Truman oder Byrnes offen die „freundliche Haltung gegenüber Rußland“ erklärten, würde das „die Luft reinigen“ und Einigungen über Iran und andere „Details“ erleichtern. Auch in Deutschland sei es möglich, die „Unstimmigkeiten und Mißverständnisse [...] in einem umfassenden, freien und offenen Gespräch“ zwischen Clay und Sokolowski auszuräumen; er habe kürzlich Clay selbst darum gebeten, aber dieser habe nicht reagiert ${ }^{227}$. Diese sowjetischen Initiativen wurden nach dem Eindruck der amerikanischen Diplomaten trotz ihres eher informellen und persönlichen Charakters auf höhere Weisung unternommen. Sie deuteten darauf hin, daß die Sowjetunion im Endstadium der Pariser Außenministerkonferenz bzw. nach deren Abschluß an einer Einigung interessiert war, auch wenn ihr offenkundiges Nahziel die Verhinderung eines "Westblocks“ in Deutschland und in Europa war $^{228}$. Es war jedoch ein „Fehler“ der Sowjets, zumindest taktisches Ungeschick, daß bei ihnen stets am ehesten an Stimmungsschwankungen ablesbar war, ob sie Erfolge unbedingt suchten oder nicht: z. B. bei dem Bericht an die Moskauer AuBenministerkonferenz 1947, als sie aus Furcht, in Moskau isoliert zu sein, den Franzosen Avancen machten, diese aber später stillschweigend ignorierten ${ }^{229}$.

Die wachsende Konkurrenz im Werben um die Deutschen führte zur stärkeren Akzentuierung der eigenen Positionen und Maßnahmen, um über ökonomische Erfolge und politische Angebote Wettbewerbsvorteile zu erzielen. Insofern wurde der Umgangston in einigen Sitzungen bereits im Sommer 1946 ,in zunehmendem Maße scharf", vor allem als angesichts steigender Spannungen in Berlin Clay die sowjetischen Deportationen von Arbeitskräften mit den gerade in Nürnberg verhandelten Zwangsdeportationen des Dritten Reiches verglich ${ }^{230}$. Zwar einigten sich die vier Mächte, als ein Stellvertreterkrieg zwischen ost- und westdeutschen Politikern bzw. Presseorganen auszubrechen drohte, in Direktive Nr. 40 vom 12. Oktober 1946 auf einen „Maulkorb-Erlaß“ für die Deutschen, denen die Kritik an alliierten Entscheidungen ebenso verboten wurde wie Äußerungen, die die alliierte Einheit (zer)stören könnten. Doch wurde damit die Verantwortung nur auf andere Schultern verlagert, denn die Besatzungsmächte wiesen regelmäßig alle Proteste gegen die fortdauernde Kritik durch „ihre“ Deutschen als ungerechtfertigt zurück. Erbittert drohte Sokolowski angesichts der „anti-sowjetischen Kampagnen“ in den Westzonen mit organisierter Revanche $^{231}$. Die Konflikte brachen im Februar 1947 nach Angriffen Sokolowskis auf die Bizone erneut auf. Die Sowjets reagierten zunächst ironisch, als sie den Westmächten ihr eigenes Argument entgegenhielten, in der SBZ sei die Zensur abgeschafft, es be-

226 NA, RG 740.00119 Control(Germany)/6-246.

227 NA, RG 740.00119 Control(Germany)/6-2846.

${ }^{228} \mathrm{Zu}$ den sowjetischen Angeboten im Juli vgl. Backer, Clay, S. 178.

229 AMAE, Y 456, BI. $88 \mathrm{f}$.

230 Vgl. unten S. 379. Noch im Dezember 1946 gratulierte der Kontrollrat auf Vorschlag der USA Stalin zum Geburtstag und feierte ihn als „einen weisen Führer“, der „für andere Völker ein getreuer Mitstreiter auf der Seite von Demokratie, Recht und Gerechtigkeit sein werde“.

231 FRUS, 1946/V, S. $740 \mathrm{ff}$. passim. 
stehe daher keine Möglichkeit, den Deutschen den Nachdruck aus ausländischen (sprich: sowjetischen bzw. westlich-kommunistischen) Zeitungen zu verbieten. Doch als die Westmächte Vergeltung androhten, wurde die Affäre noch einmal durch einen Verweis an die deutschen Redakteure beigelegt.

Nach dem Ende der Moskauer Außenministerkonferenz zeigten die Sowjets eine „merkliche Versteifung“ in ihrem Auftreten, obwohl sie diese als einzige als Erfolg gewertet hatten, da die Standpunkte in den Grundzügen herausgearbeitet und damit die Grundlagen für den Kompromiß gelegt worden seien ${ }^{232}$. Nach dem Scheitern dieses letzten, von Beginn an skeptisch betrachteten Versuchs, doch noch zu einer Einigung zu kommen, verliehen beide Seiten ihrer Enttäuschung dadurch Ausdruck, daß sie zunehmend jede formelle Rücksichtnahme aufgaben. Zunächst verliefen nach britischen Berichten, trotz aller Gegensätze und trotz gelegentlicher Schärfe des Tons, die Sitzungen weiterhin nützlich und prinzipiell „herzlich“. Aber seit dem Frühsommer 1947 war die allgemeine Klimaverschlechterung nicht mehr zu leugnen, als die Berliner Magistratskrise für eine „bedrückende Atmosphäre der Uneinigkeit“ und „bittere Gefühle“ sorgte. Doch vermochten die Westmächte keine eindeutige Linie in der sowjetischen Politik zu erkennen. Nach Einschätzung hochrangiger deutscher Kreise in der SBZ gab es noch im August 1947 innerhalb der SMAD um Sokolowski eine kooperationsbereite Richtung, die einen pragmatischen Kompromiß mit den Westmächten für möglich hielt ${ }^{233}$. In verschiedenen Bereichen zeigten die Sowjets einen „neuen kooperativen Geist“, und sei es nur aus taktischen Gründen. Im Wirtschaftsdirektorat suchte die Sowjetunion in der zweiten Jahreshälfte 1947 beharrlich die Offensive, vor allem bei Reparationen, Demontagen und der Ruhrfrage, während die Westmächte die laufenden Reparationen und die Produktion von Kriegsmaterial als ihre Diskussionswünsche dagegensetzten. Wechselseitig waren nun die Vorwürfe, in den jeweiligen Zonen isoliert und im Widerspruch zum Potsdamer Abkommen vorzugehen, und die Anwürfe wurden nicht einmal mehr eines formalen Dementis für würdig befunden. Die Gründung der Komintern setzte freilich deutlichere Signale. Offenkundig wurde der Bruch, als Clay am 27. Oktober auf einer Pressekonferenz eine antikommunistische Propagandaoffensive ankündigte, nachdem Tjulpanow auf einer SED-Konferenz die Westmächte attackiert und Sokolowski diesen im Kontrollrat in Schutz genommen hatte. Zwar wurde Clay angesichts der bevorstehenden New Yorker Außenministerkonferenz von Washington zur Zurückhaltung gemahnt und zur vorherigen Abstimmung seiner Maßnahmen aufgefordert. Doch war das nur noch taktische Rücksichtnahme, da im Kontrollrat die Vertrauensbasis nicht mehr gegeben war $^{234}$. „Ohne Glacéhandschuhe“, kommentierte das SMAD-Organ ,Tägliche Rundschau“ den Angriff, den sie mit den nationalsozialistischen „Lügenfeldzügen“ verglich und als Beweis ansah, „daß die USA nicht länger daran interessiert sind, eine gemeinsame Grundlage für einen Kompromiß in Deutschland zu finden“235. Doch als Sholto Douglas Ende Oktober 1947 sich anläßlich seines Abschieds vom Kontrollrat ent-

\footnotetext{
232 Vgl. S. 412.

233 NA, RG 59, 740.00119 Control(Germany)/8-1947. FRUS, 1947/II, S. 884 ff.

234 CP, S. 451-64, $490 \mathrm{f}$.

235 Tägliche Rundschau, 6. 11. 1947. NA, RG 59, 740.00119 Control(Germany)/11-547.
} 
täuscht über dessen magere Erfolgsbilanz äußerte, widersprach Sokolowski: „Ich neige nicht zu Pessimismus. Geduld und Arbeit werden uns über alles hinweghelfen. “236

An der Arbeitsbilanz des Kontrollrats läßt sich die „Konjunktur“ seiner Erfolge und seiner Einigungsfähigkeit ablesen.

Tab. 1: Arbeitsbilanz des Kontrollrats (August 1945 - Februar 1948) ${ }^{237}$

\begin{tabular}{|c|c|c|c|c|c|c|}
\hline \multirow[t]{2}{*}{ Zeitraum } & \multicolumn{2}{|c|}{ Kontrollrat } & \multicolumn{2}{|c|}{ Koordinationskomitee } & \multicolumn{2}{|c|}{ Veto } \\
\hline & $\begin{array}{l}\text { gebilligt, } \\
\text { Kenntnis } \\
\text { genommen }\end{array}$ & $\begin{array}{l}\text { abgesetzt, } \\
\text { vertagt }\end{array}$ & $\begin{array}{l}\text { gebilligt, } \\
\text { Kenntnis } \\
\text { genommen }\end{array}$ & $\begin{array}{l}\text { abgesetzt, } \\
\text { vertagt }\end{array}$ & Summe & SU \\
\hline Aug.-Dez.45 & 53 & 9 & 127 & 55 & 14 & 8 \\
\hline Jan.-Jun.46 & 2 & 7 & 151 & 57 & 16 & 16 \\
\hline Jul.-Dez.46 & 14 & 9 & 111 & 78 & 25 & 15 \\
\hline Jan.-Jun.47 & 32 & 5 & 103 & 58 & 21 & 10 \\
\hline Jul.-Dez.47 & 7 & 15 & 47 & 67 & 25 & 21 \\
\hline Jan.-Feb.48 & 2 & 8 & 7 & 22 & 17 & 5 \\
\hline
\end{tabular}

Nach einem ersten Hoch von je vier Gesetzen im Oktober und November 1945 erreichte der Kontrollrat seine (quantitativ) produktivste Phase von Februar bis Mai 1946 mit 18 Gesetzen. Ende Mai 1946 gab es erste Auseinandersetzungen über die Zuständigkeitsverteilung in der Kontrollbehörde und den Einsatz von Verfahrensfragen zur Blockade ihrer Arbeitsfähigkeit ${ }^{238}$. Danach flaute die Gesetzgebungstätigkeit ab; jeweils im Umfeld der Außenministerkonferenzen von New York (Ende 1946) und Moskau (Frühjahr 1947) erwies sich der Kontrollrat noch einmal als konsensfähig. Insgesamt war bei den Gesetzen eine tendenziell abnehmende Bedeutung der behandelten Gegenstände erkennbar, zumal angesichts der Regelungsunfähigkeit des Kontrollrats in allen Zonen eine konkurrierende Gesetzgebung entstand, die von den Verordnungen der Militärregierungen ebenso getragen wurde wie von der Gesetzgebung deutscher Stellen.

Allerdings scheinen alle Kontrollratsgruppen seit Anfang 1947 froh gewesen zu sein, wenn wichtige Entscheidungen vertagt wurden ${ }^{239}$; weniger im Sinne einer bewußten Konfliktstrategie, sondern infolge der internen Auseinandersetzungen über die nationale Besatzungs- und Deutschlandpolitik. Offenkundig waren es zunehmend die Westmächte, die im Kontrollrat bremsten, indem sie Auskünfte und Zugeständnisse verlangten oder Vorwände für eine Vertagung suchten. Noch blieb der Umgangston im allgemeinen gemäßigt. Im Finanzdirektorat soll noch Ende November 1947 eine „offene, aber sehr freundliche Atmosphäre“ geherrscht haben. Doch löste das Scheitern der Londoner Konferenz auch bei den Franzosen ernsthafte Überlegun-

${ }^{236}$ BA, Z 45 F/OMGUS, 2/108-3/4 (CONL/M(47)23, 30. 10. 1947).

237 Tägliche Rundschau, 26. 3. 1948, S. 2. Die Zahlen dieser sowjetischen Übersicht, die alle „Fragen“ unabhängig von ihrem Rechtscharakter zusammenfaßte, waren nach amerikanischer Bestätigung „ungefähr richtig“. NA, RG 59, 740.00119 Control(Germany)/3-2748. Nach einer amerikanischen Auflistung der Vetos legte die Sowjetunion 69 von 110 Vetos gegen die drei Westmächte ein, zwölfmal stimmten die USA gegen die anderen drei, zweimal Großbritannien und dreizehnmal Frankreich. Vierzehnmal stimmten die Angelsachsen gemeinsam gegen Frankreich und die Sowjetunion. BA, Z 45 F/OMGUS, 3/153-1/5. In der Berliner Kommandantur wurde 1945 über neun von 217 Fragen keine Einigung erzielt; 1946 waren es 129 von 199 Fragen. Belezki, Politik, S. 46.

${ }^{238}$ FRUS, 1946/V, S. $561 \mathrm{ff}$. (CORC, 29. 5. 1946).

239 FRUS, 1947/II, S. 856, 869 f. 
gen aus, ob die Aufrechterhaltung der Vier-Mächte-Verwaltung sinnvoll sei ${ }^{240}$. Die Briten diskutierten im Oktober 1947 intern, ob angesichts der sowjetischen Obstruktionspolitik die Vertreter in den Direktoraten und den unteren Organen des Kontrollrats angewiesen werden sollten, „die Diskussion [...] aller Grundsatzfragen zu vermeiden, die nur auf der Ebene des Koordinationskomitees oder der Regierungen gelöst werden können“, um eine Verschwendung von Zeit und Arbeitskraft zu vermeiden. Der Schritt wurde lediglich zurückgestellt, um nicht vor dem Londoner Außenministerrat falsche Signale zu setzen. „Was immer geschieht, wir müssen eine Fassade in Berlin aufrechterhalten, und vielleicht müssen wir uns etwas künstlich bemühen, diese Fassade so eindrucksvoll wie möglich zu gestalten. Nach unserem Gefühl sollten wir es im Augenblick ziemlich langsam angehen lassen. Aber nach dem November, wenn nicht früher, wird die Frage irgendwann auftauchen, wie weit wir unsere Bemühungen begrenzen können, auf einem toten Pferd herumzuprügeln." ${ }^{\text {“21 }}$

Angesichts der immer fruchtloseren Bemühungen um den freundlichen Schein war es kaum erstaunlich, daß Anfang 1948 die Stimmung z. B. im Wirtschaftsdirektorat ausgesprochen gereizt wurde. Dies mündete in wechselseitige Verdächtigungen und Verbalinjurien, die vorsichtshalber nicht mehr übersetzt wurden, auch wenn Tonfall und Mimik die Tendenz nur allzu deutlich werden ließen. Inhaltlich wurde im Grunde nicht mehr debattiert und argumentiert; es ging im wesentlichen nur noch um Formalien und wechselseitige Schuldzuweisungen, mit denen häufig genug die gesamten Sitzungen bestritten wurden. Im Koordinationskomitee wurde der Umgangston rüde, fast beleidigend. Während die Sowjets im Finanzdirektorat Ende Februar ihren „Wunsch nach Versöhnung“ demonstrierten, verweigerte ihr Vertreter im Arbeitsdirektorat den Dank an den scheidenden französischen Vorsitzenden und lehnte dessen Einladung zum Essen $\mathrm{ab}^{242}$. Im Kontrollrat war die Stimmung, nach der Rückkehr Sokolowskis aus Moskau am 10. Januar 1948, „ruhig und relativ angenehm“, nicht „spannungsgeladener als gewöhnlich“, im Februar dagegen „sehr spannungsgeladen“. Die Sitzung vom 10. März wurde trotz „offenerer Worte unsererseits, als wir je zuvor gesagt haben“, insgesamt als „bemerkenswert frei von den Spannungen der letzten Wochen“ beschrieben. Beim anschließenden Tee war Sokolowski deutlich bemüht, sich „liebenswürdig“ zu geben ${ }^{243}$. Doch am 20. März betrat er mit „ungewöhnlich finsterem und müdem" Gesicht den Raum zur entscheidenden Sitzung. Noch im Juni, im Anfangsstadium der Blockade Berlins, hatte Clay den Eindruck, daß Sokolowski „persönlich unglücklich“ über die Entwicklung war ${ }^{244}$. Daß es auch letzterem nicht leicht fiel, seinen Instruktionen zu folgen, verdeutlichte noch einmal die Ambivalenzen in der Geschichte des Kontrollrats: von besatzungspragmatischem Sachzwang und politischer Grundsatzentscheidung, von persönlicher Kooperationsbereitschaft und institutioneller Kooperationsunfähigkeit.

240 BA, Z 45 F/OMGUS, 2/111-1/5-6 (90. DFIN). AO, Berlin/3276/1/2007 (GFCC, 18. 12. 1947).

241 PRO, FO 1049/922 (CCG/Political Division, 21. 10. 1947). Treibende Kraft seit dem April 1947 war der britische Vertreter im Alliierten Sekretariat, Raw, der nach einem Scheitern der Londoner Konferenz und beim Fehlen einer deutschen Zentralverwaltung die Arbeit des Kontrollrats um $50-75 \%$ einzuschränken empfahl. „The Anglo-American effort would then be focussed on the West.“ Ebenda, (CCG-ASEC, 23. 4. und 1.10. 1947).

242 AMAE, Eu(1944-60)Allemagne/82, Bl. 29; Y 457 (No. 2359, 18. 3. 1948).

243 PRO, FO 1049/1392.

244 NA, RG 59, 740.00119 Control(Germany)/28-648. CP, S. 710. Das genaue Gegenteil in Clay, Entscheidung, S. 406. 